AUTARQUIA ASSOCIADA À UNIVERSIDADE DE SÃO PAULO

AVALIAÇÃO DE DOSÍMETROS DE ÓXIDO DE ALUMÍNIO PELA TÉCNICA OSL NA DOSIMETRIA DE CAMPOS DE FÓTONS CLÍNICOS UTILIZADOS NO TRATAMENTO RADIOTERÁPICO EM ARCO MODULADO VOLUMÉTRICO

Daniel Villani

Dissertação apresentada como parte dos requisitos para obtenção do Grau de Mestre em Ciências na Área de Tecnologia Nuclear - Aplicações

Orientadora:

Profa. Dra. Letícia Lucente Campos Rodrigues 


\section{INSTITUTO DE PESQUISAS ENERGÉTICAS E NUCLEARES}

Autarquia associada à Universidade de São Paulo

AVALIAÇÃO DE DOSÍMETROS DE ÓXIDO DE ALUMÍNIO PELA TÉCNICA OSL NA DOSIMETRIA DE CAMPOS DE FÓTONS CLÍNICOS UTILIZADOS NO TRATAMENTO RADIOTERÁPICO EM ARCO MODULADO VOLUMÉTRICO

Daniel Villani

Dissertação apresentada como parte dos requisitos para obtenção do Grau de Mestre em Ciências na Área de Tecnologia Nuclear - Aplicações

Orientadora:

Profa. Dra. Letícia Lucente Campos

Rodrigues

Versão Corrigida

Versão Original Disponível no IPEN

São Paulo

2017 
Aos meus pais, irmã e todos os meus amigos.

Ao tornado lindo que chegou para ficar pra sempre. "If we could only be faster, then we could outsmart time". 
"Don't only practice your art, but force your way into its secrets, for it and knowledge can raise men to the divine."

Ludwig van Beethoven 


\section{AGRADECIMENTOS}

À minha orientadora Dra. Letícia L. C. Rodrigues, pela sua excelência, experiência e conselhos profissionais, apoio e confiança. Professora, serei eternamente grato pela incrível oportunidade de crescimento pessoal e profissional que me proporcionou nesses anos do mestrado.

Ao IPEN, na pessoa do Sr. Superintendente Dr. Wilson A. Parejo Calvo, pela oportunidade de execução desse trabalho.

À Comissão Nacional de Energia Nuclear (CNEN), pela bolsa de estudos que me permitiu dedicação exclusiva à pesquisa.

À Fundação de Amparo à Pesquisa do Estado de São Paulo (FAPESP) e ao Conselho Nacional de Desenvolvimento Científico e Tecnológico (CNPq), pelo suporte financeiro.

À Dra. Linda V. E. Caldas, pela total presteza e apoio durante a realização desse trabalho e pelo uso de seus laboratórios.

À toda equipe SAPRA Landauer, que direta ou indiretamente, auxiliaram na execução desse trabalho e no meu crescimento.

À Dra. Cecilia Haddad, junto a todo corpo do setor de radioterapia do Hospital SirioLibanês pela estrutura de irradiação dos dosímetros.

Ao Dr. Roberto Sakuraba, junto ao Hospital Israelita Albert Einstein pelos conselhos e projetos futuros.

Ao Dr. Vitor Vivolo à Dra. Maria da Penha Potiens pelas calibrações, irradiações e valiosas sugestões. 
Aos meus pais Walter e Gilce por me apoiar, orientar e incentivar em todos os momentos decisivos da minha vida. Devo minha vida à dedicação e amor incondicionais de vocês!

À minha irmã Ana Beatriz, irmã querida, por sempre me fazer rir nos meus momentos de queda.

Ao tornado lindo que chegando de repente, mudou completamente minha vida e me propicia forças e motivações para seguir adiante.

A todos os colegas de disciplinas, em especial à Shirlane, Fábio, Renata, Lilian e Ivón, por todos os momentos vivenciados.

À Maíra por simplesmente tudo e mais um pouco.

Ao Dré e todos os inúmeros rolês de DeLorean.

A todos da GMR/IPEN que direta ou indiretamente contribuíram para a realização deste trabalho. 


\title{
AVALIAÇÃo DE DOSÍMETROS DE ÓXIDO DE ALUMÍNIO PELA TÉCNICA OSL NA DOSIMETRIA DE CAMPOS DE FÓTONS CLÍNICOS UTILIZADOS NO TRATAMENTO RADIOTERÁPICO EM ARCO MODULADO VOLUMÉTRICO
}

\author{
Daniel Villani \\ RESUMO
}

O tratamento utilizando Radioterapia em Arco Modulado Volumétrico é a modalidade mais moderna de radioterapia conformacional de forma que, com superposição de vários campos, as distribuições de dose forneçam uma perfeita conformação ao tumor, diminuindo a probabilidade de complicações nos tecidos normais adjacentes. Nesse sentido, muitos esforços estão sendo investidos para melhorar a conformidade de distribuição de dose, bem como a integração de técnicas de imagem para rastreamento de tumores e correção de variações inter e intrafração. Para isso, um intenso acompanhamento da qualidade dos processos e um programa de garantia de qualidade são fundamentais para a segurança dos pacientes e o cumprimento da legislação vigente; além do uso de diferentes metodologias de dosimetria para inter comparação e validação dos resultados. Este trabalho tem por objetivo avaliar e comparar o desempenho dos dosímetros OSL de óxido de alumínio $\left(\mathrm{Al}_{2} \mathrm{O}_{3}: \mathrm{C}\right)$ fabricados pela Landauer Inc. com os fabricados pela Rexon ${ }^{\mathrm{TM}}$ na dosimetria de feixes clínicos de fótons de energias altas empregados em radioterapia com tratamento em arco modulado volumétrico (VMAT) utilizando diferentes objetos simuladores. Os dosímetros foram caracterizados para radiação gama do ${ }^{60} \mathrm{Co}$ e para feixes clínicos de fótons de $6 \mathrm{MV}$ típicos de tratamentos por VMAT em condições de equilíbrio eletrônico e de dose máxima respectivamente. Testes de desempenho das leitoras TL e OSL utilizadas e repetibilidade das amostras foram avaliadas. Após realizados todos os testes, os dosímetros foram irradiados na simulação de diferentes tratamentos radioterápicos por VMAT e suas respostas comparadas ao sistema de planejamento. Todos os tipos de dosímetros apresentaram resultados satisfatórios na verificação das doses desse tipo de simulação de planejamento. Os dosímetros de $\mathrm{Al}_{2} \mathrm{O}_{3}: \mathrm{C}$ apresentaram resultados compatíveis entre si e validados pelos outros dosímetros e câmara de ionização. Em relação a melhor técnica, o sistema comercial OSL InLight apresenta maior praticidade e versatilidade para uso e aplicação na rotina clínica.

Palavras Chave: Dosimetria OSL; Dosimetria TL; VMAT; $\mathrm{Al}_{2} \mathrm{O}_{3}: \mathrm{C}$; Controle de Qualidade 


\title{
EVALUATION OF ALUMINUM OXIDE DOSIMETERS USING OSL TECHNIQUE IN DOSIMETRY OF CLINICAL PHOTOM BEAMS ON VOLUMETRIC MODULATED ARC TREATMENT
}

\begin{abstract}
Daniel Villani
ABSTRACT

Treatment using Volumetric Modulated Arc Radiation Therapy is the most modern modality of conformational radiotherapy so that, with the overlapping of several fields, the dose distributions provide a perfect conformation to the tumor, reducing the probability of complications in adjacent normal tissues. In this sense, many efforts are being invested to improve dose distribution compliance as well as the integration of imaging techniques for tumor screening and correction of inter and intrafraction variations. To this end, an intensive monitoring of the quality of the processes and a quality assurance program are fundamental for patient safety and compliance with current legislation; besides the use of different dosimetry methodologies for intercomparison and validation of the results. The aim of this study is to evaluate and compare the performance of aluminum oxide $\left(\mathrm{Al}_{2} \mathrm{O}_{3}: \mathrm{C}\right)$ OSL dosimeters manufactured by Landauer Inc. with those produced by Rexon ${ }^{\mathrm{TM}}$ in the dosimetry of high energy photon clinical bundles used in arcuate treatment Modulated volumetric (VMAT) using different simulating objects. The dosimeters were characterized for gamma radiation of the ${ }^{60} \mathrm{Co}$ and for clinical photon beams of $6 \mathrm{MV}$ typical of treatments by VMAT under conditions of electronic equilibrium and maximum dose respectively. Performance tests of the TL and OSL readers used and repeatability of the samples were evaluated. After all tests, the dosimeters were irradiated in the simulation of different radiotherapy treatments by VMAT and their responses compared to the planning system. All types of dosimeters presented satisfactory results in verifying the doses of this type of planning simulation. The $\mathrm{Al}_{2} \mathrm{O}_{3}: \mathrm{C}$ dosimeters presented compatible results and validated by the other dosimeters and ionization chamber. Regarding the best technique, the OSL InLight commercial system presents greater practicality and versatility for use and application in the clinical routine.
\end{abstract}

Key Words: OSL Dosimetry; TL Dosimetry; VMAT; $\mathrm{Al}_{2} \mathrm{O}_{3}: \mathrm{C}$; Quality Assurance 


\section{SUMÁRIO}

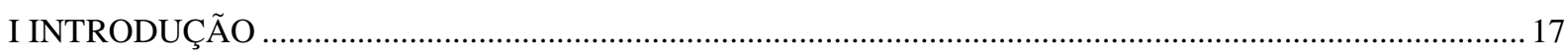

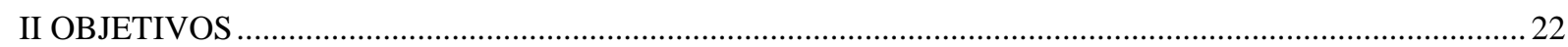

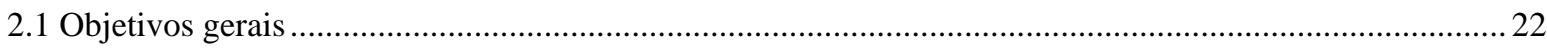

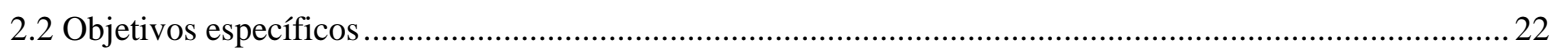

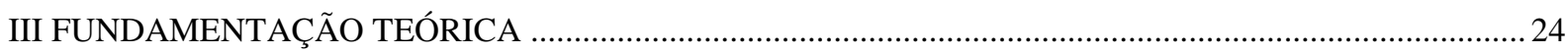

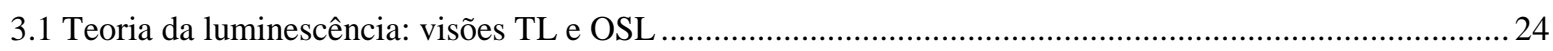

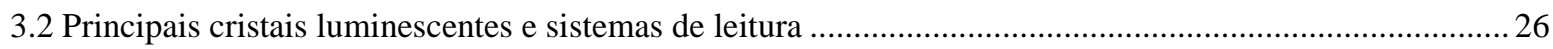

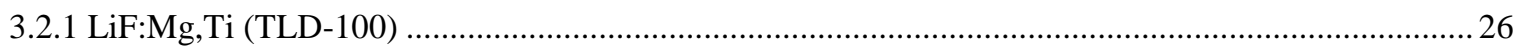

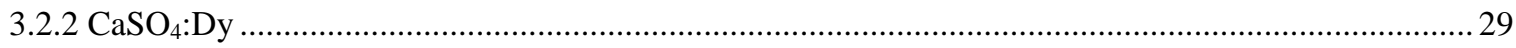

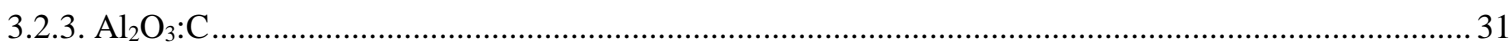

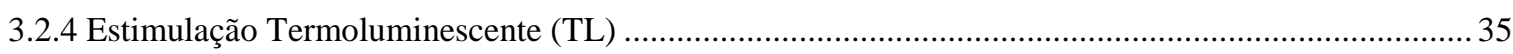

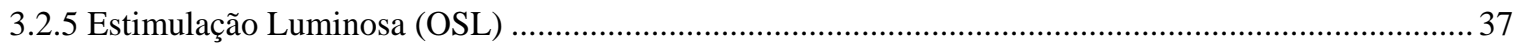

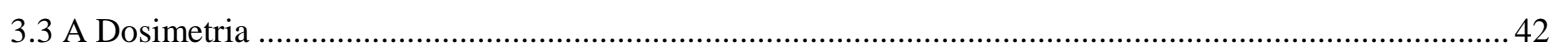

3.3.1 A Radioterapia em Arco Modulado Volumétrico (VMAT) e Controle de qualidade.............................. 43

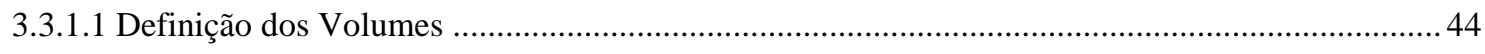

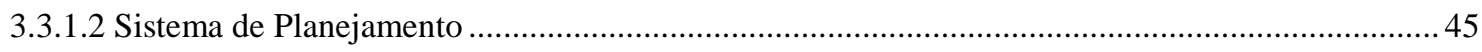

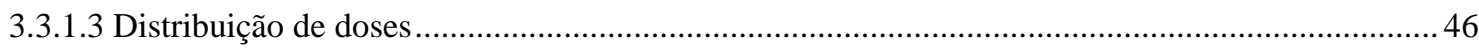

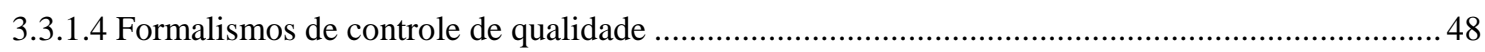

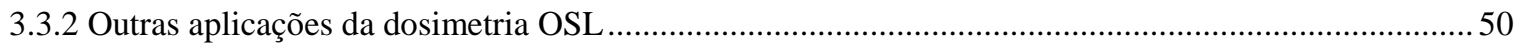

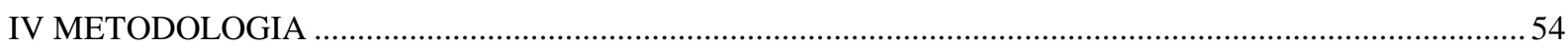

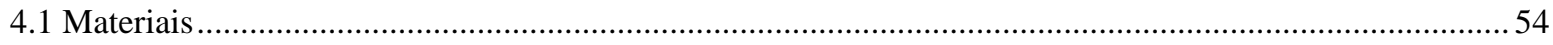

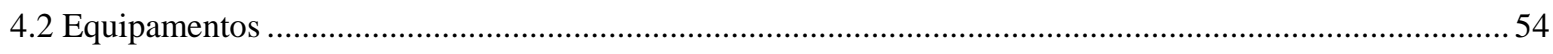

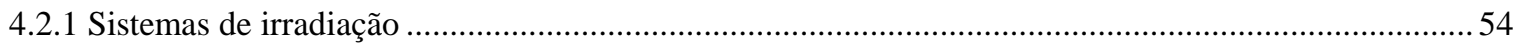

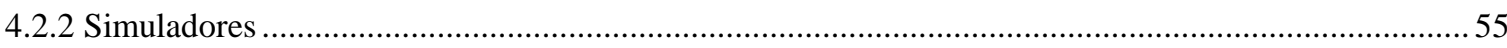

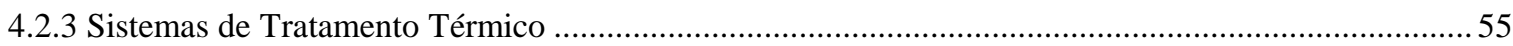




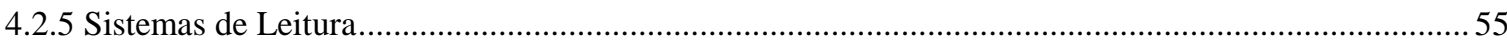

4.2.6 Sistemas de Dosimetria de Referência........................................................................................ 55

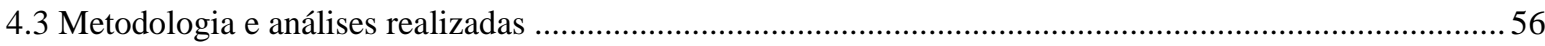

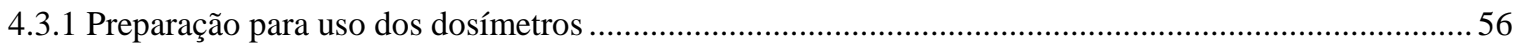

4.3.2 Seleção dos dosímetros e Testes de Desempenho ....................................................................5

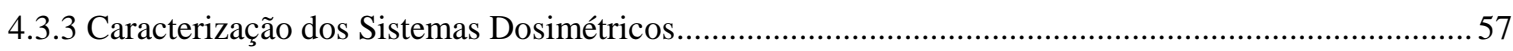

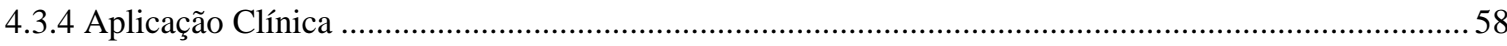

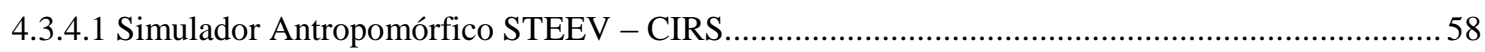

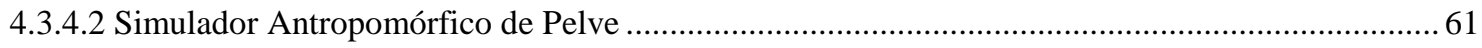

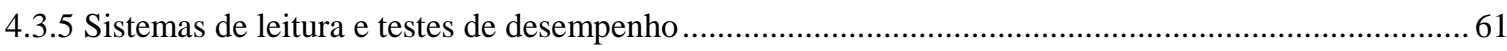

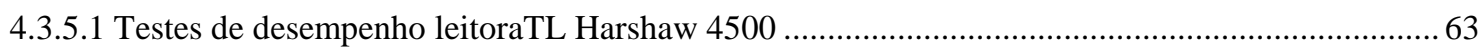

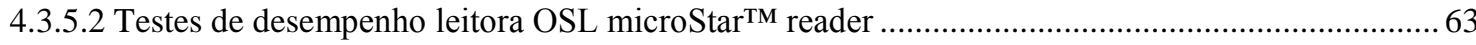

4.3.5.3 Testes de desempenho e caracterização OSL da leitora RIS $\emptyset^{\mathrm{TM}}$ TL/OSL reader ........................64

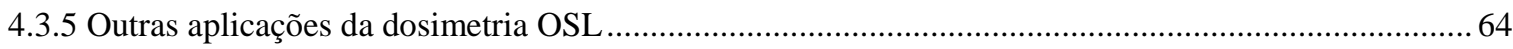

4.3.5.1 Aplicação da técnica de Luminescência Opticamente Estimulada (OSL) na monitoração de área

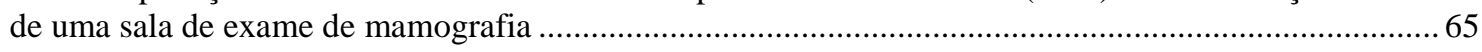

4.3.5.2 Avaliação da dose de entrada na pele e da dose glandular média em uma unidade de mamografia

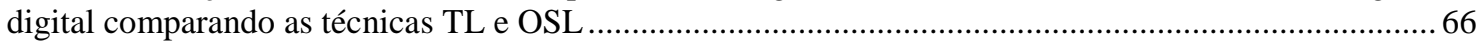

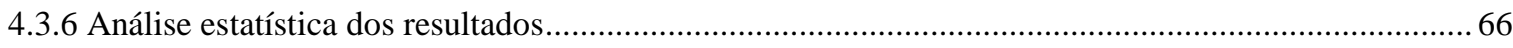

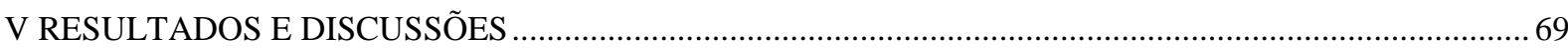

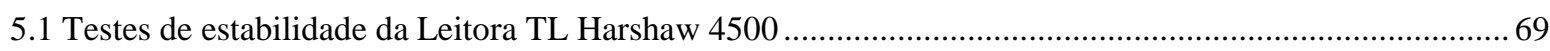

5.2 Testes de estabilidade da Leitora OSL microStar ${ }^{\mathrm{TM}}$ reader ..................................................... 70

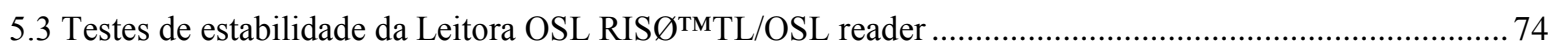

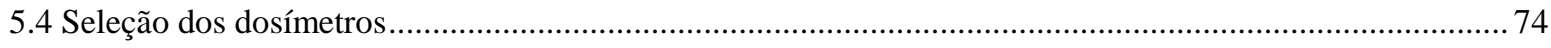

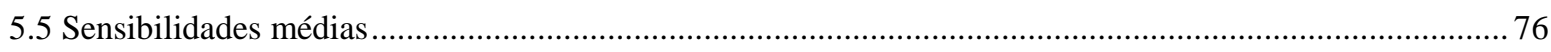

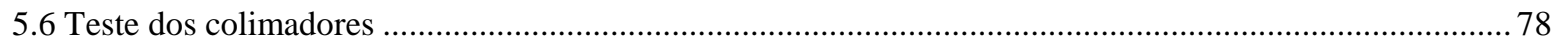

5.7 Estudo da correlação entre a resposta OSL dos dosímetros TLD-500 com a potência do arranjo de LEDs

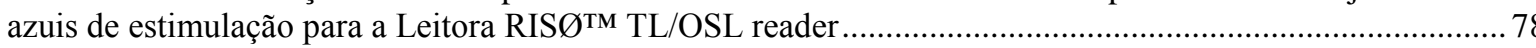

5.8 Estudo da correlação entre a resposta OSL dos dosímetros TLD-500 com o tempo de leitura para a Leitora RISØ ${ }^{\mathrm{TM}} \mathrm{TL} / \mathrm{OSL}$ reader. 
5.9 Estudo da correlação entre o "bleaching" do sinal OSL e efetividade do tempo de iluminação para diferentes doses em dosimetria de fótons

5.10 Caracterização dos Sistemas Dosimétricos

5.11 Limite inferior de detecção (LID)

5.12 Planejamento de tumor cerebral utilizando o simulador antropomórfico STEEVTM

5.13 Planejamento de tumor de próstata utilizando o simulador antropomórfico de Pelve e dosimetria de entrada na pele do paciente

5.14 Outras aplicações da dosimetria OSL

5.14.1 Aplicação da técnica de Luminescência Opticamente Estimulada (OSL) na monitoração de área de uma sala de exame de mamografia

5.14.2 Avaliação das doses de entrada na pele e das doses glandulares médias em uma unidade de mamografia digital comparando as técnicas TL e OSL

VI CONCLUSÕES

Referências Bibliográficas 


\section{LISTA DE FIGURAS}

Figura 1. Modelo de bandas simplificado com 4 níveis de armadilhamento. A) Transição eletrônica durante a fase de irradiação do material (excitação). B) Transição eletrônica durante a fase de leitura do material (relaxação) [Adaptado de 51].

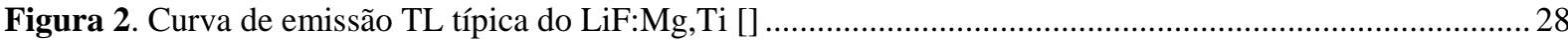

Figura 3. Curva típica de resposta em função da dose do LiF:Mg,Ti [] ................................................28

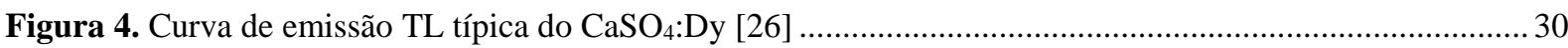

Figura 5. Curva típica de resposta em função da dose do $\mathrm{CaSO}_{4}: \mathrm{Dy}$ produzido pelo IPEN [27] ....................... 30

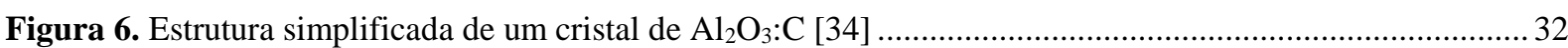

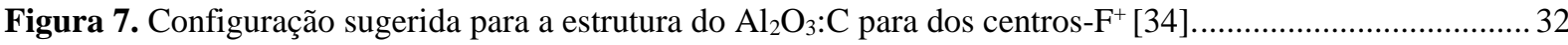

Figura 8. Curvas teóricas de sinal OSL emitido, segundo modelo que considera apenas o movimento de cargas entre diferentes níveis de armadilhas e centros de recombinação []

Figura 9. Curva de resposta em função da dose do $\mathrm{Al}_{2} \mathrm{O}_{3}: \mathrm{C}$ em pó, medida utilizando POSL e duas intensidades de feixe luminoso de estimulação [74]

Figura 10. (a) resposta OSL para doses altas de radiação gama, e (b) supralinearidade para detectores $\mathrm{Al}_{2} \mathrm{O}_{3}: \mathrm{C}$ do modelo Luxel [51]....

Figura 11. Esquema descritivo de uma leitora TL convencional com sistema de aquecimento controlado por prancheta [25].

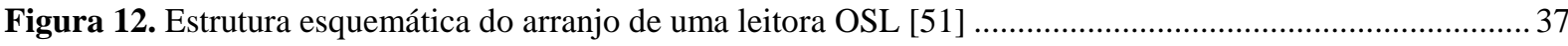

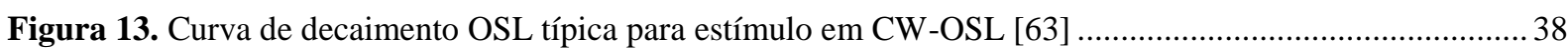

Figura 14. Perfil de decaimento OSL típico para estímulo em POSL [63] ....................................................39

Figura 15. Perfil de sinal OSL obtido realizando a leitura em LM-OSL [63] ............................................ 40

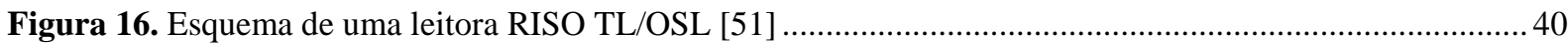

Figura 17. Especificações de emissão e transmissão para diferentes configurações da leitora RISO TL/OSL-DA20 [77]

Figura 18. (a) Leitora microStar ${ }^{\mathrm{TM}}$ com microcomputador acoplado (b) dosímetro do modelo nanoDot aberto e acoplado ao adaptador de encaixe da leitora [79]....

Figura 19. (a) Conformação do feixe de tratamento pelo colimador multilâminas (b) tratamento sendo entregue com o gantry em arco [VARIAN TRUEBEAM advertise].

Figura 20. Definição esquemática dos volumes de tratamento definidos para radioterapia

Figura 21. Exemplo de um histograma dose-volume (DVH) em radioterapia .46

Figura 22. Distribuição de dose em profundidade para diferentes energias de fótons [80] 
Figura 23. Exemplo de uma carta de isodose.(a) $\mathrm{SSD}=80 \mathrm{~cm}$, campo $10 \mathrm{x} 10 \mathrm{~cm}$ na superfície. (b) $\mathrm{SAD}=$ $100 \mathrm{~cm}$, profundidade do isocentro $=10 \mathrm{~cm}$; tamanho do campo no isocentro $=10 \times 10 \mathrm{~cm}[80]$

Figura 24. Dosímetro pessoal InLight [85]

Figura 25. Sistema Tandem dos dosímetros pessoais InLight [85]

Figura 26. Equipamentos utilizados para tratamentos pré irradiação. (a) Forno tipo mufla Vulcan. (b) Estufa cirúrgica Fanen, (c) Lâmpada de LED azul Ourolux.

Figura 27. Sistema de irradiação de geometria $4 \pi$ de ${ }^{137}$ Cs. (a) Sistema de arcos rotacionais de 30 a $60 \mathrm{~cm}$ de distância da fonte. (b) Comando digital controlador da fonte.

Figura 28. Posicionamento dos dosímetros para caracterização clínica. (a) Dosímetros posicionados sobre as placas de água sólida SW. (b) Posicionamento de duas placas SW somando profundidade de 1,5 cm.

Figura 29. Objeto simulador antropomórfico de cabeça da marca CIRS, modelo STEEV. (a) Visão geral do simulador e dos acessórios disponíveis. (b) Tomografia computadorizada em vista lateral em corte sagital mediano do simulador.

Figura 30. Moldes de cera odontológica utilizadas como posicionadores dos dosímetros.

(a) Molde com encaixe para os nanoDots e os TLD-100. (b) Molde com encaixe para os $\mathrm{CaSO}_{4}$ :Dy e TLD-500.

Figura 31. Simulador antropomórfico STEEV posicionado para aquisição da tomografia computadorizada de planejamento. (a) Simulador com os acessórios a serem encaixados dentro do volume cerebral. (b) Posicionamento do simulador inteiramente montado.

Figura 32. Simulador antropomórfico posicionado no acelerador linear VARIAN NOVALIS TX do HSL

Figura 33. Detalhes dos ajustes e irradiação do simulador de pelve. As setas indicam duas localizações dos dosímetros posicionados nas ceras odontológicas

Figura 34. Leitoras (a) TL Harshaw modelo 4500 (b) TL/OSL RIS $\varnothing$ modelo TL/OSL-DA-20 (c) OSL Landauer modelo microStar ${ }^{\mathrm{TM}}$ reader

Figura 35. (a) Colimadores para leitura $\mathrm{TL}$ dos dosímetros de $\mathrm{CaSO}_{4}: \mathrm{Dy}$. As aberturas centrais são de aproximadamente $1 \mathrm{~mm}$ e $7 \mathrm{~mm}$ respectivamente. (b) Colimadores para leitura OSL dos dosímetros $\mathrm{Al}_{2} \mathrm{O}_{3}: \mathrm{C}$ TLD500. As aberturas centrais são de aproximadamente $10 \mathrm{~mm}, 5 \mathrm{~mm}, 2 \mathrm{~mm}$ e $1 \mathrm{~mm}$ respectivamente

Figura 36. Resultados para o teste da Luz de referência. Valores médios dos conjuntos de leituras para cada ciclo e para todas as leituras e respectivos limites de aceitação.

Figura 37. Resultados para o teste de ruído da PMT. Valores médios dos conjuntos de leituras para cada ciclo e para todas as leituras e respectivos limites de aceitação......

Figura 38. Acompanhamento das contagens de fundo da leitora microStar ${ }^{\mathrm{TM}}$ reader.

Figura 39. Análise das contagens da fotomultiplicadora. Valores médios dos conjuntos de leituras para cada ciclo e para todas as leituras e respectivos limites de aceitação.

Figura 40. Análise "LED Counts". Valores médios dos conjuntos de leituras para cada ciclo e para todas as leituras e respectivos limites de aceitação.

Figura 41. Análise gráfica dos resultados obtidos para o cálculo do coeficiente de variância da leitora microStar ${ }^{\mathrm{TM}}$ reader.

Figura 42. Estudo da depreciação do sinal OSL por leitura do dosímetro. 
Figura 43. Histograma da média das três leituras TL para separação do lote dos dosímetros de LiF:Mg,Ti TLD100.

Figura 44. Histograma da média das três leituras TL para separação do lote dos dosímetros de CaSO $4: \mathrm{Dy}_{\text {....... } 75}$

Figura 45. Histograma da média das três leituras OSL para separação do lote dos dosímetros de $\mathrm{Al}_{2} \mathrm{O}_{3}$ :C TLD500.

Figura 46. Histograma da média das três leituras OSL para verificação da sensibilidade dos dosímetros nanoDot utilizados

Figura 47. Sensibilidade TL dos dosímetros TLD-100 e $\mathrm{CaSO}_{4}: \mathrm{Dy}$ para feixe de fótons gama do ${ }^{60} \mathrm{Co}$ .77

Figura 48. Sensibilidade OSL dos dosímetros de $\mathrm{Al}_{2} \mathrm{O}_{3}: \mathrm{C}$ TLD-500 e nanoDot ${ }^{\mathrm{TM}}$ para feixe de fótons gama do ${ }^{60} \mathrm{Co}$.

Figura 49. Comportamento das integrais das curvas de decaimento OSL variando a potência do arranjo de LEDs azuis.

Figura 50. Curvas de decaimento OSL obtidas pela variação da potência do arranjo de LEDs azuis 79

Figura 51. Comportamento das curvas de decaimento OSL (a) e das integrais das curvas de decaimento OSL (b) em função da variação do tempo de estímulo óptico.

Figura 52. Comportamento das respostas OSL de acordo com o tempo de tratamento óptico. (a) Resultados obtidos para os nanoDots. (b) Resultados obtidos para os TLD-500.

Figura 53. Curvas de resposta TL em função da dose dos dosímetros $\mathrm{CaSO}_{4}$ :Dy (a) e TLD-100 (b) para radiação gama do ${ }^{60}$ Co livres no ar e em equilíbrio eletrônico.

Figura 54. Curvas de resposta OSL em função da dose dos dosímetros $\mathrm{Al}_{2} \mathrm{O}_{3}: \mathrm{C}$ nanoDot (a) e TLD-500 (b) para radiação gama do ${ }^{60} \mathrm{Co}$ livres no ar e em equilíbrio eletrônico.

Figura 55. Curvas de resposta TL em função da dose dos dosímetros $\mathrm{CaSO}_{4}$ :Dy (a) e

Figura 56. Curvas de resposta OSL em função da dose dos dosímetros $\mathrm{Al}_{2} \mathrm{O}_{3}: \mathrm{C}$ nanoDot (a) e TLD-500 (b) para fótons de $6 \mathrm{MV}$

Figura 57. Distribuição de dose no simulador STEEV fornecida pelo sistema de planejamento Eclipse $10.0 \ldots 84$

Figura 58. Homogeneidade do planejamento e concordância dos valores medidos com os quatro dosímetros de estudo e a câmara de ionização PinPoint 3D.

Figura 59. (a) Distribuição de dose no simulador antropomórfico de Pelve ExacTrac fornecida pelo sistema de planejamento Eclipse 10.0.(b) localização dos dosímetros no simulador.....

Figura 60. Análise gráfica dos valores de dose planejados e a concordância obtida com os valores de dose medidos com os nanoDots.

Figura 61. Análise gráfica dos valores de dose planejados e a concordância obtida com os valores de dose medidos com os dosímetros de $\mathrm{CaSO}_{4}: \mathrm{Dy}$.

Figura 62. Curvas de resposta em função da dose para as qualidades RQR-2M (28 kVp); RQR-4M (35 kVp) e referência $\mathrm{H}_{\mathrm{x}}$.

Figura 63. (a) Dependência angular da resposta OSL dos nanoDots ${ }^{\mathrm{TM}}$ para a qualidade N-80. 
Figura 64. Perfil da distribuição de dose dada pelo campo do mamógrafo

Figura 65. Curva de resposta em função da dose dos dosímetros de $\mathrm{CaSO}_{4}$ :Dy para o mamógrafo LORAD M-IV. .93

Figura 66. Curva de resposta em função da dose dos dosímetros nanoDots para o mamógrafo LORAD M-IV. 93 


\section{LISTA DE TABELAS}

Tabela 1. Propriedades da formulação do TLD-100.

Tabela 2. Propriedades da formulação do $\mathrm{CaSO}_{4}: \mathrm{Dy}$

Tabela 3. Propriedades físicas de materiais utilizados como objetos simuladores

Tabela 4. Especificações técnicas do sistema Tandem presente nos dosímetros OSL InLight ${ }^{\mathrm{TM}}$..... 52

Tabela 5. Controle de qualidade dos dosímetros TL utilizados

Tabela 6. Especificações das qualidades de feixe de raios X utilizadas para uso em aplicação diagnóstica e área

Tabela 7. Resultados obtidos para o coeficiente de variância da leitora. .72

Tabela 8. Fatores de correção $(f c o l)$ obtidos para as leituras TL do $\mathrm{CaSO}_{4}$ :Dy e OSL dos TLD-500 .78

Tabela 9. Valores dos Limites Inferiores de Detecção (LID) de todos os dosímetros estudados para os feixes de radiação gama de ${ }^{60} \mathrm{Co}$ e fótons $6 \mathrm{MV}$.

Tabela 10. Doses planejadas no simulador STEEV fornecidas pelo sistema de planejamento Eclipse 10.0.

Tabela 11. Doses Médias, Mínimas e Máximas obtidas pelos dosímetros TL de LiF:Mg,Ti (TLD-100) e $\mathrm{CaSO}_{4}: \mathrm{Dy}, \mathrm{OSL}$ de $\mathrm{Al}_{2} \mathrm{O}_{3}: \mathrm{C}$ nanoDots e TLD-500 e câmara de ionização PinPoint $3 D$

Tabela 12. Variação nos valores de dose prescritos nas variações sem a mesa, com a mesa original e com a mesa editada.

Tabela 13. Comparação das respostas OSL dos nanoDot com as três variações de cálculo de planejamento. .... 88

Tabela 14. Comparação das respostas $\mathrm{TL}$ dos $\mathrm{CaSO}_{4}$ :Dy com as três variações de cálculo de planejamento..... 88

Tabela 15. Dose de entrada na pele (DEP) e radiação espalhada para os pontos de medida .92

Tabela 16. Valores de HVL obtidos com $\mathrm{CaSO}_{4}$ :Dy, nanoDots e PTW Diavolt Universal All-in-one QC Meter.

Tabela 17. ESD obtidas com $\mathrm{CaSO}_{4}$ :Dy, nanoDots e PTW Diavolt Universal All-in-one QC Meter...... .95

Tabela 18. Produto dos fatores g e c para simuladores de PMMA. 96

Tabela 19. MGD obtidas com $\mathrm{CaSO}_{4}$ :Dy, nanoDots e PTW Diavolt Universal All-in-one QC Meter. 96 
I Introducão 


\section{INTRODUÇÃO}

A Radioterapia utiliza radiações ionizantes para o tratamento de neoplasias malignas e visa ao extermínio do volume tumoral, de maneira exclusiva ou com terapias associadas. Possui uma das configurações mais complexas na área da saúde no âmbito de arranjo de equipamentos, tecnologias envolvidas e ainda é alvo de grandes avanços tecnológicos [1,2,3].Além do efeito curativo, esse tipo de tratamento também é uma opção eficaz para paliação e controle dos sintomas em cânceres reincidentes ou em estágios avançados, minimizando sofrimentos e proporcionando maior qualidade de vida aos pacientes [4].

$\mathrm{Na}$ radioterapia moderna, muitos esforços estão sendo investidos para melhorar a conformidade de distribuição de dose, bem como a integração de técnicas de imagem para rastreamento de tumores e correção de variações inter e intrafração [5]. Dentre elas, podemos destacar a terapia por intensidade modulada de feixe (IMRT - Intensity Modulated Radiation Therapy) [6], técnicas guiadas por imagem (IGRT - Image Guided Radiation Therapy) [7], radiocirurgiasesterotáticas (SRS - Stereotactic Radiation Surgery) [8], tratamentos em arco volumétrico conformacional (VMAT - Volumetric Modulated Arc Therapy) [9], entre outras.

O tratamento por IMRT é uma das formas da radioterapia conformacional. Consiste em modular a intensidade do feixe de múltiplos campos de radiação por meio de colimadores multilâminas (MLC - Multileaf Collimator) de forma que, com superposição destes campos, as distribuições de dose forneçam uma perfeita conformação ao tumor, diminuindo a probabilidade de complicações nos tecidos normais adjacentes $[6,10]$.

Já o VMAT é um aprimoramento da IMRT e é uma das técnicas mais recentemente utilizadas. Nela, o tratamento é fornecido também de forma conformada, mas as irradiações se dão com uma [11] ou várias rotações do gantry [12] do acelerador linear, durante o/os qual/quais as lâminas MLC se movem dinamicamente enquanto a taxa de dose e velocidade do gantry varia continuamente $[9,11,13]$. Ambas as técnicas podem ser guiadas por imagem (IGRT), desde que haja dispositivos de aquisição instantâneos acoplados ao acelerador linear, e que antes ou durante cada fração, seja feita a verificação do posicionamento e/ou movimentação dos órgãos. Tais imagens podem ser de portais $\mathrm{kV}, \mathrm{MV}$ ou Cone-Beam CT $[8,14]$.

Os processos de radioterapia são complexos e envolvem a compreensão dos princípios da física médica, radiobiologia, proteção radiológica, dosimetria, planejamento, simulação e interação da radiação com outras modalidades de tratamento [15]. Seguindo o raciocínio, um 
programa de garantia de qualidade deve ser estabelecido, avaliando fatores clínicos, dosimétricos, físicos, de transferência de informações, entre outros [2,4].

A verificação de doses nos pacientes é fundamental para garantir a qualidade no tratamento, bem como para a diminuição na recorrência de recidivas. Organizações internacionais, tais como a AAPM (American Association of Physicists in Medicine) [16] e a ESTRO (Europian Society of Therapeutic Radiology and Oncology) [17,18], constantemente publicam recomendações e manuais propondo melhorias nesses cálculos e padronização dos procedimentos.

São vários os tipos de dosímetros que vêm sendo empregados na verificação de feixes de fótons de energias altas. Dentre eles podemos citar as câmaras de ionização [19-22], dosímetros Fricke [23,24], Diodos e MOSFETs [22], dosímetros termoluminescentes (TLDs) [25-30] e, mais recentemente, os dosímetros opticamente estimulados (OSLDs) [31,32]. Esses últimos vêm obtendo destaque internacional e suas diversas aplicações vêm sendo estudadas, tais como na dosimetria clínica, dosimetria in vivo, datações arqueológicas, dosimetria retrospectiva e monitorações para fins de proteção radiológica [3139].

Os dosímetros OSL têm ganhado recente importância em radioterapia e para a dosimetria das radiações ionizantes [34-40]. O Óxido de Alumínio crescido em baixa pressão na atmosfera de Carbono $\left(\mathrm{Al}_{2} \mathrm{O}_{3}: \mathrm{C}\right)$, de maneira geral, tem fornecido bons resultados como detector luminescente [34-40]. Esses dosímetros possuem vantagens sobre os TL pela sua alta sensibilidade, extenso intervalo de linearidade em resposta à dose (exposições da ordem de $1 \mu \mathrm{Gy}$ a $10 \mathrm{~Gy}$ ) [34], maior rapidez de leitura, possibilidade de múltiplas releituras e a não necessidade de realizar o tratamento térmico (annealing) das amostras [31-34,37].

Além disso, os processos eletrônicos e características dos cristais dosimétricos utilizados são relativamente similares ao método TL, a diferença significativa está na sua leitura: a interpretação dos detectores OSL é realizada por luz Laser ou LED e a dos TL por calor [34,37]. Não havendo necessidade de aquecimento, os cristais OSL podem ser misturados e/ou envoltos em material plástico, dessa maneira, podem ser produzidos monitores mais robustos e eficientes [31,33].

Para garantir a qualidade do tratamento e manter as incertezas totais e dosimétricas em $\pm 5 \%$ conforme recomenda a ICRU (International Commissionon Radiation Units and Measurements) [41], os parâmetros a serem analisados nas medidas OSL são:

- Constância do Sinal

- Reprodutibilidade 
- Repetibilidade

- Linearidade

- Limites mínimo e máximo de detecção

- Instabilidade do Sinal

- Decaimento térmico e óptico

- Reutilização dos dosímetros

- Dependência energética da resposta

Pesquisas fazendo uso de dosímetros OSL de $\mathrm{Al}_{2} \mathrm{O}_{3}: \mathrm{C}$ na análise de feixes de fótons de energias altas aplicados em radioterapia vem sendo realizadas, desde seu uso para análise de parâmetros do feixe [40] a técnicas de dosimetria de pacientes, controle de qualidade e medidas in vivo [31-37]. No entanto, o número de artigos publicados ainda é pequeno e a falta de protocolos estabelecidos e caracterização dos OSLDs permanecem como principal obstáculo para sua popularização na dosimetria clínica [42]. Outro fator que impede maiores pesquisas nesse sentido é o alto custo a ser investido nos cristais dosimétricos e nas leitoras específicas.

Já bem estabelecidas na literatura, a maioria das experiências documentadas na dosimetria de fótons clínicos de energias altas foram realizadas utilizando dosímetros TL de Fluoreto de Lítio (LiF:Mg,Ti), tais como o TLD-100 [26], comercializado pela Harshaw Chemical Company, e os micro dosímetros de LiF [29], que são detectores semelhantes aos TLD-100, porém com dimensões de 1 x 1 x $1 \mathrm{~mm}^{3}$. Outro material TL, o Sulfato de Cálcio ( $\mathrm{CaSO}_{4}$ :Dy), fabricado e comercializado pelo Laboratório de Materiais Dosimétricos da Gerência de Metrologia das Radiações/IPEN, bastante empregado em medidas de dose em nível de radioproteção[27,28] devido à sua alta sensibilidade e baixo custo, vem sendo avaliado para fins de aplicação na dosimetria clínica. Este material também apresenta um extenso intervalo de linearidade da resposta com a radiação [27].

O Laboratório de Materiais Dosimétricos do IPEN vem pesquisando e desenvolvendo trabalhos relacionados à dosimetria de fótons e elétrons clínicos utilizando os dosímetros de LiF:Mg,Ti e $\mathrm{CaSO}_{4}: D y$ em função de objetos simuladores constituídos de diferentes materiais equivalentes ao tecido tais como: PMMA, água sólida e água, obtendo resultados extremamente satisfatórios por Nunes [43], Bravim [29,44], Sakuraba [45] e Matsushima [46]. Posteriormente, Nunes [47] desenvolveu um dosímetro TL de $\mathrm{CaSO}_{4}$ :Ce,Eu de excelente resposta tanto para dosimetria ocupacional, quanto para a clínica.

As pesquisas mais recentes do instituto têm envolvido a dosimetria de fótons de energias altas utilizados na técnica de IMRT com feixes estáticos e em arco conformacional. A tese de 
Doutorado de Matsushima [48] avaliou as respostas TL e OSL dos dosímetros de LiF, microLiF e $\mathrm{Al}_{2} \mathrm{O}_{3}: \mathrm{C}$ com planejamento IMRT estático e irradiações TSI. A tese de Doutorado de Bravim [49] avaliou as respostas TL e OSL dos mesmos dosímetros com planejamento VMAT. A tese de Doutorado Direto de Sakuraba [50] desenvolveu um sistema de verificação dosimétrica tridimensional utilizando solução Fricke gel para aplicação em campos IMRT e VMAT. 
II Objetivos 


\section{OBJETIVOS}

\subsection{Objetivos gerais}

Avaliar e comparar o desempenho dos dosímetros OSL de óxido de alumínio $\left(\mathrm{Al}_{2} \mathrm{O}_{3}\right.$ :C) fabricados pela Landauer Inc. com os fabricados pela Rexon ${ }^{\mathrm{TM}}$ na dosimetria de feixes clínicos de fótons de energias altas empregados em radioterapia com tratamento em arco modulado volumétrico (VMAT) utilizando diferentes objetos simuladores.

\subsection{Objetivos específicos}

- Avaliar as propriedades dosimétricas OSL do $\mathrm{Al}_{2} \mathrm{O}_{3}: \mathrm{C}$ para a radiação gama do ${ }^{60} \mathrm{Co}$ livre no ar e em condições de equilíbrio eletrônico;

- Avaliar o desempenho dos dosímetros OSL de $\mathrm{Al}_{2} \mathrm{O}_{3}: \mathrm{C}$ na dosimetria de feixes clínicos de fótons aplicados em radioterapia por arco volumétrico conformacional - VMAT;

- Comparar o desempenho dos dosímetros OSL de $\mathrm{Al}_{2} \mathrm{O}_{3}: \mathrm{C}$ com os dosímetros TL de LiF:Mg,Ti comercialmente disponíveis, e os de $\mathrm{CaSO}_{4}$ :Dy produzidos no IPEN;

- Verificar a aplicabilidade dessa metodologia de avaliação para as clínicas e hospitais que realizam procedimentos radioterápicos;

- Estabelecer uma metodologia para a avaliação de dose no tratamento de paciente com feixe de fótons com o planejamento em arco volumétrico conformacional - VMAT;

- Comparar os resultados obtidos com os dados do planejamento.

- Avaliar o desempenho dos dosímetros OSL de $\mathrm{Al}_{2} \mathrm{O}_{3}: \mathrm{C}$ em outras aplicações, tais como dosimetria de área, controle de qualidade e testes de desempenho em mamografia digital.

Espera-se com esse trabalho a padronização de um método de dosimetria de fótons de energias altas empregando a técnica de luminescência opticamente estimulada em planejamentos VMAT; o desenvolvimento de um sistema dosimétrico que atenda às recomendações internacionais e que atenda às necessidades de controles de dose em instituições de tratamento radioterápico com VMAT. 
III Fundamentacão Teórica 


\section{FUNDAMENTAÇÃO TEÓRICA}

\subsection{Teoria da luminescência: visões TL e OSL}

O efeito da luminescência em um material foi primeiramente documentado por Robert Boyle, em 1663, em um artigo sobre sua observação da liberação de fótons de luz quando um diamante foi aquecido (termoluminescência) [25]. Em dosimetria, essa teoria é aplicada na técnica TL, utilizando como estímulo de leitura o aumento da temperatura; e na técnica OSL, utilizando de feixes de luz laser ou LED de comprimento de onda específico. Pode ser descrito considerando a existência de dois estágios fundamentais em materiais sólidos: a perturbação do sistema em equilíbrio, levando-o para um estado metaestável; e o relaxamento do sistema estimulado termicamente, trazendo de volta o equilíbrio do sistema. [25].

Os materiais luminescentes, em suma, são cristais iônicos que possuem em sua estrutura cristalina níveis de energia. Este modelo, bem conhecido como modelo de bandas, infere a presença de três bandas de energia fundamentais: as bandas de valência (BV), de condução (BC) e proibida (BP). A banda de valência possui uma grande quantidade de elétrons, enquanto a banda de condução está completamente vazia. Ambas as bandas estão separadas pela banda proibida na qual se concentram os níveis de energia correspondentes aos "defeitos" dados pelas impurezas presentes na rede cristalina do cristal. Estes defeitos permitem, sob certas condições, a formação de estados metaestáveis de energia no material [51].

Uma vez que o material é irradiado, os elétrons que se encontram na banda de valência são excitados, passando à banda de condução, deixando no lugar deles na banda de valência, o chamado buraco. Ambos, os elétrons e buracos, nas suas respectivas bandas de condução e de valência, movimentam-se livremente até se recombinarem ou até serem capturados nas armadilhas. O total de cargas armadilhadas nesse nível de energia é proporcional ao total de dose de radiação ionizante absorvida pelo material [51]. 


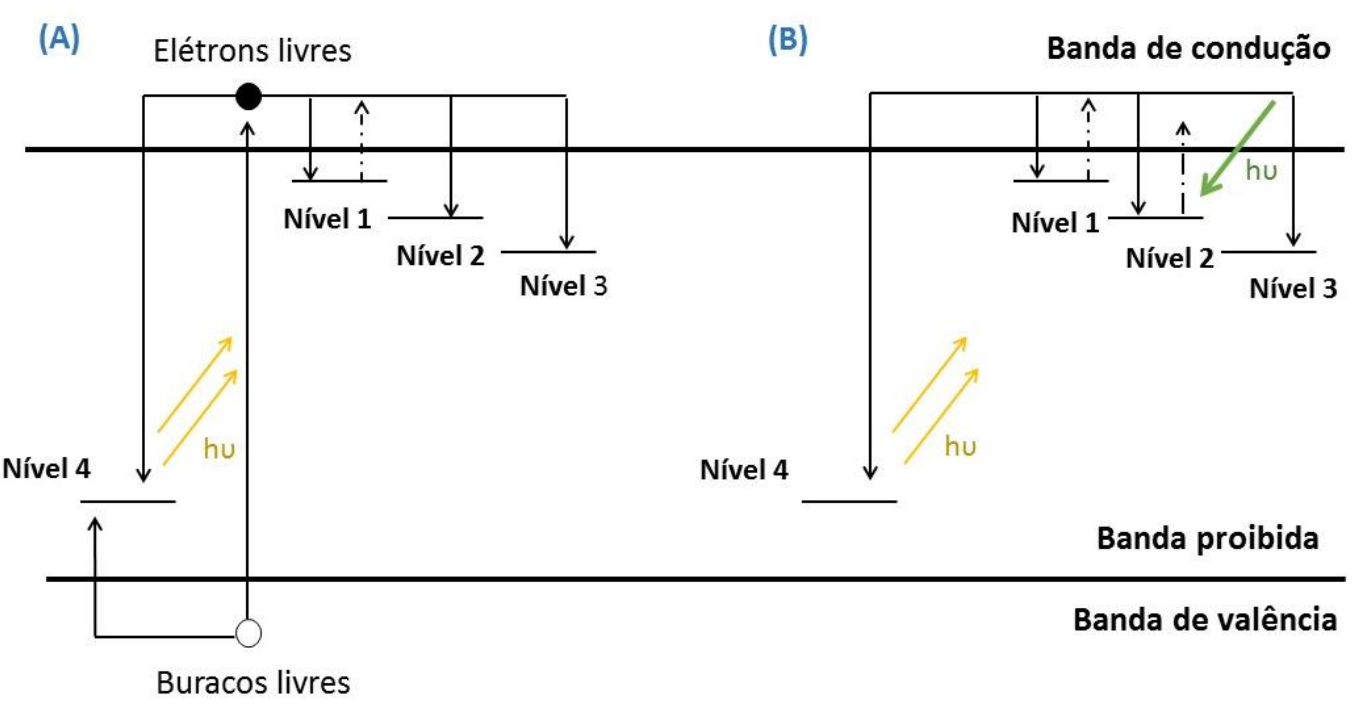

Figura 1. Modelo de bandas simplificado com 4 níveis de armadilhamento. A) Transição eletrônica durante a fase de irradiação do material (excitação). B) Transição eletrônica durante a fase de leitura do material (relaxação) [Adaptado de 51].

Para se recuperar o valor da dose de radiação depositada no material, submete-se o mesmo a uma estimulação, seja com calor (processo TL), ou luminosa de comprimento de onda específico (OSL), que faz com que as cargas armadilhadas voltem à banda de condução, resultando na liberação do par elétron-buraco e na emissão de um sinal luminoso que, por sua vez, também é proporcional à quantidade de radiação depositada.

Na Figura 1 são ilustrados os processos descritos anteriormente. Na Figura 1A as transições eletrônicas durante o processo de irradiação do material são mostradas, onde prevalece a criação do par elétron-buraco e o armadilhamento das cargas. Como pode ser observado, além das bandas de valência e de condução, existe um buraco armadilhado como centro de recombinação e quatro tipos de armadilhas para elétrons: as superficiais (Nível 1), as dosimétricas (Nível 2), as profundas (Nível 3), e as armadilhas para (Nível 4). Justamente nas armadilhas dosimétricas é onde é liberado o sinal luminoso que pode ser aproveitado na dosimetria. Já na Figura 1B são mostrados os arranjos eletrônicos provocados pela saída dos elétrons das armadilhas após o material ser estimulado opticamente. Deve ser notado que a diferença entre os estados de irradiação e de leitura é bem simples, uma vez que ambos os processos, devido à sua própria natureza, podem acontecer em qualquer uma das fases [34,51].

Tanto os elétrons como os buracos armadilhados no nível de energia 3, representado na Figura. 1B, podem se mostrar concorrentes durante os processos de irradiação/leitura devido à captura das cargas nas bandas de valência e condução. Já que as armadilhas profundas se encontram cheias, a sensibilidade do material OSL pode aumentar ou diminuir, isto vai depender 
da sua natureza. No entanto, o efeito comumente mensurável é uma dependência não desejável da sensibilidade com o histórico de irradiação do dosímetro OSL [52,53,54]. Esta situação explicaria porque as armadilhas superficiais capturam cargas que saem das armadilhas dosimétricas (Nivel 2 na Figura. 1A), provocando uma diminuição no sinal estimulado. Entretanto, o fato das armadilhas profundas estarem completamente preenchidas faz com que não sejam muito competitivas na hora de capturar as cargas, ficando desse modo mais elétrons disponíveis para a recombinação, o que aumenta significativamente a sensibilidade dos dosímetros.

Esses defeitos na rede cristalina podem ser introduzidos como um resultado do equilíbrio termodinâmico, dopando o cristal durante o seu processo de crescimento e tratamento póscrescimento ou irradiação com partículas energéticas ou fótons. Esses níveis de energia introduzidos pelos defeitos são responsáveis pelo armadilhamento de elétrons e buracos que podem se recombinar. Na ausência de estimulação térmica ou óptica, essa concentração de elétrons e buracos armadilhados pode permanecer estável por longos períodos de tempo, representando um estado metaestável no cristal [51].

\subsection{Principais cristais luminescentes e sistemas de leitura}

\subsubsection{LiF:Mg,Ti (TLD-100)}

O LiF, na sua forma comercial TLD-100 (LiF:Mg,Ti) foi o principal material utilizado em dosimetria TL desde sua introdução no mercado e até hoje é o mais popular empregado em dosimetria pessoal devido a sua equivalência ao tecido humano [55]. O dosímetro foi desenvolvido em colaboração com John R. Cameron pela Harshaw Chemical Company (EUA), que o comercializa como TLD-100 e suas variantes isotópicas TLD-600 e TLD-700 na forma de pó, bastões, discos e pastilhas de 3,2 x 3,2 $\mathrm{mm}^{2}$ e espessuras de 0,14 a 0,90 mm, com massa entre 0,3 e $5 \mathrm{mg}[25]$.

A equivalência do TLD-100 ao tecido é bastante apropriada e a dependência de sua resposta com a energia, taxa de dose e temperaturas de utilização e armazenamento são pequenas no intervalo de doses da radioterapia. É possível alcançar, na prática clínica, uma precisão melhor que $\pm 5 \%$ com as medidas feitas com o LiF:Mg,Ti, de modo que o seu uso nas aplicações médicas é muito recomendável [56,57]. De modo a aumentar a sensibilidade desse 
tipo de dosímetro sua formulação baseia-se aproximadamente de $180 \mathrm{ppm} \mathrm{Mg}^{+2}$ e 10 ppm de $\mathrm{Ti}^{+4}$. Na Tabela 1 são apresentadas algumas características dos dosímetros TL de LiF:Mg,Ti.

Tabela 1. Propriedades da formulação do TLD-100 [Adaptada de 58-60]

\begin{tabular}{|c|c|}
\hline Propriedade & TLD-100 \\
\hline \multirow{3}{*}{ Constituição isotópica } & 7,4 \\
\hline & 92,6 \\
\hline & $\mathrm{Mg}, \mathrm{Ti}$ \\
\hline Número atômico efetivo $(\mathrm{Z})$ & 8,2 \\
\hline Densidade $\left(\mathrm{g} \cdot \mathrm{cm}^{-3}\right)$ & 2,64 \\
\hline Máximo comprimento de onda da luz emitida (nm) & 400 \\
\hline Intervalo de dose útil & $50 \mu \mathrm{Gy}$ a $10{ }^{3} \mathrm{~Gy}$ \\
\hline Decaimento térmico da resposta TL do pico principal a $20^{\circ} \mathrm{C}$ & $<10 \%$ ao ano \\
\hline Supralinearidade (radiação de fótons) (Gy) & 10 \\
\hline Tratamento térmico pré-irradiação & $400{ }^{\circ} \mathrm{C}$ por $1 \mathrm{~h}$ \\
\hline (ciclos seguidos de resfriamento rápido) & $100{ }^{\circ} \mathrm{C}$ por $2 \mathrm{~h}$ \\
\hline Antecedência máxima da irradiação & $24 \mathrm{~h}$ \\
\hline
\end{tabular}

Na Figura 2 está representada a curva de emissão TL típica do LiF:Mg,Ti (TLD-100), respectivos picos de emissão. Essa curva é obtida pela intensidade de sinal luminescente emitido pelo material durante um ciclo de aquecimento em função da temperatura de aquecimento do cristal. Os picos 4 e 5 são os mais utilizados para a leitura da resposta TL, denominados picos dosimétricos. Na curva de emissão TL do LiF:Mg,Ti são observados vários picos de emissão TL, os quais dependem de fatores como: tratamentos pré e pós-irradiação, dose e tipo de radiação, comprimentos de ondas do espectro no qual os dados estão sendo registrados e a sensibilidade do lote de TLDs fornecido pelo fabricante $[25,55]$. 


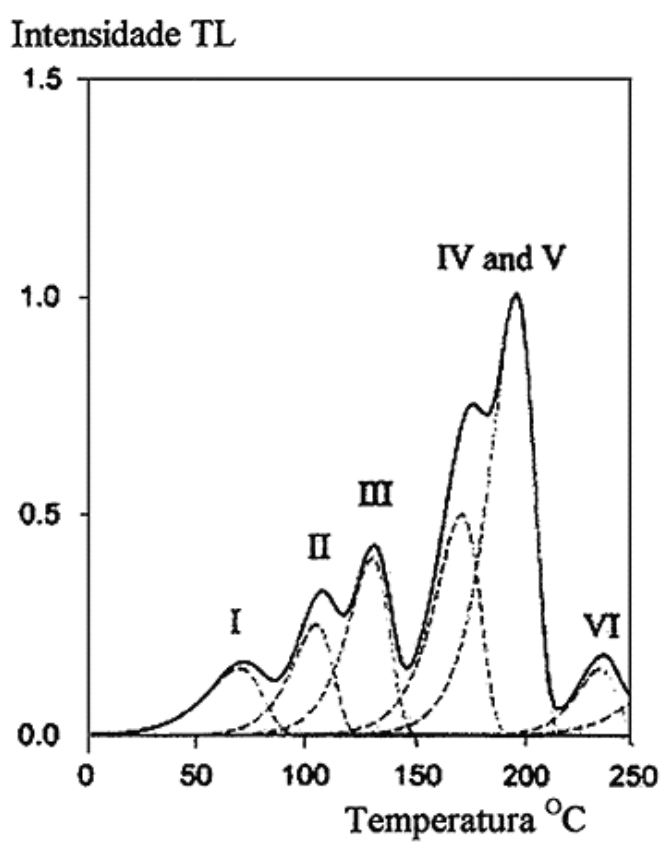

Figura 2. Curva de emissão TL típica do LiF:Mg,Ti [61]

O TLD-100 apresenta perda de 1,5\% da sua sensibilidade a cada $10 \mathrm{~Gy}$ de dose absorvida, com sua reprodutibilidade e repetibilidade variando em até $5 \%$ para uma mesma dose com diferentes ciclos de leitura. Seu decaimento térmico ("fading") varia entre 5 e $10 \%$ ao ano à temperatura ambiente, decaimento óptico desprezível, resposta linear em relação à dose está no intervalo de $\mu \mathrm{Gy}$ a $10 \mathrm{~Gy}$, com sua saturação em $10^{3}$ Gy (Figura 3) e limite inferior de detecção de aproximadamente $500 \mu \mathrm{Gy}[25,55,61]$.

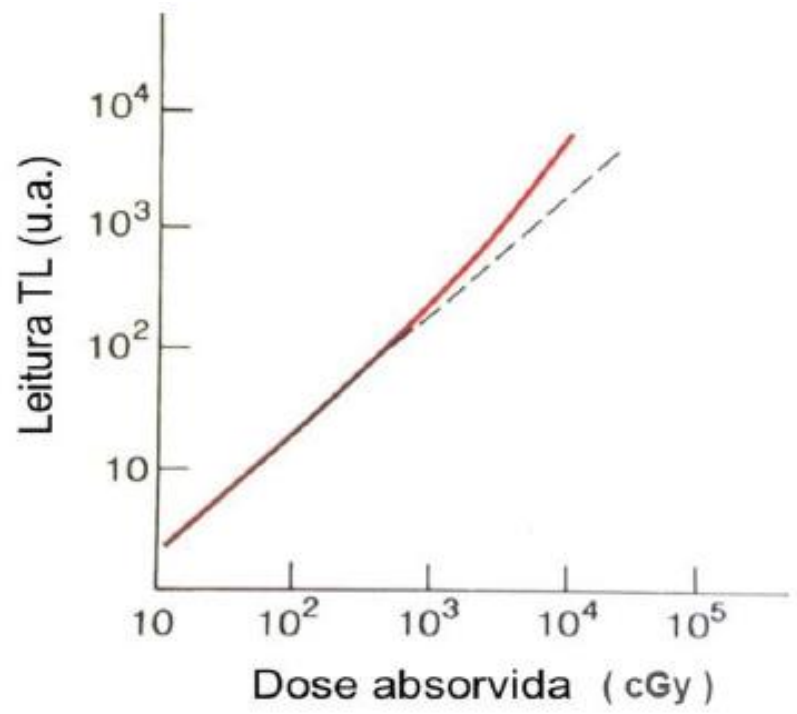

Figura 3. Curva típica de resposta em função da dose do LiF:Mg,Ti [62] 


\subsection{2 $\mathrm{CaSO}_{4}: \mathrm{Dy}$}

$\mathrm{O} \mathrm{CaSO}_{4}$ :Dy é um dosímetro desenvolvido e produzido pelo Laboratório de Materiais Dosimétricos(LMD-IPEN), comercializado na forma de pó e pastilhas de $6 \mathrm{~mm}$ de diâmetro com 0,2 e $0,8 \mathrm{~mm}$ de espessura, com massa de 10 a $50 \mathrm{mg}$, respectivamente. Ele é utilizado na monitoração das radiações de fótons e beta e vem sendo amplamente utilizado em medidas de doses no nível de radioproteção [26-28].

Seu número atômico efetivo é de 104 a 118\% superior ao do tecido humano, considerando este 7,0 ou 7,5. Entretanto, levando em consideração suas dependências energética, com a taxa de dose, com a temperatura de utilização e armazenamento, esse fator insere poucas incertezas no intervalo de doses e qualidades de feixe da radioterapia. Essas características tornam o dosímetro de $\mathrm{CaSO}_{4}$ :Dy uma boa alternativa para as aplicações da dosimetria na área médica. As propriedades da formulação do $\mathrm{CaSO}_{4}$ :Dy são dadas na Tabela 2 [26-28].

Tabela 2. Propriedades da formulação do $\mathrm{CaSO}_{4}$ :Dy [Adaptada de 26,28,60]

\begin{tabular}{cc} 
Propriedade & CaSO4:Dy \\
\hline Material ativador & Dy \\
Número atômico efetivo $(\mathrm{Z})$ & 15,3 \\
Densidade $\left(\mathrm{g} \cdot \mathrm{cm}^{-3}\right)$ & 4,93 \\
Decaimento térmico do pico principal à temperatura & $5 \%$ ao ano \\
ambiente & 100 \\
Supralinearidade para fótons (Gy) & $300^{\circ} \mathrm{C}$ por $3 \mathrm{~h}$ \\
Tratamento térmico pré irradiação & $24 \mathrm{~h}$ \\
Antecedência máxima da irradiação (fim do ciclo)
\end{tabular}

A Figura 4 mostra a curva de emissão do $\mathrm{CaSO}_{4}$ :Dy. Nela são observados dois picos de emissão distintos, o primeiro na temperatura de $145^{\circ} \mathrm{C}$ e o segundo a $250^{\circ} \mathrm{C}$, os quais são associados a armadilhas de dois níveis de energia diferentes [26]. 


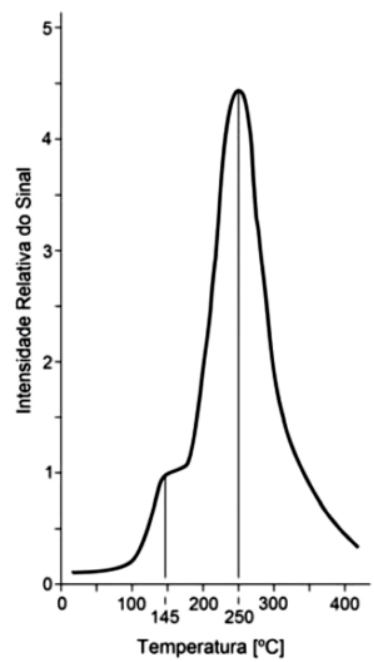

Figura 4. Curva de emissão TL típica do $\mathrm{CaSO}_{4}: \mathrm{Dy}[26]$

$\mathrm{O} \mathrm{CaSO}_{4}$ :Dy possui sensibilidade cerca de uma ordem de magnitude maior que o LiF:Mg,Ti e sua resposta pode ser de 30 a 50 vezes maior para uma mesma dose irradiada. Sua reprodutibilidade e repetibilidade variam em até $5 \%$ para uma mesma dose com diferentes ciclos de leitura. Seu decaimento térmico é cerca de $5 \%$ por um período de 6 meses à temperatura ambiente, decaimento óptico desprezível, resposta linear em relação à dose está geralmente no intervalo de $\mu \mathrm{Gy}$ a $10 \mathrm{~Gy}$, supralinearidade até $5 \mathrm{kGy}$ e saturação em $10^{4} \mathrm{~Gy}$ (Figura 5) e limite inferior de detecção de aproximadamente $1 \mu \mathrm{Gy}[26,27,55]$.

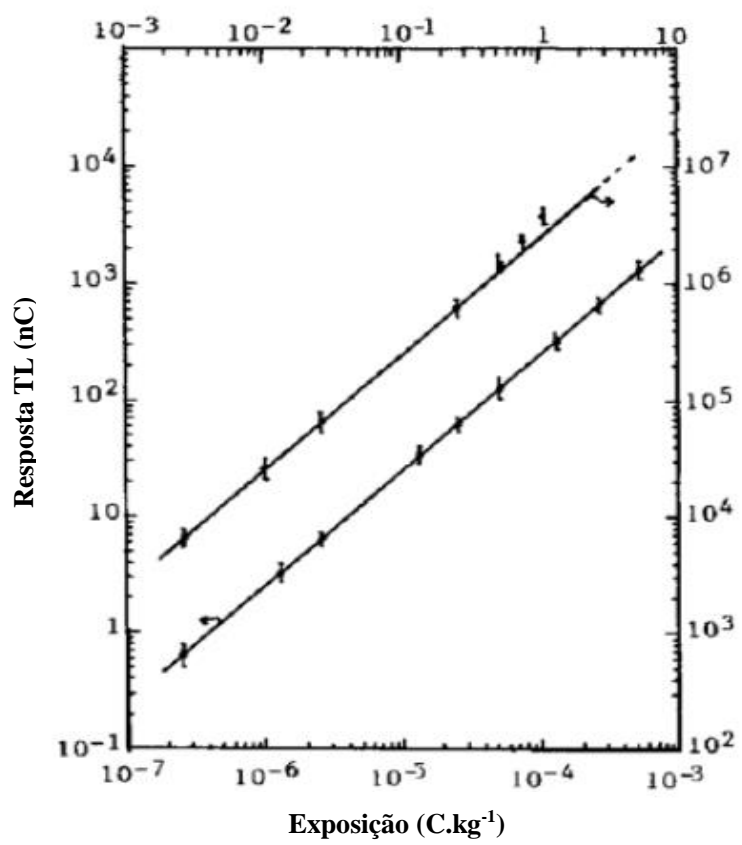

Figura 5. Curva típica de resposta em função da dose do $\mathrm{CaSO}_{4}:$ Dy produzido pelo IPEN [27] 


\subsection{3. $\mathrm{Al}_{2} \mathrm{O}_{3}: \mathrm{C}$}

O material ideal para uso em dosimetria OSL deve satisfazer características, por vezes conflitantes: possuir armadilhas profundas e termicamente estáveis para armazenar em longo prazo as informações dosimétricas sem perdas significativas e, ao mesmo tempo, estas armadilhas devem ser opticamente acessíveis usando fontes de luz com comprimentos de onda separados das bandas de emissão dos centros de recombinação. Isto implica que não há diferenças entre materiais OSL e TL, e que todos os fósforos eficientes em dosimetria podem apresentar ambas as propriedades $[34,63]$.

O uso de compostos de óxido de alumínio como material dosimétrico começou no início dos anos 50. Inicialmente testados como compostos $\alpha-\mathrm{Al}_{2} \mathrm{O}_{3}: \mathrm{C}$ na dosimetria TL, o material foi dopado com inúmeros elementos ( $\mathrm{Si}, \mathrm{Ti}, \mathrm{Mg}, \mathrm{Y}, \mathrm{Cr}$ ). Porém, não apresentava uma sensibilidade significativa como material OSL [64-71]. No final dos anos 80 começou a ser testada a introdução do carbono como material dopante resultando nos primeiros dosímetros TL de alta sensibilidade [72] e posteriormente como excelente material OSL $[73,74]$.

Como dosímetro $\mathrm{OSL}, \mathrm{o} \mathrm{Al}_{2} \mathrm{O}_{3}: \mathrm{C}$ se mostrou promissor por possuir uma boa relação entre o sinal luminoso emitido e a dose de radiação absorvida, um decaimento do sinal (fading) baixo ou nulo e uma excelente estabilidade com respeito às condições ambientais.

Os cristais de $\mathrm{Al}_{2} \mathrm{O}_{3}$ (Figura 6) possuem uma estrutura hexagonal compacta. Para dopálo com carbono, comumente é utilizada a técnica de Stepanov, que consiste em submeter cristais de $\mathrm{Al}_{2} \mathrm{O}_{3}$ a altas temperaturas numa atmosfera rica em carbono, para logo a seguir serem cristalizados a baixa pressão. Sob tais condições, vacâncias de oxigênio (centros F) estáveis são criadas pelo processo de "coloração subtrativa". A ocupação das vacâncias de oxigênio por dois elétrons dá origem a um centro-F neutro, enquanto a ocupação por um elétron forma, no que diz respeito à estrutura, uma vacância carregada positivamente, um centro- $\mathrm{F}^{+}$. Estes centros se identificam pela forte absorção de energia na banda de $205 \mathrm{~nm}$, atribuída aos centros-F e pelas duas sobreposições nas bandas de 230 e $255 \mathrm{~nm}$ atribuídas às transições de energia nos centros-F+ [34]. 


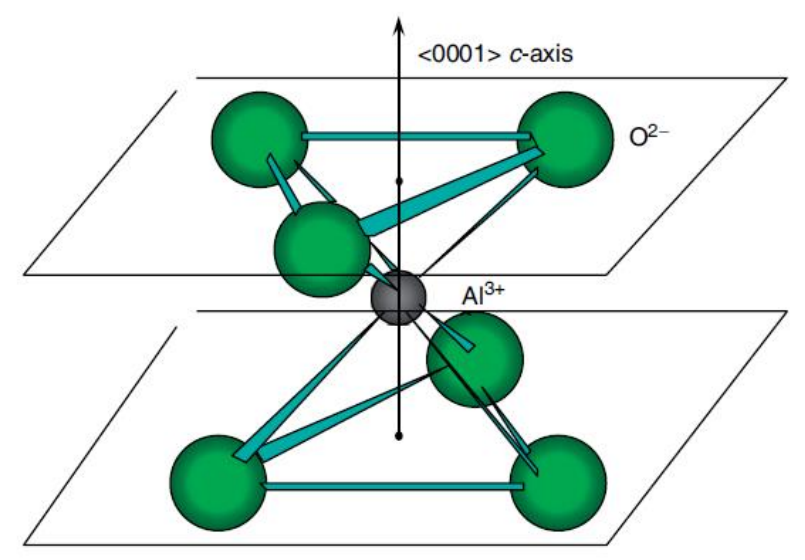

Figura 6. Estrutura simplificada de um cristal de $\mathrm{Al}_{2} \mathrm{O}_{3}: \mathrm{C}[34]$

A produção de centros-F+ (Figura 7) durante a irradiação do $\mathrm{Al}_{2} \mathrm{O}_{3}: \mathrm{C}$ provoca um aumento significativo da sensibilidade do material. Esta situação é sugerida porque as vacâncias de oxigênio na forma de centros- $\mathrm{F}^{+}$, formadas nos cristais iônicos de $\mathrm{Al}_{2} \mathrm{O}_{3}$ dopado com carbono numa atmosfera rarefeita, são consequência da compensação fornecida pelas cargas dos íons de carbono bivalentes, substituindo os íons trivalentes de $\mathrm{Al}_{3}{ }^{+}$[34].

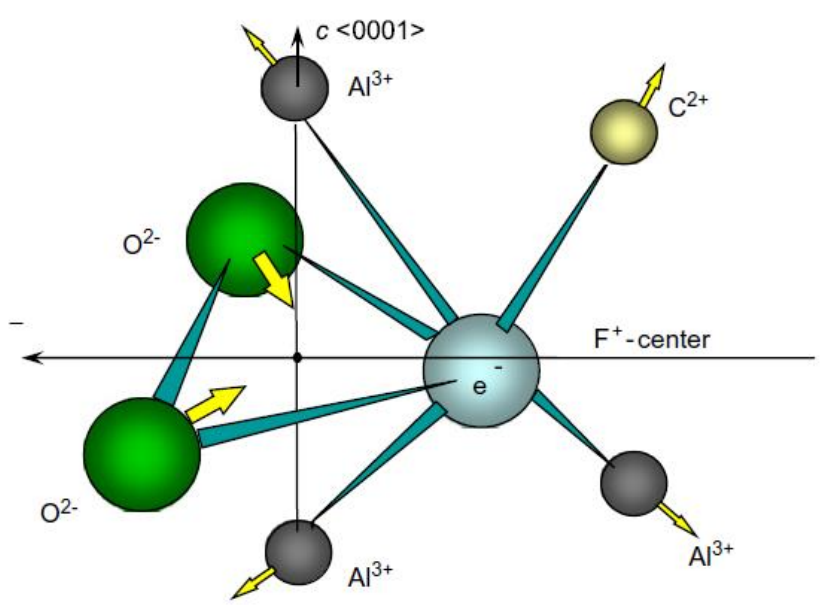

Figura 7. Configuração sugerida para a estrutura do $\mathrm{Al}_{2} \mathrm{O}_{3}: \mathrm{C}$ para dos centros- $\mathrm{F}^{+}$[34].

São considerados importantes parâmetros dosimétricos do $\mathrm{Al}_{2} \mathrm{O}_{3}: \mathrm{C}$ sua alta sensibilidade à radiação (obtendo respostas da ordem de $1 \mu \mathrm{Gy}$ ); seu extenso intervalo de linearidade em função da dose absorvida; o fato de possuir baixo sinal de fundo abaixo do nível de estimulação óptica, ótima combinação das profundidades de energia térmica e óptica das armadilhas e a aceitável seção de choque de fotoionização do comprimento de onda da luz de estimulação [34,51]. 
Assim como os outros dosímetros, o $\mathrm{Al}_{2} \mathrm{O}_{3}: \mathrm{C}$ também possui sua curva de emissão TL. Entretanto, para fins práticos e, levando em consideração o uso do material, a Figura 8 mostra a curva de decaimento do sinal para estímulo luminoso contínuo, e considerando o modelo de bandas demonstrado na Figura 1.

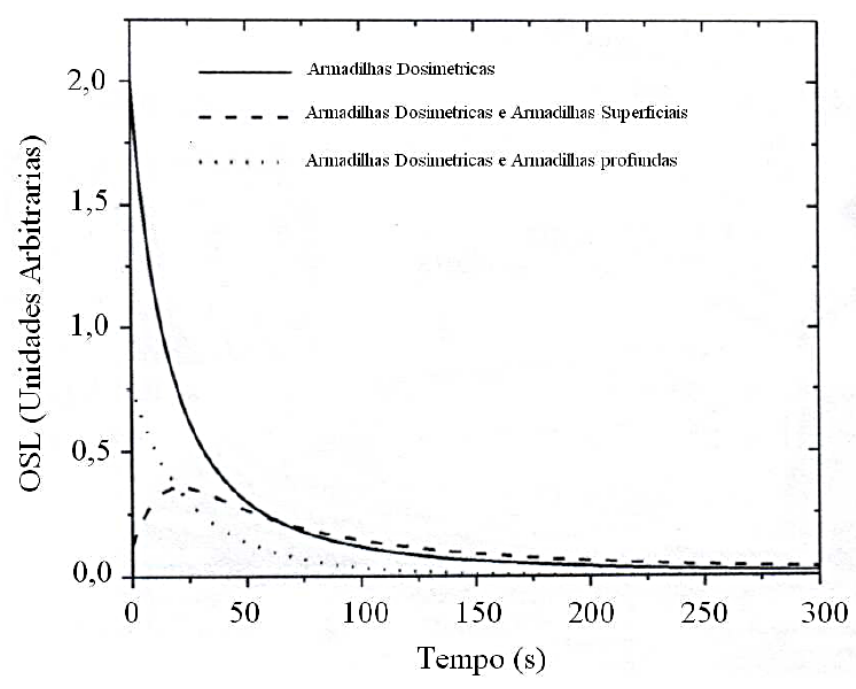

Figura 8. Curvas teóricas de sinal OSL emitido, segundo modelo que considera apenas o movimento de cargas entre diferentes níveis de armadilhas e centros de recombinação [75].

A resposta OSL do $\mathrm{Al}_{2} \mathrm{O}_{3}$ :C é relatada como sendo linear ao longo de uma ampla gama de doses, conforme mostrado na Figura 9 para o intervalo a partir de $\sim 10^{-4}$ a $10 \mathrm{~Gy}$.

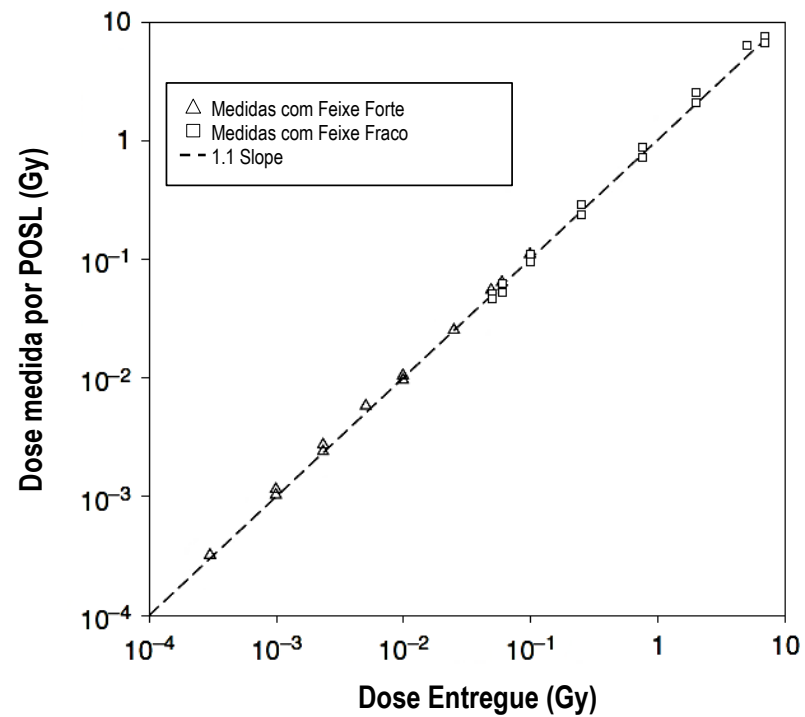

Figura 9. Curva de resposta em função da dose do $\mathrm{Al}_{2} \mathrm{O}_{3}: \mathrm{C}$ em pó, medida utilizando POSL e duas intensidades de feixe luminoso de estimulação [74] 
No entanto, em doses elevadas, a resposta se desvia da linearidade, tornando-se supralinear e, em seguida, sublinear. O grau de supralinearidade é observado a depender da escolha do sinal (intensidade OSL inicial ou área total OSL) e na banda de emissão monitorizada (apenas emissão dos centros-F, apenas a emissão de UV, ou uma combinação de ambas as bandas) [51].

A dependência em relação à escolha do sinal é ilustrada na Figura 10a, na qual apresenta curvas de resposta em função da dose utilizando o sinal inicial OSL ou área total OSL (ambos normalizados para uma dose de 1 Gy) para doses de cerca de até $600 \mathrm{~Gy}$. Em doses abaixo de $1 \mathrm{~Gy}$, a intensidade inicial OSL e a área total OSL são proporcionais um ao outro. No entanto, como o aumento da dose, a intensidade OSL inicial torna-se mais supralinear do que a área total OSL. Os fatores de supralinearidade estão demonstrados na Figura 10b [51].
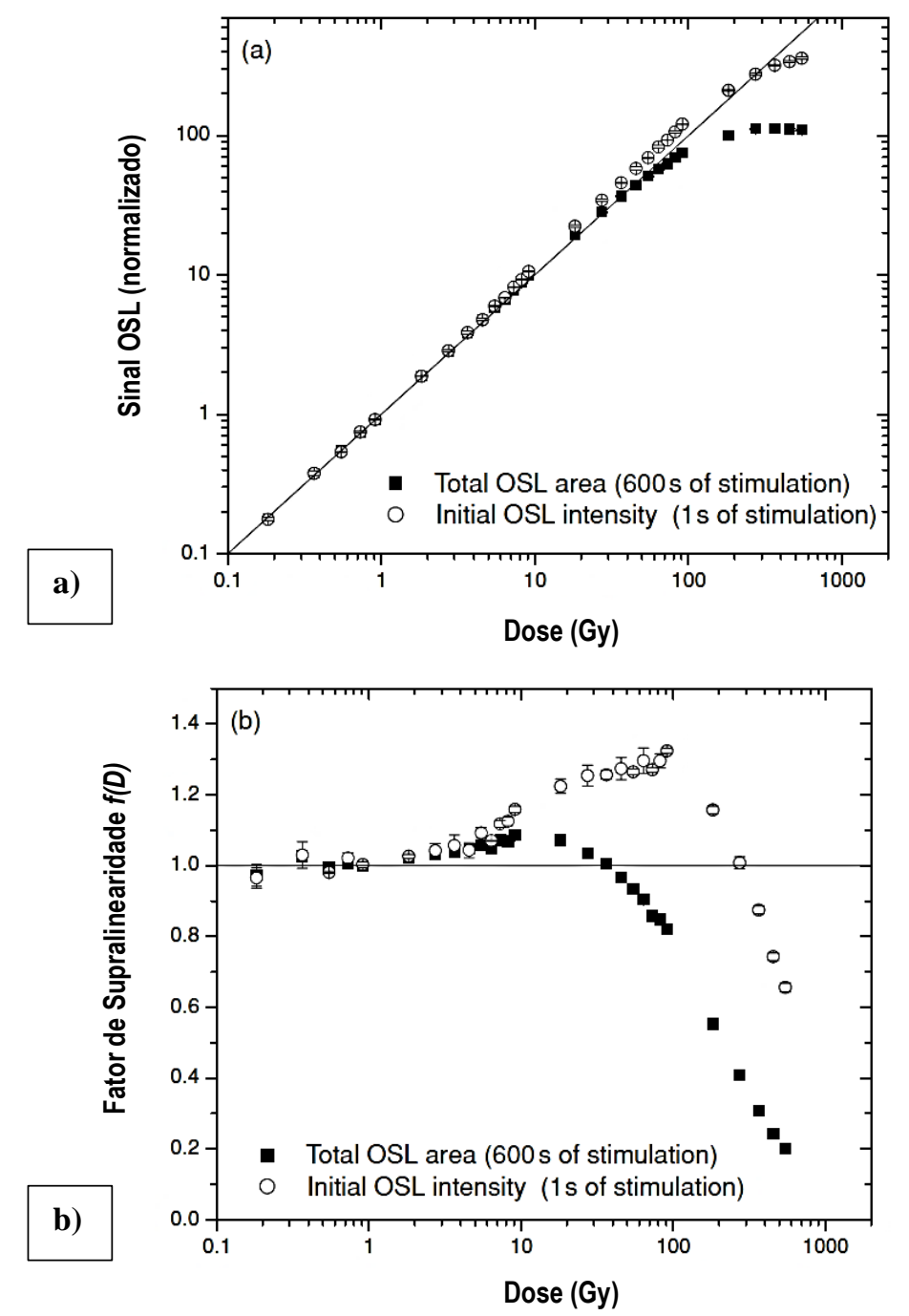

Figura 10. (a) Resposta OSL para doses altas de radiação gama, e (b) supralinearidade para detectores $\mathrm{Al}_{2} \mathrm{O}_{3}: \mathrm{C}$ do modelo Luxel [51] 
Os resultados apresentados nas Figuras 10 a e b [51] foram obtidos com a estimulação verde utilizando um leitor RIS $\varnothing$ e filtros Hoya U-340 (7,5 milímetros de espessura), além de um filtro de $2 \mathrm{~mm}$ de espessura SCHOTT WG-360 em frente do tubo fotomultiplicador (PMT). Os filtros selecionam qual das emissões do material a serem avaliadas. Os dados foram calculados usando tanto a intensidade OSL inicial da área total OSL [51].

O sinal armazenado no material é estável, apresentando decaimento térmico entre 3 e $5 \%$ ao ano e, em determinadas condições, esse mesmo resultado pode ser obtido após 10 sucessivas releituras da mesma amostra. O limite inferior de detecção do material se encontra entre 1 e $5 \mu \mathrm{Gy}$. [34,63].

\subsubsection{Estimulação Termoluminescente (TL)}

A instrumentação necessária para a realização da leitura Termoluminescente desses cristais é ligeiramente simples. O arranjo é composto, basicamente, de um sistema de aquecimento (podendo ser a gás ou elétrico) e uma fotomultiplicadora acoplada, para captar e amplificar a luz emitida. A utilização de filtros na leitura permite a discriminação de sinais indesejados, como da emissão de luz infravermelha por parte dos elementos submetidos a temperaturas elevadas $[55,59]$.

Os leitores podem ser manuais ou automáticos. Leitores automáticos podem processar diversos monitores inteiros, sem necessidade de intervenção do operador. Os monitores são normalmente colocados em fila em cassetes no leitor que os abre e lê, ininterruptamente, armazenando suas leituras para posterior análise ou já calculando as doses, conforme um algoritmo preestabelecido. Em leitores manuais, é preciso abrir os monitores e manusear cada TLD individualmente, colocando-os em pranchetas no interior do leitor [25,55,59]. A Figura 11 esquematiza, de forma simplificada, o arranjo instrumental de uma leitora TL. 


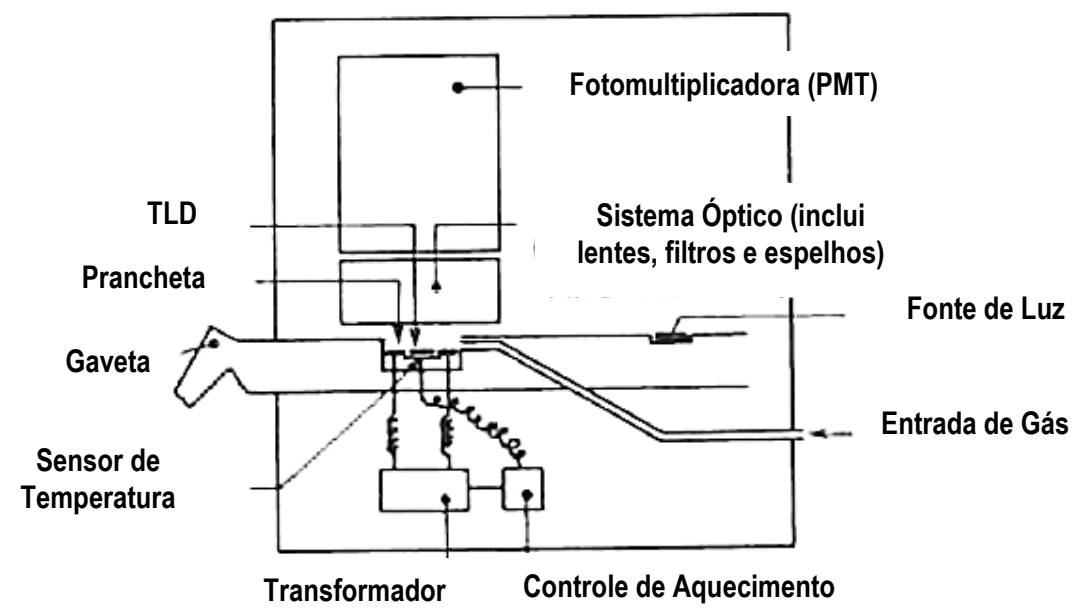

Figura 11. Esquema descritivo de uma leitora TL convencional com sistema de aquecimento controlado por prancheta [25]

O aquecimento de um leitor TL pode ser feito por contato, por aquecimento gasoso, por luz infravermelha, por laser, e outros. A taxa de aquecimento pode variar de poucos graus a dezenas de graus por segundo. A esse fator se dá o nome de "time temperature profile - TTP". Para cada tipo de cristal TL existem recomendações dos fabricantes para o perfil de aquisição do sinal. Um fato importante em um sistema de aquecimento de um leitor TL é que este seja capaz de garantir a reprodutibilidade do ciclo térmico [25].

A luz emitida pelo TLD, depois de passar através de um sistema de filtros ópticos, é detectada por um tubo fotomultiplicador (PMT), que pode ser utilizado em modo de integração de corrente ou contagem de fótons. O mais comum em leitores comerciais é o modo de corrente integrada, onde os fótons são convertidos em corrente elétrica e integrada no tempo como carga, sendo que o sinal pode ser coletado por outros instrumentos de saída de dados analógicos ou digitais $[25,55]$.

O próprio leitor pode fornecer apenas um registro do sinal integrado, possuir um mostrador analógico ou um visor que mostre o sinal luminoso em função do tempo de aquisição, ou pode-se ter armazenamento de toda a curva no software de leitura acoplado a leitora TL, com possibilidade até de deconvolução destas, com uso de algoritmos sofisticados de cálculo de dose. Para atingir a eficiência máxima de detecção, toda a luz produzida pelo TLD deve atingir a camada sensível do detector de luz, o que poderia ser obtido através do contato direto entre o TLD e o fotocatodo; e o tubo fotomultiplicador deve ser escolhido de forma que sua sensibilidade seja máxima na região de comprimento de onda do material TL $[25,55]$.

Para testar a sensibilidade do sistema, toda leitora utiliza uma fonte de luz de referência. Uma fonte de luz constante colocada na mesma posição do TLD pode detectar mudanças de 
sensibilidade tanto do tubo fotomultiplicador quanto do sistema ótico ou do circuito eletrônico. Normalmente, estas fontes de luz são feitas com isótopos radioativos de meias-vidas longas $\left({ }^{14} \mathrm{C}\right.$ ou $\left.{ }^{90} \mathrm{Sr}\right)$ encapsulados em materiais cintiladores, mas podem ser usados também LEDs. A luz emitida por esta fonte de referência deve ter composição espectral similar à do TLD em uso. Esta luz de referência pode fazer parte do leitor (fonte interna) ou ser um acessório independente (fonte externa) [25].

\subsubsection{Estimulação Luminosa (OSL)}

Assim como os leitores TL, os leitores OSL consistem em dois elementos essenciais: uma fonte de luz para estimular o cristal e um transdutor de luz para detectar a luminescência do detector. Um filtro de estimulação é normalmente colocado entre a fonte de luz e o detector OSL para selecionar o comprimento de onda de estimulação ou a banda que é ótima para um material OSL específico. O sinal é detectado pelo transdutor de luz de alta sensibilidade e baixo ruído, tipicamente um tubo fotomultiplicador (PMT). Os filtros de detecção são colocados entre o PMT e o detector OSL para bloquear a luz de estimulação dispersa e isolar bandas de emissão OSL específicas característicos do material OSL. Os elementos ópticos e o suporte do detector são fixados no lugar num invólucro estanque à luz [51]. A Figura 12 esquematiza o arranjo de uma leitora OSL típica.

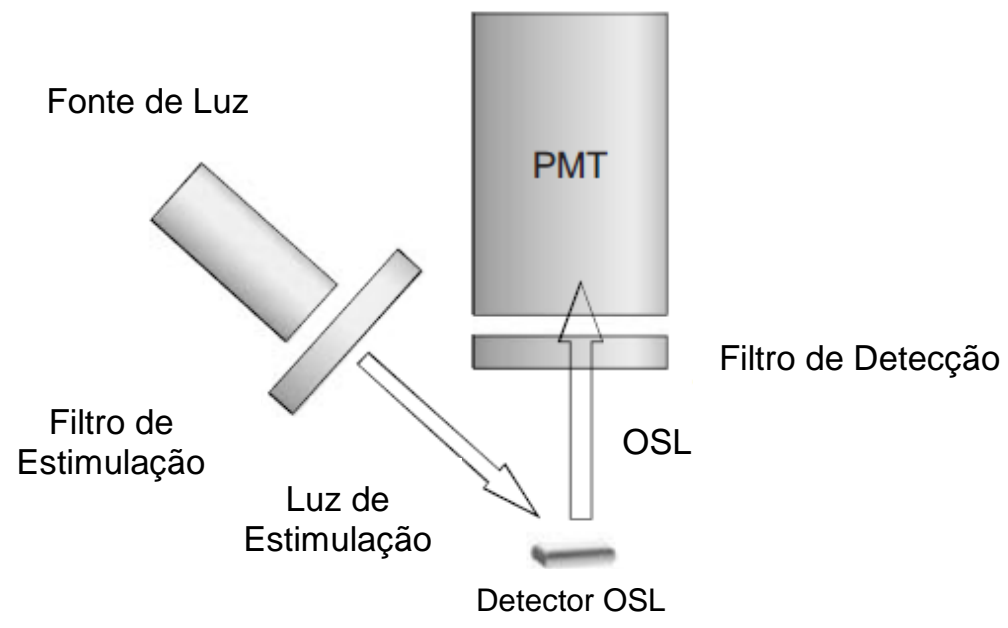

Figura 12. Estrutura esquemática do arranjo de uma leitora OSL [51]

O problema essencial na concepção de um leitor OSL é discriminar a luz de estimulação, que tem intensidades de muitas ordens de magnitude, enquanto otimiza a coleta de sinal OSL 
pelo transdutor de luz. Como exemplo, para uma intensidade de estimulação típica de $10 \mathrm{mWcm}^{-2}$ de luz verde $(525 \mathrm{~nm})$ há mais de $10^{16}$ fótons $\mathrm{cm}^{-2} \cdot \mathrm{s}^{-1}$ atingindo a posição do detector. Em contraste, o número de fótons de OSL detectados pela PMT pode ser da ordem de apenas algumas centenas de fótons por segundo para doses muito baixas [51].

Sendo assim, este é um problema de razão sinal-ruído significativo e o arranjo de leitura OSL envolve a escolha criteriosa da luz de estimulação, dos filtros de estimulação, transdutor de luz e filtros de detecção apropriados para cada material. Podem também ser utilizados elementos ópticos adicionais (espelhos ou lentes) para aumentar a coleta de fótons e a intensidade do sinal OSL detectado, enquanto se diminui a intensidade da luz difusa da fonte de estimulação [51].

A forma de estimular opticamente o material OSL tem mudado muito com o tempo, devido ao alto grau de controle que a estimulação permite com diversas fontes de luz. Basicamente, podem ser mencionadas as três mais comumente utilizadas e que se classificam como: com ondas contínuas, pulsadas ou com modulação linear [34,51,63].

A estimulação OSL com ondas contínuas (Continuous-Wave OSL - CW-OSL) é abordagem de leitura OSL mais simples e consiste em estimular o detector com luz de intensidade constante. Neste caso, a discriminação entre o sinal OSL emitido pela amostra e a luz de estimulação baseia-se apenas na separação dos comprimentos de onda ( $\lambda_{\text {osL }} \neq \lambda_{\text {estim}}$ ). Portanto, é essencial que a banda de transmissão dos filtros de detecção não se sobreponha ao espectro da luz estimulação, que é determinada pela fonte de luz e filtros ópticos utilizados em frente do mesmo. CW-OSL é o método de estimulação mais utilizado na dosimetria e datação devido à sua simplicidade e desempenho frequentemente satisfatório [51]. A Figura 13 mostra o perfil de decaimento do sinal OSL em função do tempo de estímulo óptico utilizando CWOSL.

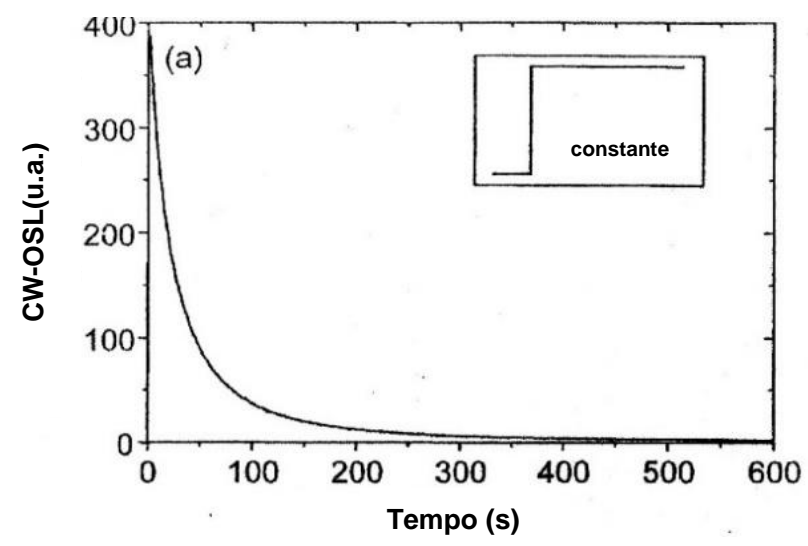

Figura 13. Curva de decaimento OSL típica para estímulo em CW-OSL [63] 
Apesar da simplicidade da técnica CW-OSL, a necessidade de remover completamente a luz de estimulação dispersa requer frequentemente a utilização de filtração óptica que acaba por reduzir significativamente a intensidade do sinal OSL medido. Este problema é mais crítico quanto menor for a separação de comprimento de onda entre a luz de estimulação e a banda de emissão de OSL [51].

Em algumas situações, particularmente medidas de doses baixas, pode ser vantajoso adicionar uma discriminação temporal entre a luz de estimulação e a emissão de sinal OSL em vez de filtros ópticos extras. Isto pode ser feito utilizando uma fonte de luz pulsada e um sistema de detecção fechado que detecta o sinal OSL apenas no período entre os impulsos de estimulação, quando não há luz dispersa. A esta modalidade de leitura OSL deu-se o nome de OSL pulsada (Pulsed OSL POSL). Esta técnica baseia a verificação e detecção da intensidade luminosa em função da integração de vários pulsos luminosos por vez. Para isto, a frequência de pulsação utilizada pode ser da ordem de até milhares de hertz [51]. A Figura 14 demonstra o perfil de decaimento OSL típico para estímulo em POSL.

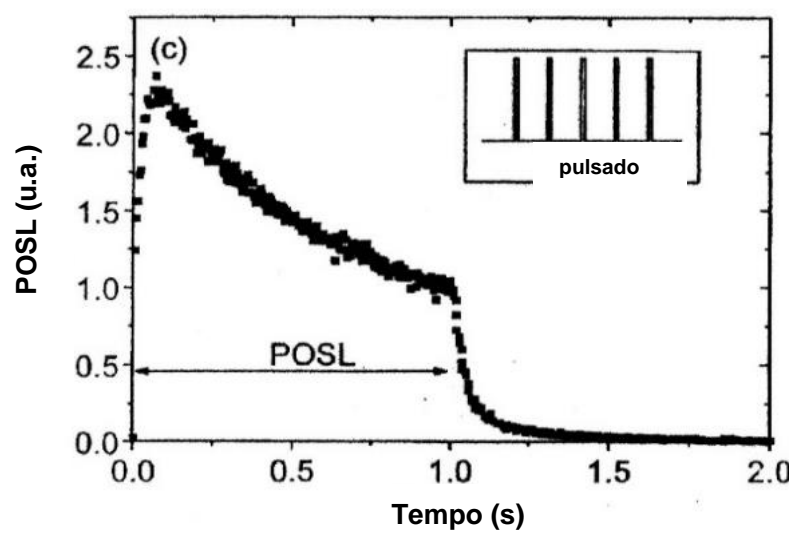

Figura 14. Perfil de decaimento OSL típico para estímulo em POSL [63]

Considerando que CW-OSL e POSL são as variáveis de estimulação predominantes em dosimetria, o alto grau de controle na intensidade de estimulação (por exemplo, controlando a corrente LED) abre a possibilidade de outros modos de estimulação a ser concebidos. Outra variação consiste em cortar bruscamente o estímulo luminoso, cuja intensidade é aumentada linearmente em função do tempo, enquanto é realizada a verificação da intensidade de sinal OSL coletado. Este método também conhecido por OSL por modulação linear (Linear Modulation $O S L$ - LM-OSL). Usando a técnica de LM-OSL, a intensidade de OSL em função do tempo mostra um aumento linear inicial à medida que a intensidade aumenta, seguida de uma diminuição devido à depleção da concentração de carga aprisionada [34,51]. Portanto, os 
gráficos de intensidade LM-OSL são curvas em forma de pico, em vez de decaimentos de tipo exponencial, evidenciado na Figura 15.

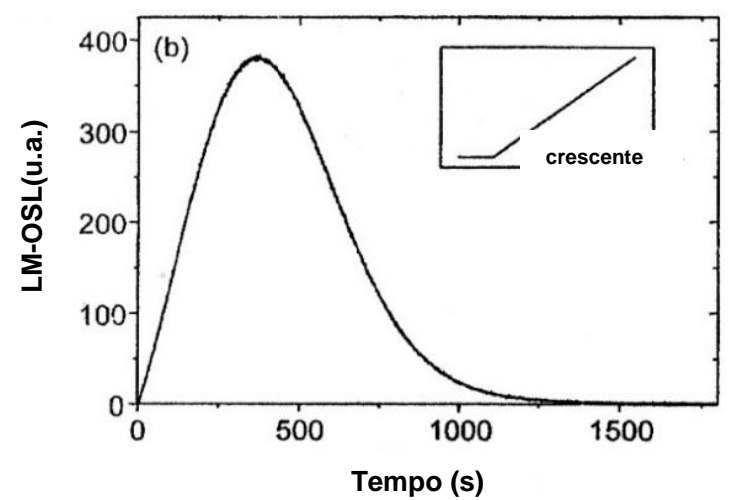

Figura 15. Perfil de sinal OSL obtido realizando a leitura em LM-OSL [63]

Desde meados da década de 90, o RIS $\varnothing$ National Laboratory, da Dinamarca, introduziu no mercado a leitora automática de alta capacidade TL/OSL-DA-15, principalmente para uso em dosimetria de datação [37,76]. Esta leitora possui a capacidade de ler tanto dosímetros TL como OSL e possui arranjo tipo carrossel, como esquematizado na Figura 16.

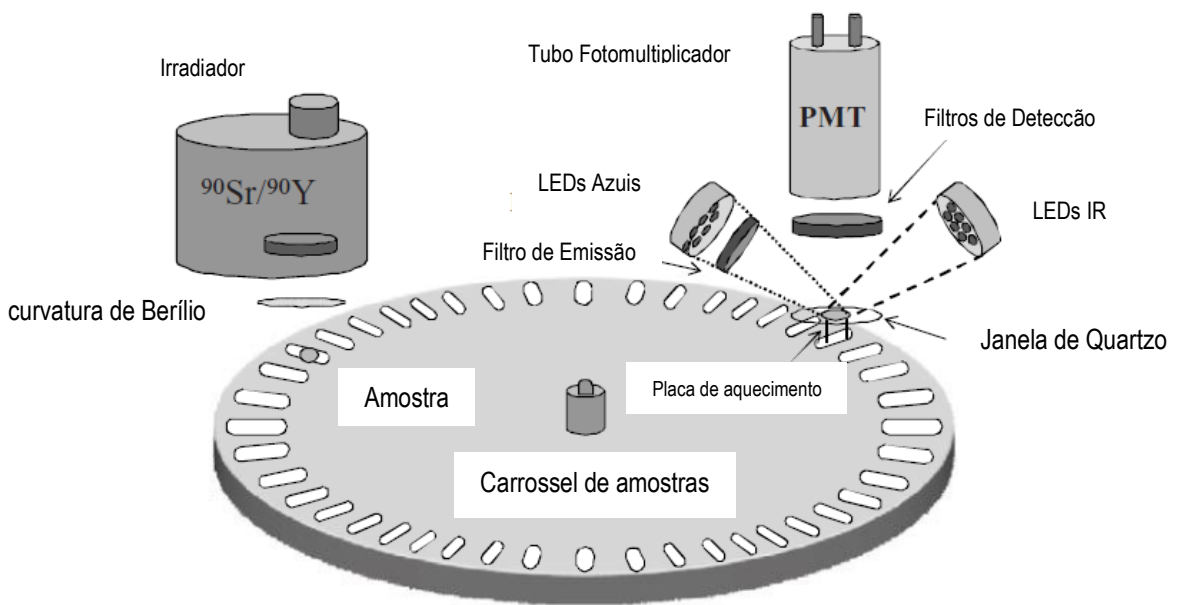

Figura 16. Esquema de uma leitora RISO TL/OSL [51]

Os modelos mais atuais, como por exemplo o TL/OSL-DA-20 do Laboratório de Materiais Dosimétricos do IPEN, oferecem dois arranjos de LEDs para estimulação óptica: azul e infravermelho (IR), seja em CW ou LM-OSL. Os LEDs IR estão arranjados em 3 grupos com 7 LEDs cada, com $145 \mathrm{~mW} . \mathrm{cm}^{-2}$ de potência total. Os LEDs azuis apresentam pico de emissão em $470 \mathrm{~nm}$, com $20 \mathrm{~nm}$ de largura a meia altura arranjados em 4 grupos com 7 LEDs e $80 \mathrm{nW} . \mathrm{cm}^{-2}$ de potência total. Para determinar as faixas de comprimento de onda de transmissão 
durante as medições, a leitora também oferece dois filtros: o Hoya U-340 e o Schott 39. Para aquisição do sinal OSL, a leitora está equipada com o tubo fotomultiplicador (PMT) padrão bialkali EMI 9235QB [51,63,77]. Mais especificações sobre as emissões e transmissões desses itens estão mostradas na Figura 17.

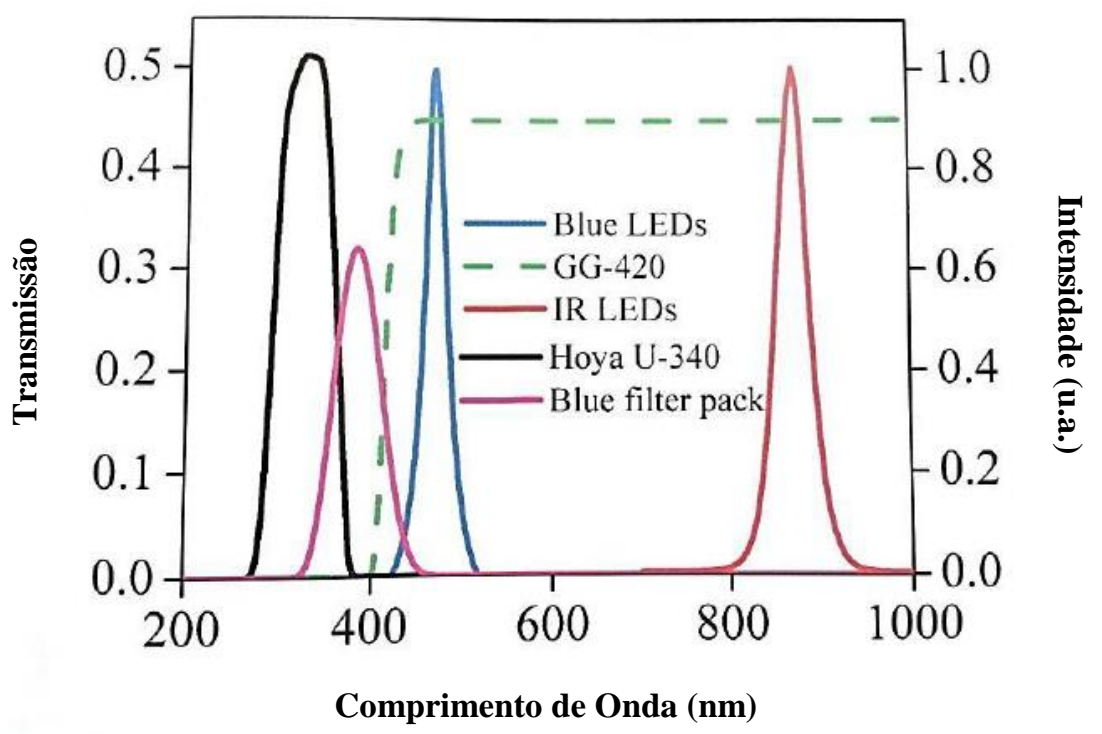

Figura 17. Especificações de emissão e transmissão para diferentes configurações da leitora RISO TL/OSL-DA-20 [77]

A empresa norte-americana Landauer Inc., lançou no final dos anos noventa o sistema Luxel $^{\mathrm{TM}}$ que utiliza o sistema de leitura pulsado através de LEDs emitindo em $532 \mathrm{~nm}$ (verde) com a desvantagem de que os dosímetros só podiam ser lidos na própria empresa. Já em 2006 lançaram o sistema comercial InLight ${ }^{\mathrm{TM}}$ com opções automáticas e/ou manuais e portáteis. Embora o sistema só possa ser utilizado com os dosímetros $\mathrm{Al}_{2} \mathrm{O}_{3}: \mathrm{C}$ InLight ${ }^{\mathrm{TM}}$, o objetivo foi tornar o uso da dosimetria OSL mais acessível e prático, já que o sistema desenvolvido inicialmente para a monitoração individual, foi testado para aplicações de dosimetria clínica com bons resultados $[37,78,79]$.

O sistema InLight ${ }^{\mathrm{TM}}$ utiliza uma matriz de 36 LEDs: todos os 36 (feixe forte) são iluminados para leituras de doses baixas e apenas 6 LEDs (feixe fraco) são iluminados para leituras de doses elevadas. Um pré-teste sob a janela aberta do dosímetro determina a intensidade de LED necessária. Na versão portátil utiliza o leitor microStar ${ }^{\mathrm{TM}}$, capaz de ler medidores de monitoração pessoal InLight ${ }^{\mathrm{TM}}$ ou nanoDots ${ }^{\mathrm{TM}}$. Foi projetado para uma variedade de aplicações, incluindo a dosimetria médica e possui dimensões de aproximadamente $30 \times 20$ × $10 \mathrm{~cm}$ e pesa aproximadamente $15 \mathrm{~kg}$ (Figura 18) [79]. 

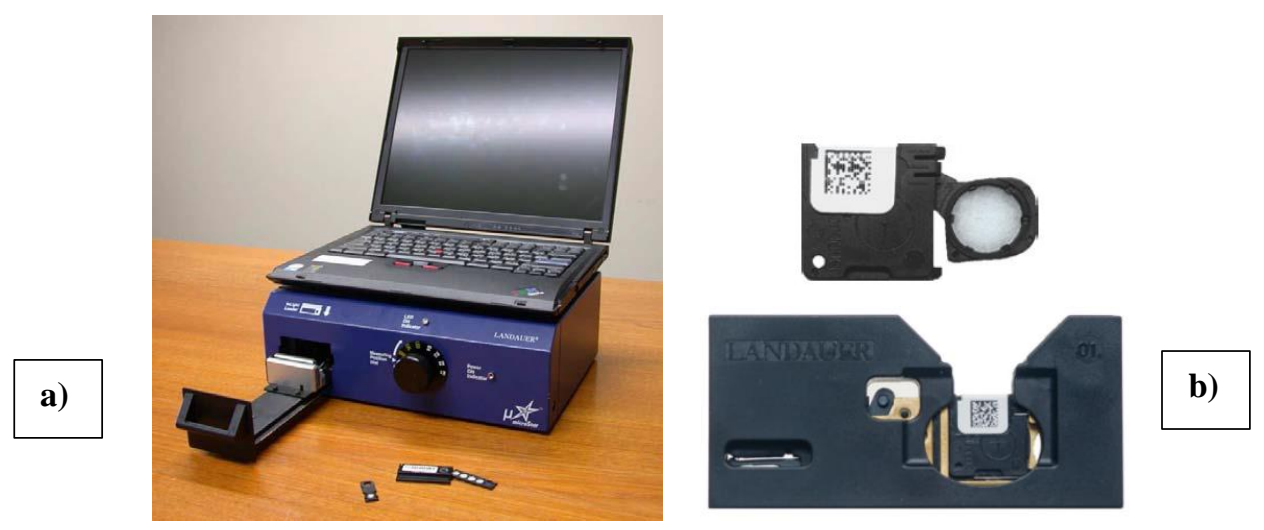

Figura 18. (a) Leitora microStar ${ }^{\mathrm{TM}}$ com microcomputador acoplado (b) dosímetro do modelo nanoDot aberto e acoplado ao adaptador de encaixe da leitora [79]

Para controlar e monitorar a operação, o microStar ${ }^{\mathrm{TM}}$ tem um mostrador e duas luzes indicadoras. O leitor liga através de um cabo USB a um computador externo que controla a configuração, análise e gravação de dados por meio do software ' $\mu$ Star reader'. Procedimentos de controle de qualidade (QC) para garantir resultados de dose precisos incluem: a medição de uma luz padrão de calibração de baixa intensidade (CAL); corrente escura (DARK); intensidade total de LED (LED); a capacidade de calibrar para qualquer conjunto de condições de referência; e o uso de dosímetros de controle de qualidade para testes de CQ periódicos. A frequência dos procedimentos de controle de qualidade é definida pelo usuário e depende da precisão desejada. Para medições normais (viés < $5 \%$ ), a calibração é necessária uma vez por mês ou após o transporte [79].

\subsection{A Dosimetria}

A dosimetria é o método mediante o qual realizamos a medida da dose gerada por um feixe de radiação ionizante. Este procedimento é um dos aspectos mais importantes na garantia da qualidade dos tratamentos na radioterapia. No que diz respeito à radioterapia, é possível subdividi-la em três grandes áreas:

1. Dosimetria física,

2. Dosimetria clínica,

3. Dosimetria in-vivo.

A primeira está relacionada aos parâmetros dos equipamentos utilizados nos tratamentos, sendo parte importante na garantia de um tratamento adequado do paciente. Um exemplo é a dosimetria precisa do feixe terapêutico. A dosimetria clínica cuida do comportamento do feixe de radiação interagindo com o paciente durante seu percurso. Ela é o 
planejamento do tratamento propriamente dito. Procura garantir que as doses prescritas pelo radioterapeuta para o volume alvo, nas condições específicas do tratamento, sejam aquelas efetivamente entregues, produzindo o menor dano possível aos tecidos sadios. Por último, a dosimetria in-vivo, avalia e verifica se a dose que foi planejada para o tratamento em função das características específicas de cada paciente está sendo administrada corretamente dentro das margens de erro aceitáveis.

\subsubsection{A Radioterapia em Arco Modulado Volumétrico (VMAT) e Controle de qualidade}

Na radioterapia moderna, muitos esforços estão sendo investidos para melhorar as linhas de distribuição de dose, bem como a integração de técnicas de imagem para rastreamento tumores e correção de variações inter e intrafrações [5]. Entre eles, destacam-se a Radioterapia Modulada por Intensidade (IMRT), as Radioterapias Estereotácticas (SRS), a Terapia Volumétrica de Arco Modulado (VMAT), entre outras, seguidas por orientação de imagem.

A radioterapia em arco modulado volumétrico (VMAT) tornou-se uma alternativa de tratamento bem-sucedida. Ela se baseia na radioterapia de intensidade modulada (IMRT), fornecendo feixes bem conformados na região de interesse, onde a radiação de fluência contínua é entregue com uma ou mais rotações do cabeçote ("gantry") de um acelerador linear equipado com colimador multilâminas (Multileaf collimator - MLC), enquanto a velocidade do "gantry" e a taxa de dose variam continuamente [6,7]. Estudos comparativos entre os planos IMRT e VMAT apresentaram que o VMAT minimiza o tempo de tratamento, reduzindo as incertezas associadas ao movimento do paciente e toxicidade do tecido sadio ao redor do volume-alvo [8].

O colimador multilâminas consiste em finas lâminas de chumbo cujas mobilidades são independentes entre si, possibilitando que o campo de tratamento assuma qualquer forma. Por meio de um sistema de planejamento (TPS - Treatment Planning System) com um software específico para IMRT/VMAT, realiza-se a otimização do plano de Radioterapia, modificando a intensidade do feixe em cada ponto de cada campo de tratamento, de acordo com as doses definidas pelo médico. Este processo, denominado de planejamento inverso, oferece uma adequação de dose ainda melhor aos volumes tumorais, com proteção mais significativa das estruturas críticas normais, mesmo quando comparado à Radioterapia Tridimensional Conformada [80]. A Figura 19 nos mostra a conformação do feixe de tratamento pelo colimador multilâminas (a) e o tratamento sendo entregue com o gantry em arco (b). 


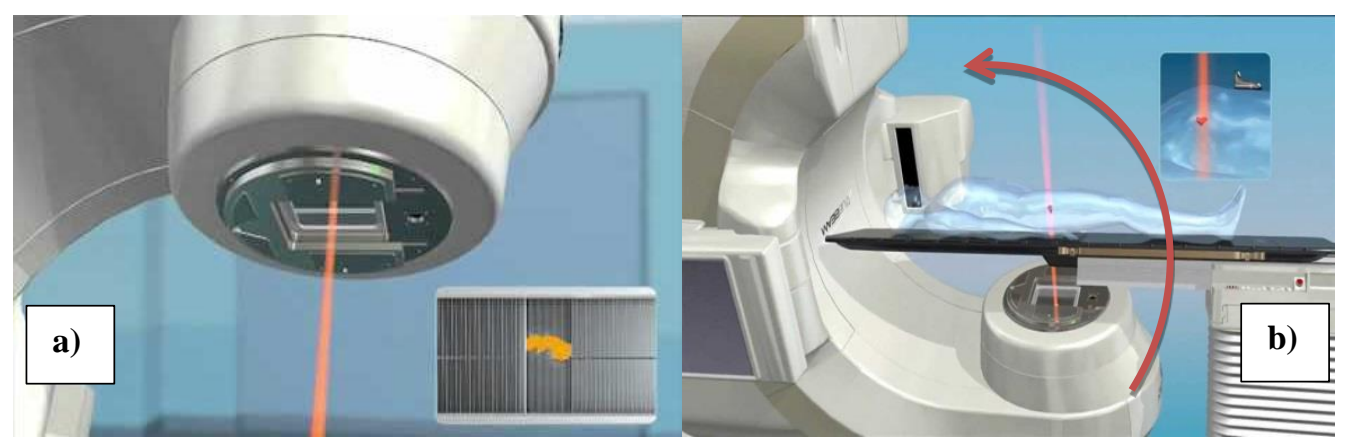

Figura 19. (a) Conformação do feixe de tratamento pelo colimador multilâminas (b) tratamento sendo entregue com o gantry em arco [VARIAN TRUEBEAM advertise].

\subsubsection{Definição dos Volumes}

Em um formalismo, a International Commissionon Radiation Units and Measurements (ICRU), em seu documento $\mathrm{n}^{\circ} 83$, apresenta definições referentes aos tecidos envolvidos nos tratamentos de radioterapia. Seu uso é obrigatório e se faz necessário durante o processo de planejamento a fim de manter controlar a entrega de dose no paciente. O ICRU 83 [81] define:

- GTV (gross tumor volume) - volume tumoral macroscópico: tumor bruto palpável ou extensão visível/demonstrável e o local de crescimento do tumor.

- CTV (clinical target volume) - volume alvo clínico: volume que contém o GTV e margens de regiões com probabilidade subclínica relevante para tratamento.

- ITV (internal target volume) - volume do alvo interno: volume do CTV acrescido de uma margem relativas ao tamanho, forma e posição do CTV no paciente.

- PTV (planning target volume) - volume alvo de planejamento: conceito geométrico inserido para o planejamento do tratamento e avaliação.

- OAR (organs at risk) - órgãos de risco: tecidos adjacentes que se forem irradiados podem sofrer significativa morbidade e, assim, podem causar influência no planejamento do tratamento e/ou dose prescrita.

- $\quad$ PRV (planning organ at risk volume) - volume de planejamento do órgão de risco: OAR acrescido de margens que considerem as incertezas e variações no posicionamento durante o tratamento.

- TV (treated volume) - volume tratado: volume de tecido englobado pela superfície de isodose selecionada e especificada pelo radioterapeuta apropriada para o tipo de tratamento que pode ser paliativo ou curativo, dentro dos limites aceitáveis de complicações. 
- $\quad$ RVR (remaining volume at risk) - volume restante em risco: diferença entre o volume delimitado pelo contorno externo do paciente e pelos CTVs e OARs.

Em uma perspectiva ilustrada, a Figura 20 demonstra esquematicamente, a compreensão dos volumes definidos.

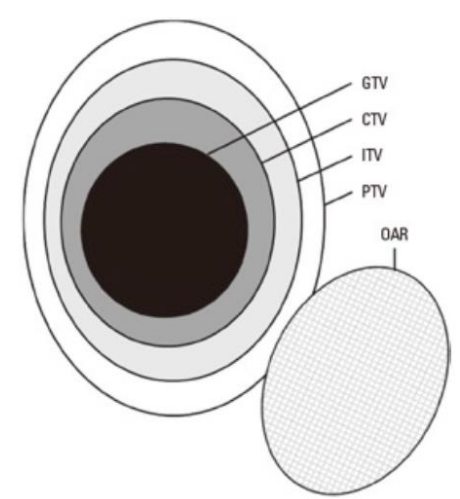

Figura 20. Definição esquemática dos volumes de tratamento definidos para radioterapia

\subsubsection{Sistema de Planejamento}

Os sistemas de planejamento possuem papel fundamental no processo em si e na qualidade dos tratamentos em radioterapia. Com os sistemas $3 \mathrm{D}$, além de possibilitarem a conformação dos volumes com grande precisão, podem fornecer radiografias reconstruídas do ponto de vista do feixe (“Beam's Eye View"-BEV) que, por sua vez, podem ser utilizadas para a localização dos campos e comparada aos campos de tratamento em tempo real [80].

O planejamento convencional consiste da aquisição de uma tomografia computadorizada - CT (em alguns casos, também se utiliza ressonância magnética - RM) e delimitação, a partir das imagens corte a corte, das estruturas dentro da região do tratamento. Depois de desenhadas as estruturas, o TPS gera o posicionamento dos campos por meio das projeções das imagens perpendicularmente ao raio central e, por fim, ocorre a otimização desse plano para as doses desejadas [80].

Para os tratamentos com IMRT e VMAT, utiliza-se a técnica de planejamento inverso. Nesse processo, depois de desenhadas as estruturas são definidos os critérios para o planejamento (dose relativa que cada órgão pode receber) e o próprio TPS determina a forma e composição dos campos (ou arcos) que satisfazem os critérios estabelecidos anteriormente. Nesse tipo de planejamento, a otimização também pode ser utilizada [80]. 
Outra ferramenta importante vinda dos sistemas de planejamento são os gráficos de histogramas dose-volume (dose-volume histogram - DVH). Eles permitem a comparação distinta das distribuições de doses, e fornecem um sumário detalhado de toda a matriz de dose 3D. Com isso, é mostrada a quantidade de volume-alvo ou estruturas adjacentes que podem estar recebendo doses superiores às especificadas para o plano de tratamento. No entanto, os histogramas não fornecem informação espacial e não podem substituir outras formas de controle de qualidade [80]. A Figura 21 mostra um exemplo de DVH típico de um tratamento.

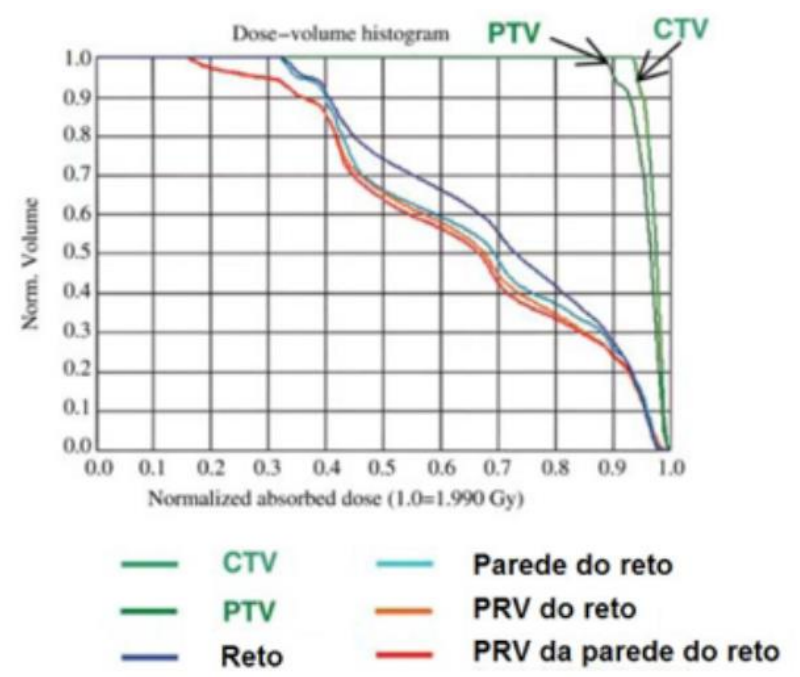

Figura 21. Exemplo de um histograma dose-volume (DVH) em radioterapia

Vale ressaltar que, cada TPS possui uma plataforma diferente. No Brasil, os sistemas de planejamento mais utilizado são os da VARIAN, bem como aceleradores lineares da mesma marca.

\subsubsection{Distribuição de doses}

Os dados da distribuição básica de dose são medidos geralmente em objetos simuladores equivalentes a tecido ( "phantoms”), já que é muito difícil medir as distribuições de dose direto nos pacientes. Objetos simuladores de água, objetos que se aproximam ao número atômico da água ou objetos antropomórficos são utilizados para fins de controle de qualidade de tratamentos individuais, tampouco para avaliação do desempenho dos aceleradores lineares [80].

Quando um feixe de radiação incide sobre um objeto simulador (consequentemente em um paciente), a dose absorvida varia com a profundidade, sendo que essa variação é dependente da qualidade do feixe, energia efetiva, tamanho do campo, distância foco-superfície e 
colimação. Sendo assim, o cálculo de dose deve considerar todos esses parâmetros, avaliando principalmente a distribuição de dose no eixo axial do feixe, definindo as distribuições de dose em profundidade (porcentagem de dose em profundidade - PDP) [80]. A PDP pode ser calculada por meio da Equação 1:

$$
P D P=\left(\frac{D_{d}}{D_{0}}\right) \cdot 100
$$

onde $D_{d}$ é a dose na profundidade $d$ no eixo central do feixe, $D_{0}$ é a dose de referência na profundidade de equilíbrio eletrônico nesse mesmo eixo. A PDP diminui com o aumento da profundidade, devido a efeitos de atenuação da radiação pelo meio, e com o inverso quadrado da distância (com exceção da região de build-up). A Figura 22 mostra esse comportamento para diferentes energias efetivas de feixe.

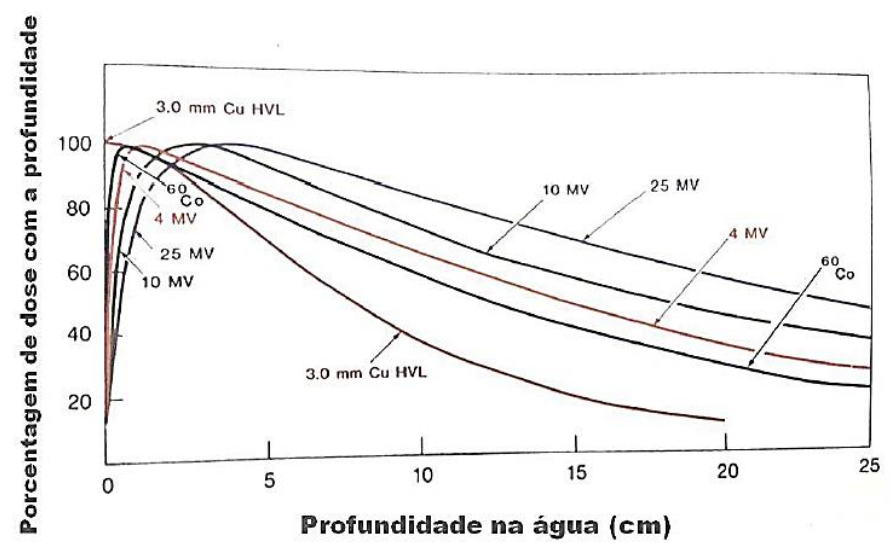

Figura 22. Distribuição de dose em profundidade para diferentes energias de fótons [80]

Tendo em vista representar a variação planar ou volumétrica da dose absorvida, essas distribuições são retratadas por cartas de isodose. As cartas de isodose são como mapas de distribuição de dose em uma região de interesse de um tratamento, e auxiliam na visualização da distribuição de dose no volume alvo e nos tecidos ao redor do tumor [80]. Para obter as curvas de isodose pode ser realizado um procedimento experimental utilizando um tanque de acrílico preenchido com água, realizando medidas de dose de vários pontos ao longo da profundidade do eixo central do campo e relacionando-as com a máxima dose na região de equilíbrio eletrônico.

Em uma segunda categoria de carta de isodose, as isodoses são normalizadas a certa profundidade além da profundidade de dose máxima, correspondendo ao eixo de rotação de 
uma unidade de terapia isocêntrica [80]. Na Figura 23 são apresentados os dois tipos de cartas de isodose para feixe de radiação gama do ${ }^{60} \mathrm{Co}$.

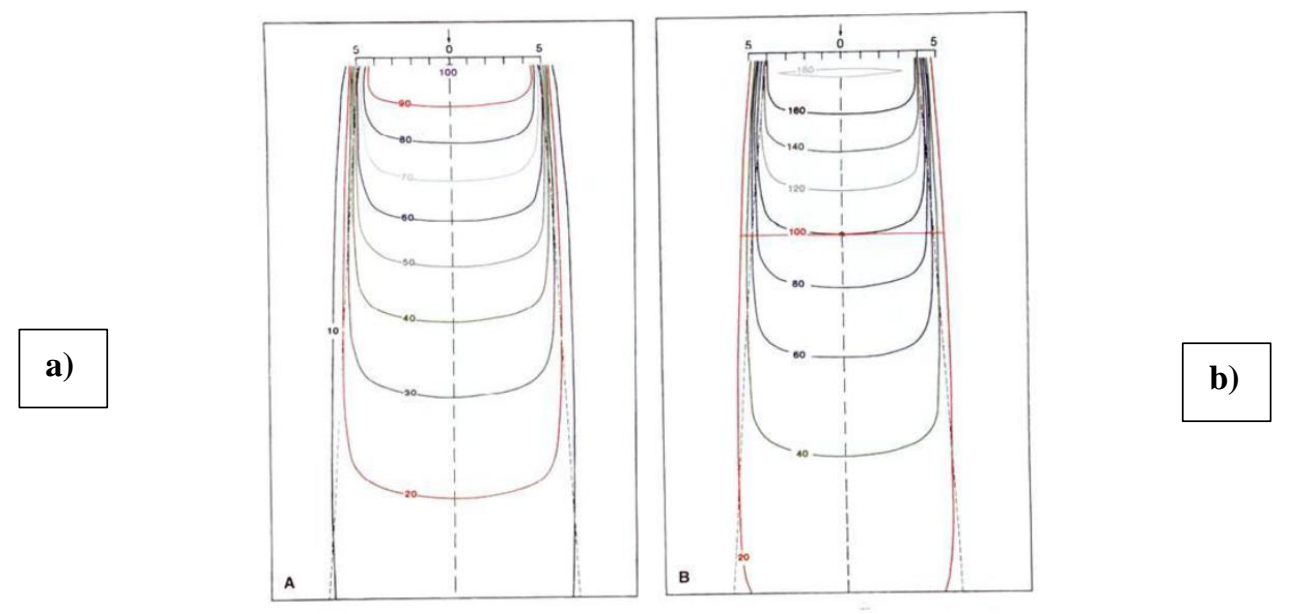

Figura 23. Exemplo de uma carta de isodose.(a) $\mathrm{SSD}=80 \mathrm{~cm}$, campo $10 \times 10 \mathrm{~cm}$ na superfície. (b) $\mathrm{SAD}=100 \mathrm{~cm}$, profundidade do isocentro $=10 \mathrm{~cm}$; tamanho do campo no isocentro $=10 \times 10 \mathrm{~cm}[80]$.

\subsubsection{Formalismos de controle de qualidade}

Todo plano de tratamento tem que ser o fruto da inter-relação entre os físicos-médicos responsáveis pelo planejamento e os radioterapeutas. Entretanto, em todas as etapas de um processo de planejamento ou tratamento, incertezas são introduzidas. É um fato inevitável num processo que envolve vários parâmetros entre o paciente a ser tratado e o equipamento a ser utilizado. Dentre os aspectos que introduzem as incertezas mais relevantes neste processo, podemos considerar:

- A localização e forma do volume-alvo,

- Os algoritmos utilizados para o cálculo de dose,

- A calibração do aparelho de tratamento,

- O posicionamento do paciente,

- Os movimentos involuntários do paciente;

- As diferentes formas anatômicas de cada paciente.

Tendo isso em vista, um rígido controle de qualidade se faz necessário para minimizar essas incertezas. Por meio dos relatórios $\mathrm{n}^{\circ} 24$ e $\mathrm{n}^{\circ}$ 83, a ICRU faz a seguinte recomendação quanto aos valores aceitáveis de incerteza dosimétrica total em radioterapia: “...a evidência 
disponível para alguns tipos de tumores aponta a necessidade de exatidão de $5 \%$ na liberação da dose no volume alvo se a erradicação do tumor primário for desejada. ”[81].

Essa recomendação também pode ser encontrada no Task Group 40 (TG-40) da Associação Americana de Físicos em Medicina (AAPM) [41,81]. A partir disso, as medidas dosimétricas são realizadas de acordo com formalismos estabelecidos pela AAPM e pela Agência Internacional de Energia Atômica (IAEA).

Como mencionado anteriormente, devido à dificuldade em realizar o controle dosimétrico diretamente no paciente, são utilizados objetos simuladores. Alguns deles são definidos pela ICRU de acordo com suas características físicas e, dentre eles, estão os simuladores padrão, que possuem $30 \mathrm{~cm}$ de lado; os simuladores de referência, cuja homogeneidade e características são bem conhecidas; os simuladores padrão de água e simuladores antropomórficos heterogêneos com formato de corpo humano [41,81]. Na Tabela 3 estão descritas as propriedades físicas de alguns materiais utilizados como objetos simuladores.

Tabela 3. Propriedades físicas de materiais utilizados como objetos simuladores [81]

Material Composição Densidade de Número de $\quad Z_{\text {ef }}$
química massa $\left(\mathrm{g} / \mathrm{cm}^{3}\right) \quad$ elétrons $/ \mathrm{g}\left(\mathbf{x 1 0 ^ { 2 3 }}\right)$

\begin{tabular}{ccccc}
\hline Água & $\mathrm{H}_{2} \mathrm{O}$ & 1,00 & 3,34 & 7,42 \\
$\begin{array}{c}\text { Poliestireno } \\
\text { Plexigas (perspex, } \\
\text { Lucite) }\end{array}$ & $\left(\mathrm{C}_{8} \mathrm{H}_{8}\right)_{\mathrm{n}}$ & $1,03-1,05$ & 3,24 & 5,69 \\
$\begin{array}{c}\text { Polietileno } \\
\text { Parafina }\end{array}$ & $\left(\mathrm{C}_{3} \mathrm{H}_{2} \mathrm{O}_{8}\right)_{\mathrm{n}}$ & $1,16-1,20$ & 3,24 & 6,48 \\
& $\left(\mathrm{CH}_{2}\right)_{\mathrm{n}}$ & 0,92 & 3,44 & 6,16 \\
& $\mathrm{C}_{\mathrm{n}} \mathrm{H}_{2 \mathrm{n}+2}$ & $0,87-0,91$ & 3,44 & 5,42 \\
Mistura a & & 3,34 & \\
& base de & 1,00 & & \\
& resina epóxi & & & \\
\hline
\end{tabular}

O TG-51 é um protocolo de dosimetria de referência clínica para radioterapias externas que utilizam feixes de fótons de energias nominais entre ${ }^{60} \mathrm{Co}$ e $50 \mathrm{MeV}$ e para feixes de elétrons de 4 a $50 \mathrm{MeV}$. Todas as dosimetrias de referência desse protocolo são realizadas com câmaras de ionização, havendo a necessidade de calcular as doses absorvidas em água, em um objeto simulador de água e o tamanho de campo para feixe de fótons definido em 10 x $10 \mathrm{~cm}$ [82]. 
O Technical Report Series (TRS) 398 [83] estabelece o código de práticas mais recente para a dosimetria e controle de equipamentos em radioterapia. Por meio dele, o desenvolvimento de padrões primários para dose absorvida na água para feixe de fótons de altas energias e elétrons traz a oportunidade de utilização desses padrões como base para estabelecer uma dosimetria baseada em dose absorvida na água para praticamente todas as qualidades de feixe.

\subsubsection{Outras aplicações da dosimetria OSL}

A OSL foi sugerida pela primeira vez como uma ferramenta de dosimetria nos anos 1950 e 1960. Os principais obstáculos para a aplicação de OSL encontrados naquela época foram: desvanecimento forte no caso de materiais de sulfureto de banda relativamente estreitos como $\mathrm{MgS}$, CaS e SrS dopados com íons de terras raras como Sm e Eu. O quartzo fundido dobrado por $\mathrm{Cu}^{+}$foi sugerido como um sensor para o sistema de dosimetria de fibra óptica médica OSL. A OSL tornou-se popular na década de 1980 com seu uso em arqueologia e datação geológica pela técnica de dosimetria retrospectiva [34].

Os fósforos de imagem como $\mathrm{BaBrF}: \mathrm{Eu}, \mathrm{Y}_{2} \mathrm{SiO}_{5}: \mathrm{Ce}, \mathrm{Sm}$ fosfato de bário dopado com elementos de terras raras, $\mathrm{KBr}$ :In e técnicas de imagem baseadas na sua estimulação óptica com lasers foram desenvolvidos com sucesso, e alguns deles agora são utilizados em radiografia diagnóstica digital. Imaging Plates (IPs - placas detectoras que substituíram os filmes fotográficos nas técnicas diagnósticas) com base em fluoróides e estrôncio ativados com európio e sistemas de leitura são comercialmente produzidos pela Fuji, Siemens, AGFA, Kodak, General Electric e outros fabricantes de equipamentos médicos. Os sistemas de radiologia digital computadorizada (CR), que se baseiam em princípio na técnica OSL mostram excelente desempenho de imagem, mas não são capazes de fazer medições dosimétricas precisas principalmente devido à baixa estabilidade térmica de armadilhas que resulta em desvanecimento relativamente forte do sinal armazenado nas placas [84].

Nesse mesmo contexto a Landauer Inc. desenvolveu o sistema comercial InLight ${ }^{\mathrm{TM}}$ descrito anteriormente, e sua utilização em dosimetria pessoal utilizando os modelos de dosímetros Luxel ${ }^{\mathrm{TM}}$ e o Inlight ${ }^{\mathrm{TM}}$. O Inlight ${ }^{\mathrm{TM}}$, demonstrado na Figura 24, é o dosímetro OSL

utilizado no Brasil para monitoração individual pela SAPRA Landauer. É constituído por um suporte de plástico, que se fecha para segurar um pacote de dosímetro plástico. O pacote dosímetro contém os filtros de metal / plástico e uma lâmina de plástico contendo os elementos 
detectores. Os elementos detectores são camadas de $\mathrm{Al}_{2} \mathrm{O}_{3}: \mathrm{C}$ intercaladas entre duas camadas de poliéster para uma espessura total de $0,3 \mathrm{~mm}$ [85].

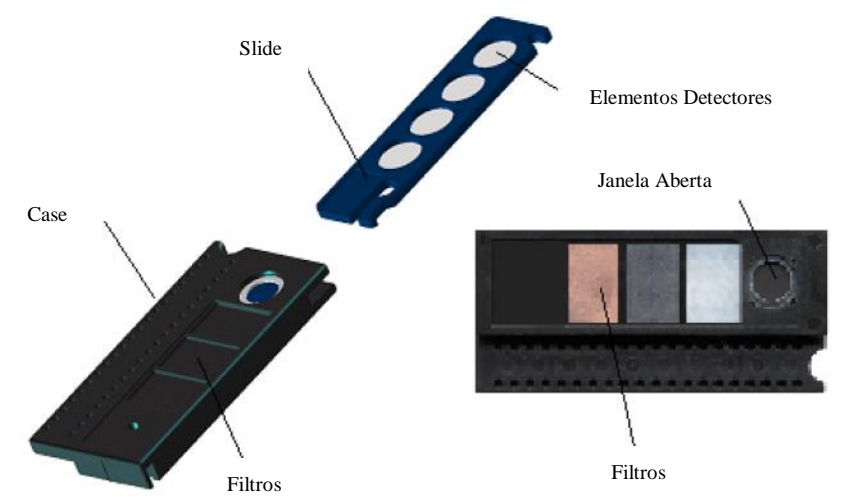

Figura 24. Dosímetro pessoal InLight [85]

$\mathrm{O}$ arranjo de filtros permite identificar a qualidade de feixe pela qual o dosímetro possa ter sido irradiado, bem como determinar a energia efetiva desse feixe pelo sistema Tandem (Figura 25).

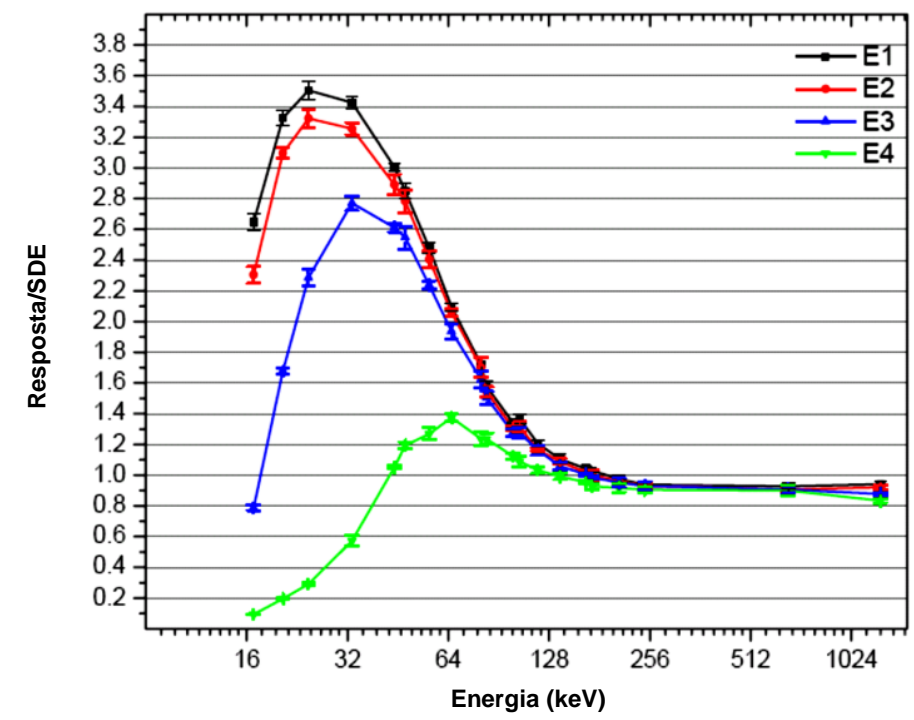

Figura 25. Sistema Tandem dos dosímetros pessoais InLight [85]

As especificações técnicas de cada um dos absorvedores desse sistema Tandem estão descritos na Tabela 4. 
Tabela 4. Especificações técnicas do sistema Tandem presente nos dosímetros OSL InLight ${ }^{\mathrm{TM}}$ Espessura $\left(\mathbf{m g} / \mathrm{cm}^{2}\right)$

Absorvedor (incluindo o suporte de plástico)

\begin{tabular}{ccc}
\hline Janela de Plástico & 18,2 & 36,8 \\
Papel, Filtro de Plástico & 403,2 & 403,2 \\
Papel, Filtro de cobre & 673,4 & 673,4 \\
Papel, Filtro de Chumbo & 1110,9 & 1110,9 \\
\hline
\end{tabular}

Frente

Trás

[85]

$\mathrm{Na}$ face frontal do dosímetro são impressas as informações de identificação, cadastro do usuário e código de série do dosímetro. Cada dosímetro possui um número de série de identificação. Esse modelo é capaz de detectar fótons (X e gama) com energias entre $5 \mathrm{keV}$ a $20 \mathrm{MeV}$ na faixa de $5 \mu \mathrm{Gy}$ a $10 \mathrm{~Gy}$, além de partículas beta com energia média a partir de $150 \mathrm{keV}$ na faixa de $20 \mu \mathrm{Gy}$ a $10 \mathrm{~Gy}[85]$.

Além da dosimetria pessoal, monitoração de áreas e dosimetria ambiental também são aplicações muito utilizadas [63]. Pesquisas mais recentes utilizando desse sistema tem obtido bons resultados para aplicações diagnósticas, bem como em controle de qualidade dos equipamentos. Al-Senan e Hatab, [86] investigaram a viabilidade do uso dos nanoDots na faixa de energia utilizada na imagem diagnóstica. Vrieze et al, [87] determinaram a precisão e precisão das medições de CTDI(100) utilizando dosímetros OSL comercialmente disponíveis (Landauer, Inc.) variando fatores tais como largura do feixe, potencial do tubo e material atenuante. Zhang D et al. [88] apresentaram a concepção e o procedimento de um método experimental para aquisição de um mapa de dose de órgãos densamente amostrado para aplicações de CT, com base nos dosímetros nanoDots e simuladores antropomórficos ATOM padrão. Endo et al. [89] realizaram um estudo que teve como objetivo mensurar o produto doseárea (DAP) das unidades de CT de feixe cônico (Cone-Beam CT) de área limitada utilizadas pelos consultórios odontológicos, e avaliar a análise racional do DAP com auxílio de dosímetros OSL. Sanchez et al. [90] avaliaram as doses de radiação no cristalino dos urologistas durante os procedimentos intervencionistas e comparou-as com os valores medidos durante radiologia intervencionista, cardiologia e cirurgia vascular. As medições foram realizadas em uma sala cirúrgica utilizando um arco cirúrgico em C móvel e dosímetros OSL e eletrônicos (usados sobre o avental de chumbo). 
IV Metodologia 


\section{METODOLOGIA}

\subsection{Materiais}

- 25 Dosímetros de $\mathrm{Al}_{2} \mathrm{O}_{3}: \mathrm{C}$ fabricados pela empresa Landauer Inc., fornecidos pela sede nacional SAPRA Landauer, do modelo nanoDot ${ }^{\mathrm{TM}}$ Dosimeter, com valores nominais de $5 \mathrm{~mm}$ de disco de $\mathrm{Al}_{2} \mathrm{O}_{3}: \mathrm{C}$ de diâmetro e $0,2 \mathrm{~mm}$ de espessura, envoltos em uma capa plástica a prova de luz de 10 × 10 × $2 \mathrm{~mm}^{3}$;

- 25 Dosímetros de $\mathrm{Al}_{2} \mathrm{O}_{3}: \mathrm{C}$ TLD-500 fabricados pela Rexon ${ }^{\mathrm{TM}}$, com 5 mm de diâmetro e $1 \mathrm{~mm}$ de espessura;

- 25 Dosímetros de LiF:Mg,Ti fabricados pela Thermo Scientific com 3,15 mm de lado e $0,9 \mathrm{~mm}$ de espessura; e

- 25 Dosímetros de $\mathrm{CaSO}_{4}$ :Dy fabricados pelo IPEN com $6 \mathrm{~mm}$ de diâmetro e 0,8 mm de espessura.

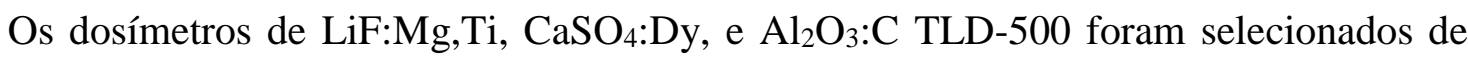
acordo com sua repetibilidade e sensibilidade à radiação gama do ${ }^{137} \mathrm{Cs}$. As sensibilidades individuais dos dosímetros variaram no máximo em $\pm 5 \%$ em relação à sensibilidade média do lote.

\subsection{Equipamentos}

\subsubsection{Sistemas de irradiação}

- Irradiador gama de geometria $4 \pi$ de ${ }^{137} \mathrm{Cs}$ de atividade de $38,11 \mathrm{GBq}$ em 17 de Abril de 2014 do Laboratório de Dosimetria Termoluminescente (LDT/IPEN);

- Irradiador gama de ${ }^{60} \mathrm{Co}$ de atividade de 0,339 TBq em Setembro de 1999 do Laboratório de Calibração de Instrumentos (LCI/IPEN);

- Acelerador Linear de Partículas da marca VARIAN ${ }^{\text {TM }}$, modelo NOVALIS TX acoplado com um colimador multileaf de 120 lâminas de 2,25 mm de largura do Hospital SírioLibanês, utilizando feixe de fótons de $6 \mathrm{MV}$, com taxa de dose máxima de 1400 $\mathrm{UM} /$ minuto. 
- Mamógrafo da marca VMI, modelo Graph Mammo AF, pertencente ao Laboratório de Calibração de Instrumentos - LCI/IPEN;

- Mamógrafo da marca Lorad, modelo M-IV com sistema CR AGFA acoplado pertencente a VAS Radiologia;

- Sistema Raios X Pantak/Seifert ISOVOLT 160 HS, pertencente ao LCI/IPEN;

\subsubsection{Simuladores}

- Placas de PMMA de dimensão 90 x 50 × $3 \mathrm{~mm}^{3}$;

- Placas de água sólida SW de dimensão 30 x 30 x $1 \mathrm{~cm}^{3}$;

- Simulador antropomórfico de cabeça e pescoço da marca CIRSTM, modelo STEEV Stereotactic End-To-End Verification;

- Simulador antropomórfico de pelve ExacTrac ${ }^{T M}$ Verification Phantom;

- Simulador radiográfico de mama Nuclear Associates, modelo 18-220;

\subsubsection{Sistemas de Tratamento Térmico}

- Forno tipo mufla da marca Vulcan®, modelo 3-550 PD;

- Estufa cirúrgica da marca Fanen®, modelo 315-IEA 11200.

\subsubsection{Sistema de Tratamento Óptico}

- Lâmpadas de diodo emissor de luz (LED) azul da marca Ourolux®, de 1,3 watts de potência (composta por 30 LEDs).

\subsubsection{Sistemas de Leitura}

- Leitora TL/OSL da marca RISO ${ }^{\mathrm{TM}}$, modelo TL/OSL-DA-20;

- Leitora OSL da marca Landauer, modelo Inlight ${ }^{\mathrm{TM}}$ microStarreader;

- Leitora TL da marca Harshaw ${ }^{\mathrm{TM}}$, modelo 4500.

\subsubsection{Sistemas de Dosimetria de Referência}

- Câmara de ionização da marca PTWTM, modelo Farmer ${ }^{\mathrm{TM}} 0,6 \mathrm{~cm}^{3}$ a prova d'água; 
- Câmara de ionização da marca PTW'TM, modelo PinPoint ${ }^{\mathrm{TM}} 3 D$;

- Medidor Universal da marca PTW, modelo Diavolt All-in-one QC Meter.

\subsection{Metodologia e análises realizadas}

\subsubsection{Preparação para uso dos dosímetros}

Antecedendo qualquer uso específico dos dosímetros, os mesmos foram submetidos a diferentes técnicas de tratamento, seja térmico ou óptico. Para cerca de 50 dosímetros termoluminescentes TLD-100 de LiF:Mg,Ti, foi adotado tratamento térmico pré-irradiação de uma hora no forno Vulcan (Figura 26 a) a uma temperatura de $400^{\circ} \mathrm{C}$, seguido de duas horas na estufa Fanem (Figura 26 b) a uma temperatura de $100^{\circ} \mathrm{C}$. Para cerca de 50 dosímetros de $\mathrm{CaSO}_{4}$ :Dy, foi de $300^{\circ} \mathrm{C}$ no forno Vulcan por 3 horas. Tratamentos estes bem consolidados na literatura[26,55].

Para os dois tipos de dosímetros de $\mathrm{Al}_{2} \mathrm{O}_{3}$ : $\mathrm{C}$ não foram encontradas recomendações de tempo de tratamento óptico. Sendo assim, um estudo de tempo de tratamento óptico foi realizado, analisando a resposta residual das amostras para diferentes valores de dose irradiados de acordo com diferentes tempos de exposição à luz LED (Figura 26 c), variando de 1 minuto até 24 horas.
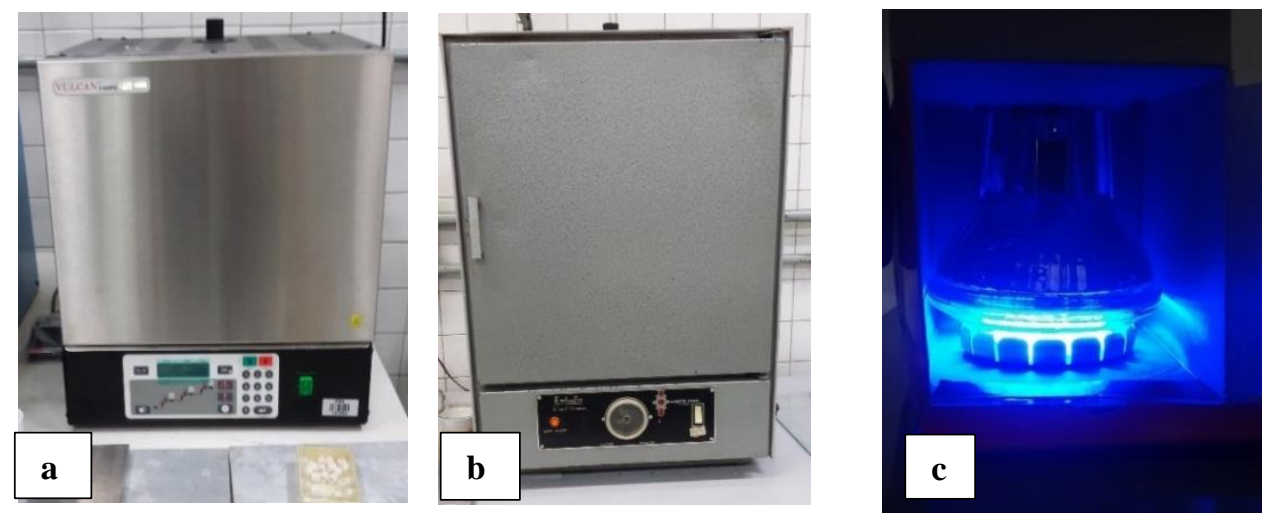

Figura 26. Equipamentos utilizados para tratamentos pré irradiação. (a) Forno tipo mufla Vulcan. (b) Estufa cirúrgica Fanen, (c) Lâmpada de LED azul Ourolux. 


\subsubsection{Seleção dos dosímetros e Testes de Desempenho}

Os dosímetros TL TLD-100 e $\mathrm{CaSO}_{4}$ :Dy utilizados nesse trabalho haviam sido previamente selecionados de acordo com sua repetibilidade e sensibilidade entre $\pm 5 \%$ em relação a ${ }^{60} \mathrm{Co}[44,49]$. Contudo, devido à extensa utilização das pastilhas e exposição a doses altas de radiação, uma verificação dessa seleção foi realizada. Aproximadamente 45 dosímetros de LiF:Mg,Ti TLD-100, $\mathrm{CaSO}_{4}$ :Dy e $\mathrm{Al}_{2} \mathrm{O}_{3}: \mathrm{C}$ da Rexon ${ }^{\mathrm{TM}}$ foram posicionados entre placas de PMMA de $90 \times 50 \times 3 \mathrm{~mm}^{3}$ e foram irradiados com $10 \mathrm{mGy}$ utilizando uma fonte padrão de geometria $4 \pi$ de ${ }^{137}$ Cs (Figura 27) livre no ar e em equilíbrio eletrônico, lidos e tratados; repetindo o processo por três vezes. Com os resultados obtidos e analisados, as pastilhas foram selecionadas com valores de sensibilidade e repetibilidade melhores que $\pm 5 \%$ em relação à média. Para as análises dosimétricas seguintes, as pastilhas TL foram separadas em 5 grupos de 5 dosímetros para levantamento da curva de resposta em função da dose, limites inferiores de detecção e avaliação das doses de fundo (BG).

Os nanoDots são fabricados e selecionados pela Landauer Inc., já apresentam um fator de correção de sensibilidade por lote. Contudo, para averiguação das sensibilidades individuais, e por recomendações do fabricante para uso em dosimetria oncológica[91], os 22 dosímetros utilizados para esse trabalho passaram pelo mesmo processo.

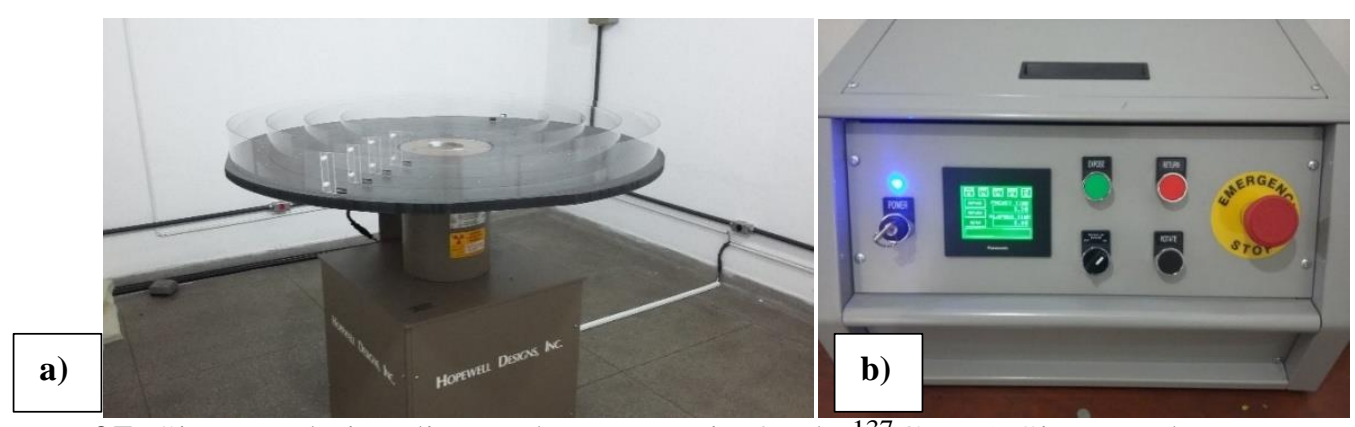

Figura 27. Sistema de irradiação de geometria $4 \pi$ de ${ }^{137}$ Cs. (a) Sistema de arcos rotacionais de 30 a $60 \mathrm{~cm}$ de distância da fonte. (b) Comando digital controlador da fonte.

\subsubsection{Caracterização dos Sistemas Dosimétricos}

Para caracterização de referência, foram obtidas curvas de resposta em função da dose para ${ }^{60} \mathrm{Co}$ no intervalo de doses de $1 \mathrm{mGy}$ a $10 \mathrm{~Gy}$, livre no ar e em condições de equilíbrio eletrônico. Para utilização clínica, os dosímetros foram irradiados em feixe de fótons de $6 \mathrm{MV}$ do acelerador linear VARIANTM NOVALIS TX no intervalo de doses de 0,25 a $3 \mathrm{~Gy}$, utilizando placas SW de água sólida em profundidade de máxima dose (em torno de 1,5 cm), com 
correções por meio da dosimetria absoluta de dose absorvida na água (Figura 28). Foi utilizado arranjo de irradiação com campo 10 x $10 \mathrm{~cm}^{2}$ a uma distância foco-superfície (SSD) de $100 \mathrm{~cm}$. Os dados obtidos para correção pela dosimetria absoluta (Anexo I), adquiridos utilizando uma câmara de ionização PTWTM Farmer de acordo com protocolo IAEA TRS 398.

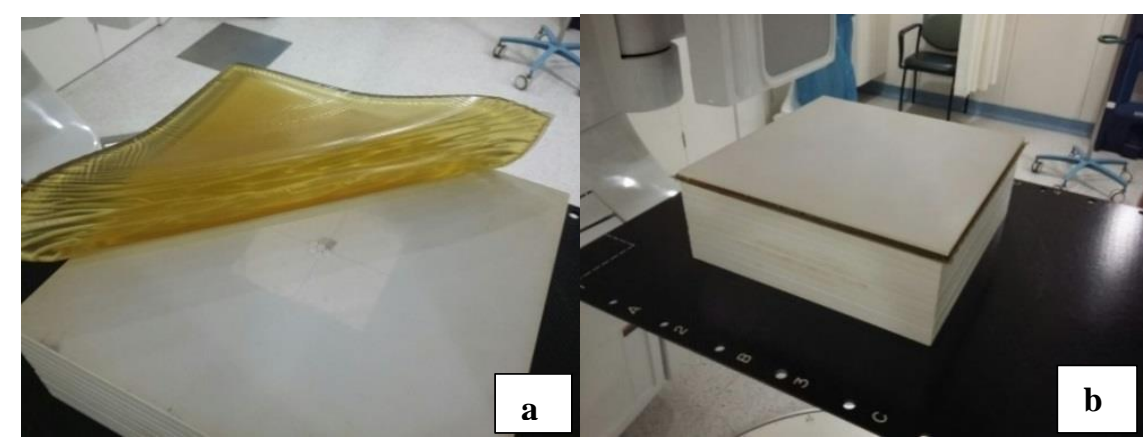

Figura 28. Posicionamento dos dosímetros para caracterização clínica. (a) Dosímetros posicionados sobre as placas de água sólida SW. (b) Posicionamento de duas placas SW somando profundidade de $1,5 \mathrm{~cm}$.

\subsubsection{Aplicação Clínica}

\subsubsection{Simulador Antropomórfico STEEV - CIRS}

Foi utilizando um simulador antropomórfico da marca CIRS ${ }^{\mathrm{TM}}$, modelo Stereotactic End-to-End Verification - STEEV (Figura 29). O simulador tecido equivalente possui diversas peças que possibilitam acomodar dosímetros e câmaras de ionização em diferentes posições na região cerebral e pescoço. Com isso, é possível simular tratamentos em toda a região de cabeça, cérebro e pescoço com maior rigidez anatômica e confiabilidade.

Após a aquisição de uma tomografia computadorizada - CT, foi realizado um planejamento de tratamento de tumor cerebral com proteção de tronco encefálico, quiasma e globos oculares. Para o planejamento utilizou-se do sistema VARIAN Eclipse ${ }^{\mathrm{TM}}$ 10.0, e a tecnologia VARIAN RapidArc ${ }^{\mathrm{TM}}$ de tratamento em VMAT, com algoritmo de cálculo VARIAN AAA ${ }^{\mathrm{TM}}$. 

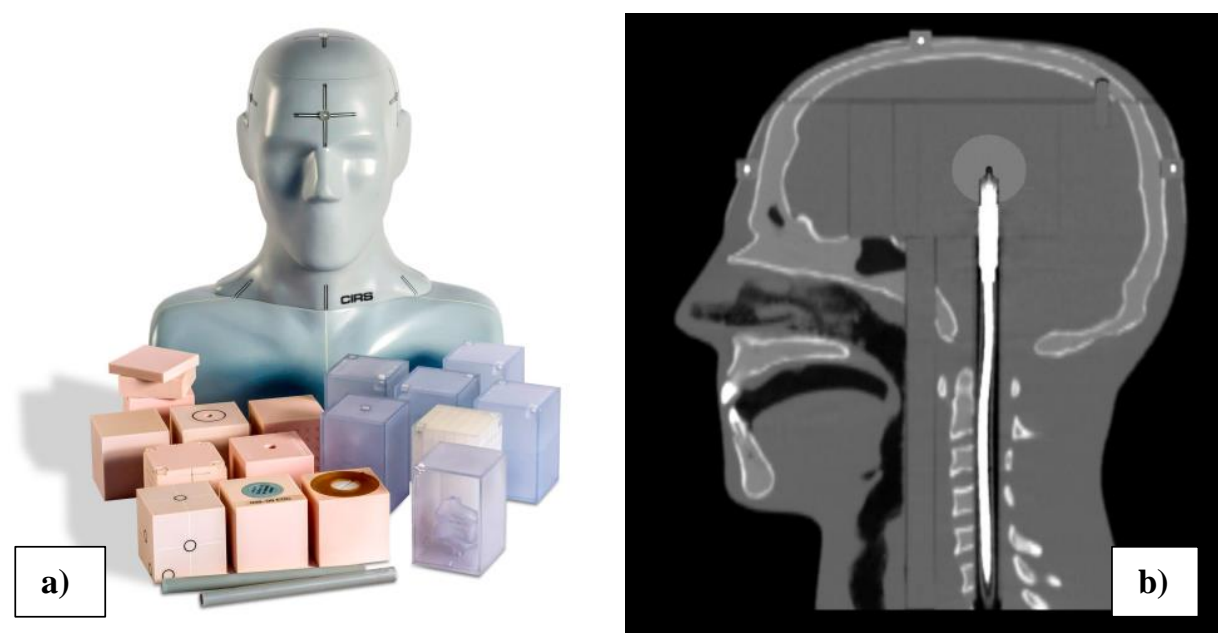

Figura 29. Objeto simulador antropomórfico de cabeça da marca CIRS, modelo STEEV. (a) Visão geral do simulador e dos acessórios disponíveis. (b) Tomografia computadorizada em vista lateral em corte sagital mediano do simulador.

O volume tumoral a ser tratado com o planejamento VMAT foi determinado por um dos cubos acessórios do fabricante, o qual possui uma massa simuladora de tecido tumoral. Essas peças acessórias apresentam geometria perfeitamente ajustada para os encaixes no simulador, havendo a necessidade de adaptadores que possibilitem a acomodação dos dosímetros. Para isso, foram desenvolvidos pequenos moldes de cera odontológica para fixar os dosímetros na posição central do volume alvo (Figura 30).
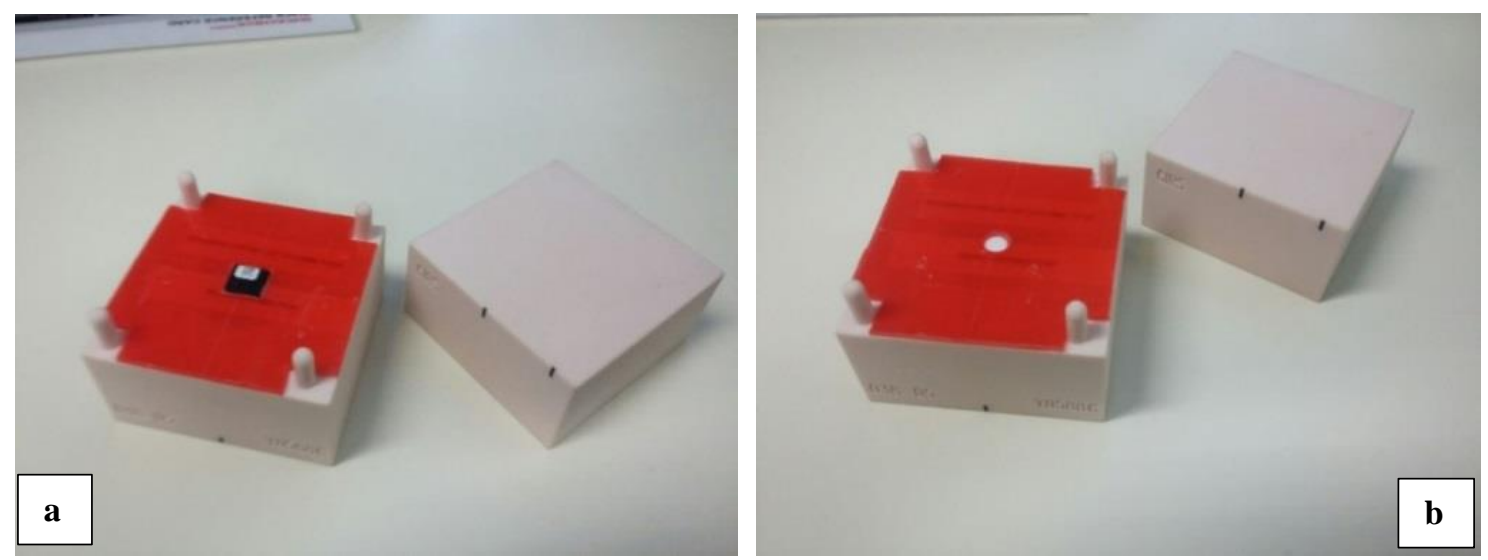

Figura 30. Moldes de cera odontológica utilizadas como posicionadores dos dosímetros. (a) Molde com encaixe para os nanoDots e os TLD-100. (b) Molde com encaixe para os $\mathrm{CaSO}_{4}: \mathrm{Dy}$ e TLD-500. 

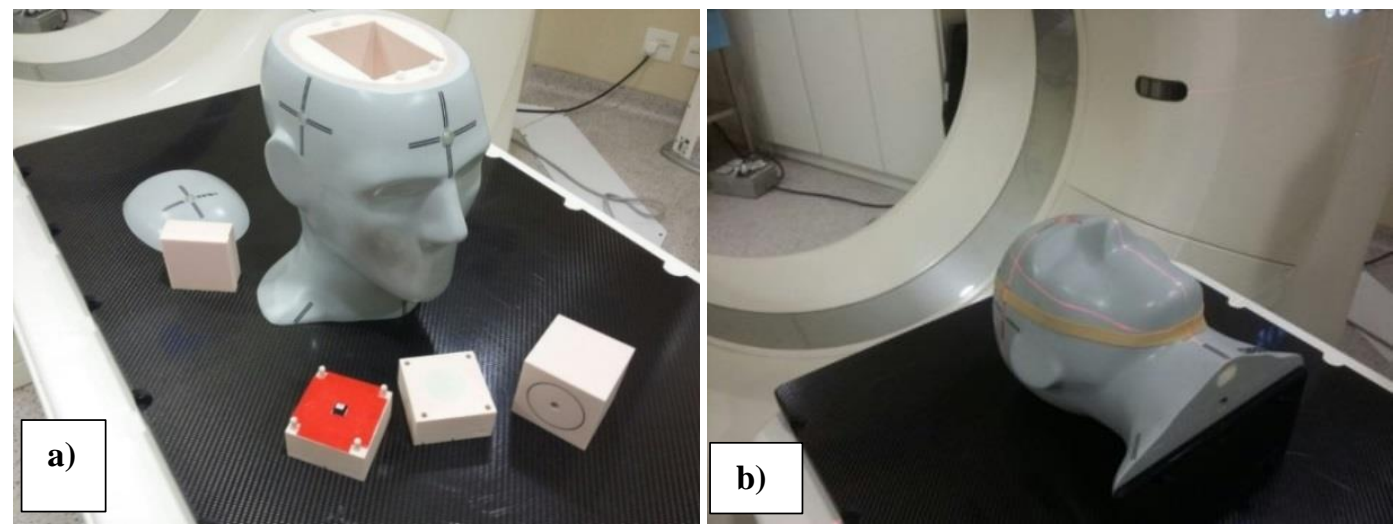

Figura 31. Simulador antropomórfico STEEV posicionado para aquisição da tomografia computadorizada de planejamento. (a) Simulador com os acessórios a serem encaixados dentro do volume cerebral. (b) Posicionamento do simulador inteiramente montado.

Duas tomografias foram adquiridas (Figura 31): uma para o planejamento com os dosímetros, e outra para uma câmara de ionização da marca PTW, modelo PinPoint TM3D. Depois de feito o planejamento, o tratamento foi executado utilizando os dosímetros TLD-100, $\mathrm{CaSO}_{4}: \mathrm{Dy}$, nanoDots, TLD-500 separadamente. Esse processo foi repetido cinco vezes para melhorar a estatística da pesquisa, e pelo fato de ter sido possível acoplar apenas um dosímetro de cada vez. Para fins de comparação, foi feita em paralelo uma checagem dosimétrica utilizando câmara de ionização. A Figura 32 demonstra o simulador sendo irradiado no acelerador linear.

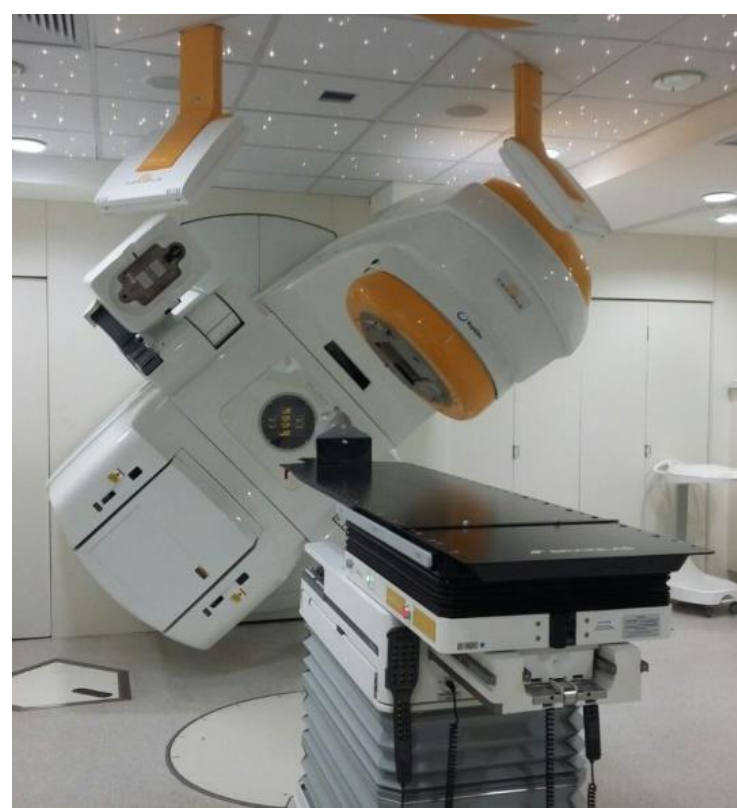

Figura 32. Simulador antropomórfico posicionado no acelerador linear VARIAN NOVALIS TX do HSL 


\subsubsection{Simulador Antropomórfico de Pelve}

Em outro estudo de aplicação clínica, foi utilizado um simulador de pelve humana da marca ExacTrac ${ }^{\mathrm{TM}}$, modelo ExacTrac ${ }^{\mathrm{TM}}$ Verification Phantom. Esse simulador é rotineiramente utilizado para controles de qualidade de localização e posicionamento de pacientes e controle de qualidade de imagem na aquisição de tomografias cone-beam e localização pelo sistema ExacTrac ${ }^{\mathrm{TM}}$.

Foi feito um planejamento de tumor de próstata e, nesse estudo, por meio da dose de entrada na pele, foi avaliado qual das três variações do cálculo de dose do sistema de planejamento concordaria com os resultados dosimétricos das irradiações: a não utilização da mesa de tratamento, a utilização da mesa padrão do sistema e a utilização de uma mesa editada pelos físicos do hospital. Para isso, foram posicionados dois dosímetros na parte anterior (sobre a bexiga), dois na parte posterior (no final da coluna espinal), um na lateral direita da pelve e um anterior superior, fora do campo de tratamento. Nessas irradiações, moldes de cera dental também foram utilizados para acomodar os dosímetros e para proporcionar a densidade eletrônica necessária para medições de dose de entrada na pele. Os detalhes do posicionamento estão demonstrados na Figura 33.

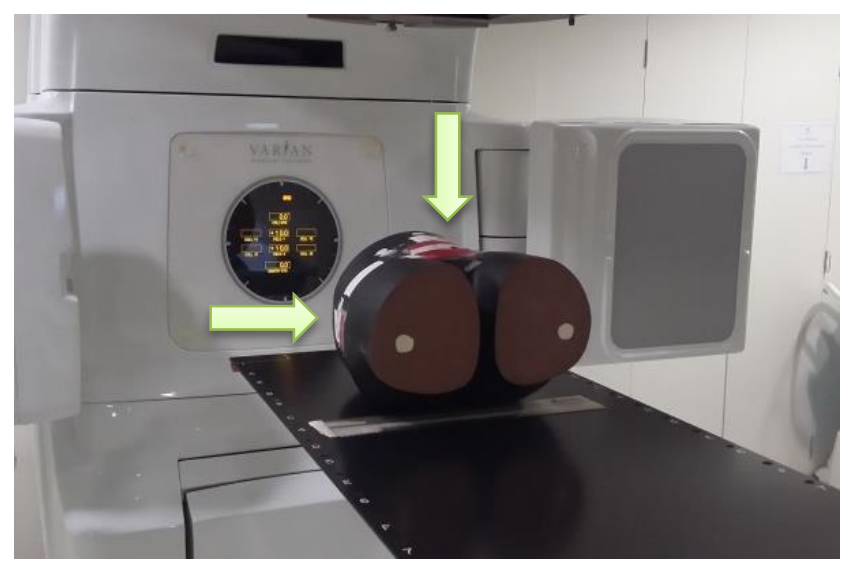

Figura 33. Detalhes dos ajustes e irradiação do simulador de pelve. As setas indicam duas localizações dos dosímetros posicionados nas ceras odontológicas.

\subsubsection{Sistemas de leitura e testes de desempenho}

As leituras TL foram realizadas utilizando a leitora TL Harshaw modelo 4500 (Figura 34 a). As leituras OSL dos TLD-500 foram realizadas na leitora TL/OSL RIS $\varnothing$ modelo TL/OSL-DA-20 (Figura 34 b), utilizando modo de intensidade de iluminação constante (CW) por LED azul, com pico de emissão $470 \mathrm{~nm}$ e filtro Hoya U-340. As leituras OSL dos 
nanoDots foram feitas na leitora específica do sistema Inlight ${ }^{\mathrm{TM}}$, a microStar ${ }^{\mathrm{TM}}$ reader $_{\text {(Figura }}$ $34 \mathrm{c})$.

Como os sistemas de fotomultiplicadora possuem limites de leitura em contagens por segundo, para as leituras TL do $\mathrm{CaSO}_{4}$ :Dy e para as leituras OSL dos TLD-500 foram utilizados colimadores. Estes são confeccionados com papel cartão e material plástico maleável preto com pequenas aberturas centrais, para que não haja saturação dos sistemas devido a emissão muito intensa de sinal pelos dosímetros. Os colimadores utilizados para as leituras TL estão apresentados na Figura 35a e para as leituras OSL na Figura 35b. Para a Leitora RISØ, a relação das respostas OSL com a variação da intensidade e do tempo do LED de estimulação também foram avaliadas.
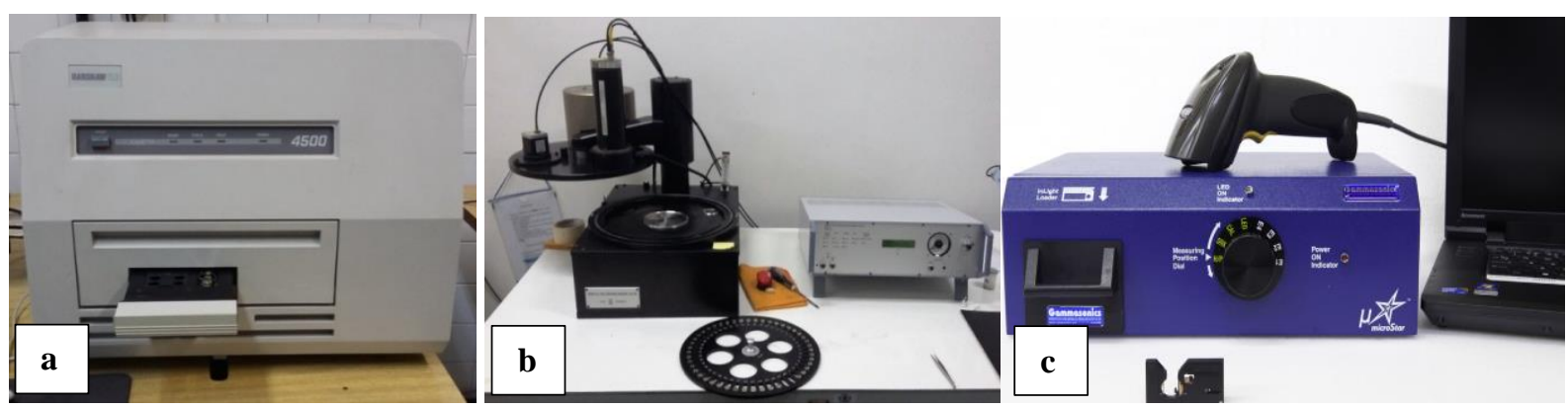

Figura 34. Leitoras (a) TL Harshaw modelo 4500 (b) TL/OSL RIS $\emptyset$ modelo TL/OSL-DA-20

(c) OSL Landauer modelo microStar ${ }^{\mathrm{TM}}$ reader

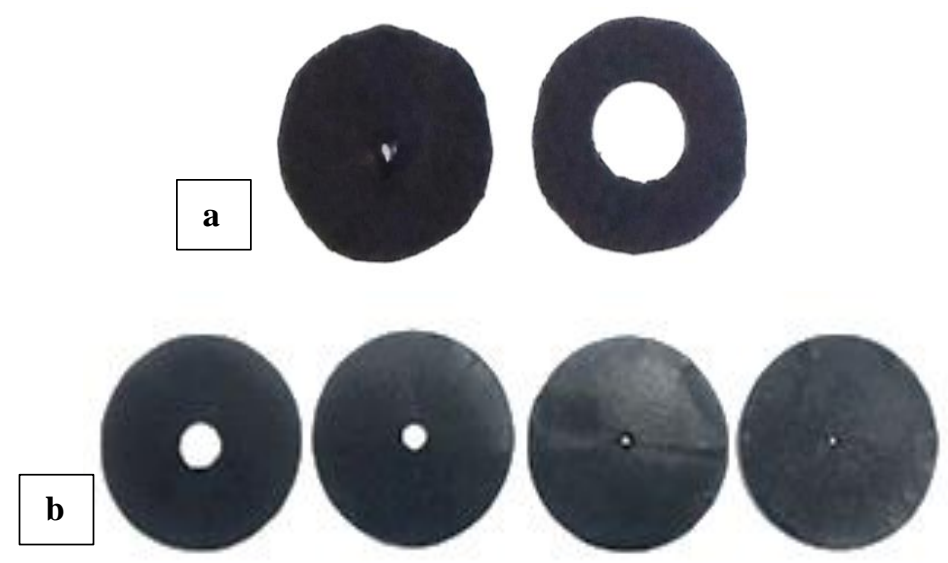

Figura 35. (a) Colimadores para leitura TL dos dosímetros de $\mathrm{CaSO}_{4}: \mathrm{Dy}$. As aberturas centrais são de aproximadamente $1 \mathrm{~mm}$ e $7 \mathrm{~mm}$ respectivamente. (b) Colimadores para leitura OSL dos dosímetros $\mathrm{Al}_{2} \mathrm{O}_{3}: \mathrm{C}$ TLD-500. As aberturas centrais são de aproximadamente $10 \mathrm{~mm}, 5 \mathrm{~mm}, 2 \mathrm{~mm}$ e $1 \mathrm{~mm}$ respectivamente

As leituras foram feitas sempre $24 \pm 2$ horas depois das irradiações, e sempre iniciadas pelos dosímetros de fluoreto de lítio, dado seu decaimento térmico mais intenso que os demais materiais. Esse tempo de espera ocorre para que haja estabilização das armadilhas nos materiais. 
A temperatura e umidade do ar das salas de leitura foram monitoradas para que se mantivessem em torno de $21^{\circ} \mathrm{C}$ e abaixo de $50 \%$ respectivamente.

\subsubsection{Testes de desempenho leitoraTL Harshaw 4500}

Foram realizados sistematicamente dois testes para verificação das variações dos parâmetros padrão da leitora: luz padrão de referência interna (Reference Light) e razão sinal/ruído da fotomultiplicadora (PMT Noise). Ao se iniciar um ciclo de leituras, e a cada dez pastilhas lidas, os testes eram repetidos. A variância do conjunto de leituras não deveria ser maiores que $5 \%$.

Os parâmetros apresentados na Tabela 5 [10] foram verificados periodicamente com a finalidade de assegurar a estabilidade do sistema de dosimetria TL, composto essencialmente pelo forno destinado ao tratamento térmico, pela leitora TL e pelos próprios dosímetros, utilizado na dosimetria dos feixes.

Tabela 5. Controle de qualidade dos dosímetros TL utilizados

\begin{tabular}{ccc}
\hline Parâmetro & Frequência & Observações \\
\hline Razão sinal/ruído & A cada leitura & Variação dentro de $10 \%$ \\
Luz padrão & & Repetibilidade de $0,5 \%$ \\
Sensibilidade individual ao ${ }^{60} \mathrm{Co}$ & Mensalmente & $\begin{array}{c}\text { Comparar com referência } \\
\text { Curvas de emissão }\end{array}$ \\
Temperatura do forno & Na seleção dos dosímetros & Ou suspeita de problemas \\
\hline
\end{tabular}

\subsubsection{Testes de desempenho leitora OSL microStar $^{\mathrm{TM}}$ reader}

Usando um conjunto de dosímetros CQ, é necessário estabelecer a precisão intrínseca da leitora microStar [79]. Não é necessária essa verificação a cada calibração, mas previamente a uma grande utilização da leitora, é um teste útil para determinar a incerteza intrínseca das medições e determinar se a sua leitora está funcionando devidamente. $\mathrm{O}$ teste consiste nos seguintes passos:

- Irradie um conjunto de dosímetros CQ, com uma dose conhecida e analise-o dez vezes. Certifique-se de remover o adaptador da unidade e o dosímetro do adaptador entre cada análise para mediar quaisquer variações mecânicas em abertura/posicionamento o dosímetro. 
- Observe os valores de contagem ("counts") obtidos, ou, se já estiver com uma calibração definida, os próprios valores de dose podem ser utilizados. Exporte-os usando a função "Import/Export" do software da leitora.

- Calcule o coeficiente de variância (CV), definido como a razão do desvio padrão pela média dessas dez leituras. Este é o 1- $\sigma$ (ou 68\%) intervalo de confiança para a leitora. Este resultado deve ser inferior a $2 \%$ e é, tipicamente, muito menor $(\sim 1 \%)$. Se não for, recomenda-se repetir o teste com outros dois dosímetros CQ e calcule a média dos $3 \mathrm{CV}$. Se o resultado é ainda maior do que $2 \%$, então é provável que o adaptador dos dosímetros não esteja abrindo suavemente.

Para efeitos de comparação, uma análise similar aos para a leitora Harshaw foi realizada levando os parâmetros padrão da leitora: acompanhamento das contagens de fundo (DarkCounts), teste de luz de calibração (CalibrationCounts) e teste do LED de referência (LED Counts). Para estes itens, também foram realizados os cálculos dos $\mathrm{CV}$ pelas médias de todas as contagens. Para esses itens, os CV não devem ser superiores $\mathrm{a} \leq 3 \%$.

\subsubsection{Testes de desempenho e caracterização OSL da leitora RIS ${ }^{\mathrm{TM}}$ TL/OSL reader}

Para uso e manuseio rotineiro da leitora RISO TL/OSL reader, alguns pequenos testes de verificação de funcionamento foram realizados anteriormente a todas as leituras OSL, seguindo o manual de uso do fabricante [77]. Dentre eles:

- O funcionamento dos botões e mecanismos de abrir e fechar a abertura do carrossel.

- Contagens de fundo da fotomultiplicadora.

- Funcionamento do LED azul de estimulação.

Testes de desempenho mais avançados são realizados periodicamente pela equipe de manutenção do fabricante. Vale ressaltar que, controles de fluxo de nitrogênio, funcionamento da luz de estimulação infravermelha e do irradiador também são especificados pelo fabricante, porém não se aplicam a esse estudo.

\subsubsection{Outras aplicações da dosimetria OSL}


Foram realizados estudos para a utilização dos dosímetros OSL nanoDot para monitoração de área e testes de desempenho para feixes de qualidade diagnóstica utilizados em mamografia digital.

\subsubsection{Aplicação da técnica de Luminescência Opticamente Estimulada (OSL) na monitoração de área de uma sala de exame de mamografia}

O InLight ${ }^{\mathrm{TM}}$ System foi avaliado para utilização em monitoração de área de uma sala de exames de mamografia no Instituto de Pesquisas Energéticas e Nucleares (IPEN). Três curvas de resposta em função da dose foram obtidas: uma curva de referência para $662 \mathrm{keV}$ de ${ }^{137} \mathrm{Cs}$ livre no ar e em equilíbrio eletrônico $\mathrm{H}^{*}(\mathrm{~d})$; e duas qualidades de mamografia disponíveis no Sistema Pantak (RQR-2M e RQR-4M).

Foi avaliada a dependência angular dos nanoDots ${ }^{\mathrm{TM}}$, e um sistema Tandem foi criado com perfil de dependência energética das respostas OSL com e sem filtro de cobre (Precision Brand $^{\mathrm{TM}}$, espessura nominal de $0,127 \mathrm{~mm}$ ) relativas a ${ }^{137} \mathrm{Cs}$, para auxiliar na estimativa de energias efetivas. As especificações das qualidades de feixe utilizadas irradiações estão descritas na Tabela 6.

Tabela 6. Especificações das qualidades de feixe de raios $X$ utilizadas para uso em aplicação diagnóstica e área

\begin{tabular}{ccccc}
\hline Qualidade & $\begin{array}{c}\text { Voltagem } \\
(\mathbf{k V p})\end{array}$ & $\begin{array}{c}\text { HVL } \\
(\mathbf{m m})\end{array}$ & $\begin{array}{c}\text { Filtração } \\
(\mathbf{m m})\end{array}$ & $\begin{array}{c}\text { Energia Efetiva } \\
(\mathbf{k e V})\end{array}$ \\
\hline RQR-2M $^{\mathrm{a}, \mathrm{b}}$ & 28 & $0,37(\mathrm{Al})$ & $0,07(\mathrm{Mo})$ & 15,7 \\
RQR-4M $^{\mathrm{a}, \mathrm{b}}$ & 35 & $0,41(\mathrm{Al})$ & $0,07(\mathrm{Mo})$ & 16,25 \\
RQR7 $^{\mathrm{b}}$ & 90 & $2,95(\mathrm{Al})$ & $2,5(\mathrm{Al})$ & 33,05 \\
$\mathrm{~N}^{\mathrm{b}} 60^{\mathrm{b}}$ & 60 & $0,25(\mathrm{Cu})$ & $0,6(\mathrm{Cu})$ & 48 \\
$\mathrm{~N}^{-80}$ & 80 & $2,0(\mathrm{Cu})$ & $0,58(\mathrm{Cu})$ & 65 \\
$\mathrm{~N}-150^{\mathrm{b}}$ & 150 & $0,733(\mathrm{~Pb})+3,0(\mathrm{Sn})$ & $2,36(\mathrm{Cu})$ & 118 \\
\hline
\end{tabular}

${ }^{\mathrm{a}}$ Qualidades utilizadas para caracterização; ${ }^{\mathrm{b}}$ Qualidades utilizadas para obtenção da curva Tandem

As medições foram realizadas em um mamógrafo VMI GraphMammo AF. Para obtenção do perfil de campo de entrada, os dosímetros foram posicionados de forma matricial sobre placas de PMMA simuladoras de mama. Para medir espalhamento, os nanoDots ${ }^{\mathrm{TM}}$ foram posicionados a $53 \mathrm{~cm}$ de distância na altura da bandeja de exames ao redor do equipamento, na parte traseira, e na posição do operador. Placas de PMMA simuladoras de mama foram utilizadas como espalhadores. Os valores de dose foram obtidos após 25 disparos no 
equipamento utilizando a técnica manual de $28 \mathrm{kVp}$ de tensão, $80 \mathrm{~mA}$ de corrente e $110 \mathrm{mAs}$, sem o uso do colimador de campo.

\subsubsection{Avaliação da dose de entrada na pele e da dose glandular média em uma unidade de mamografia digital comparando as técnicas TL e OSL}

Esse trabalho propõe a utilização dos dosímetros TL de $\mathrm{CaSO}_{4}$ :Dy produzidos pelo IPEN e os dosímetros nanoDot de $\mathrm{Al}_{2} \mathrm{O}_{3}: \mathrm{C}$ na avaliação da dose de entrada na pele (ESD) administrada as pacientes, bem como a camada semi-redutora (HVL) e as doses glandulares médias (MGD) em uma unidade mamográfica digital, comparando essas duas técnicas com os resultados obtidos usando um medidor eletrônico PTW Diavolt Universal All-in-one QC Meter.

Um simulador de mama Nuclear Associates, modelo 18-220 (licenciado pelo Colégio Americano de Radiologia - ACR), foi colocado sob o compressor na mesa de exames. Uma imagem de raio $\mathrm{X}$ foi adquirida usando o modo de exposição totalmente automático (Auto-kV) da unidade digital LORAD M-IV. Então, conhecendo a qualidade do feixe que o sistema de aquisição foi calibrado para obtenção da imagem do simulador, os dosímetros TL e OSL foram calibrados no intervalo de Kerma no ar de 3 a 20 mGy desta qualidade usando um medidor de QC all-in-one PTW DIAVOLT UNIVERSAL no centro do campo de radiação.

A camada semi-redutora (HVL) foi avaliada pelo medidor QC e ambos os materiais dosimétricos e, finalmente, uma mamografia foi tomada novamente, posicionando o medidor de CQ e os dosímetros para uma posição de exame, para calcular e comparar os resultados obtidos para a dose de entrada na pele (ESD) e a dose glandular média (MDG).

\subsubsection{Análise estatística dos resultados}

De acordo com as especificações do Guia para Expressões de Incerteza de Medições ISO GUM [92] as incertezas associadas às medidas realizadas podem ser classificadas como incertezas do tipo A e do tipo B. As incertezas do tipo A são determinadas ou estimadas por análises estatísticas, enquanto que as incertezas do tipo B são determinadas ou estimadas por outros métodos (não estatísticos), ou seja, por julgamentos científicos de incertezas não estatísticas; exigindo conhecimento da distribuição de probabilidade associada. Elas incluem influências nos processos de medidas, aplicação dos fatores de correção ou de dados físicos obtidos da literatura [10]. 
Portanto, as incertezas do tipo A são incertezas de caráter aleatório, devido à dispersão do valor dos resultados obtidos em torno do valor verdadeiro, ou seja, como o desvio padrão da média. As incertezas do tipo B são incertezas devido ao conjunto de medições que apresenta valores igualmente espaçados do valor verdadeiro, originados de erros instrumentais, ambientais e observacionais. A incerteza total das medidas é dada pela Equação 2 [93].

$$
\sigma_{\text {total }}^{2}=\sigma_{\text {estatístico }}^{2}+\sigma_{\text {sistemático }}^{2}
$$

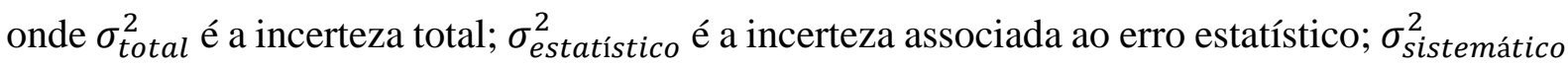
é a incerteza associada ao erro sistemático. seguir:

Para título de cálculos das incertezas do tipo A, foram utilizadas as Equações 3 e 4, a

Desvio padrão amostral:

$$
\sigma_{\left(y_{i}\right)}=\sqrt{\frac{1}{n-1} \sum_{i=1}^{n}\left(y_{i}-\bar{y}\right)^{2}}
$$

Desvio padrão da média:

$$
\sigma_{(\bar{y})}=\frac{\sigma_{\left(y_{i}\right)}}{\sqrt{n}}
$$


V Resultados e Discussões 


\section{RESULTADOS E DISCUSSÕES}

\subsection{Testes de estabilidade da Leitora TL Harshaw 4500}

A Figura 36 apresenta os resultados do teste da luz padrão de referência (Reference Light) da leitora Harshaw 4500. Foram calculadas as médias dos conjuntos de leituras para cada ciclo em função das datas de leitura, a média de todas as leituras de luz padrão, e os limites de aceitação, definidos pela variação máxima de $5 \%$ em relação à média de todas as leituras feitas.

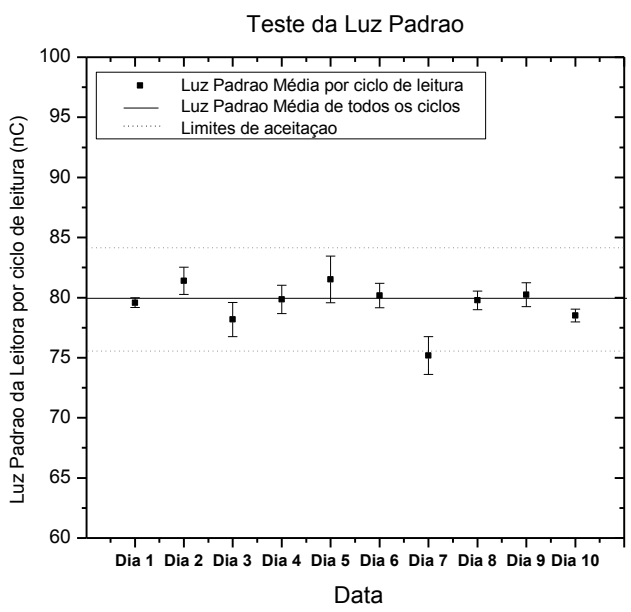

Figura 36. Resultados para o teste da Luz de referência. Valores médios dos conjuntos de leituras para cada ciclo e para todas as leituras e respectivos limites de aceitação.

A maioria dos valores das médias obtidas encontra-se dentro dos limites aceitáveis ( $\pm 5 \%$ de todos os ciclos de leitura). A variação da média do 'Dia 7' desvia do limite estipulado, com possível justificativa de que no dia da leitura ocorreram fortes flutuações na corrente elétrica do instituto devido ao clima. Constatado isso, as leituras nesse dia foram descartadas e novas leituras foram realizadas apenas quando estabilizado o clima local.

A Figura 37 apresenta os resultados do teste da razão sinal/ruído (PMT Noise) da leitora Harshaw 4500. Foram calculadas as médias dos conjuntos de leituras para cada ciclo em função das datas de leitura, a média de todas as leituras da razão sinal/ruído, e os limites de aceitação, definidos pela variação máxima de $5 \%$ em relação à média de todas as leituras feitas. 


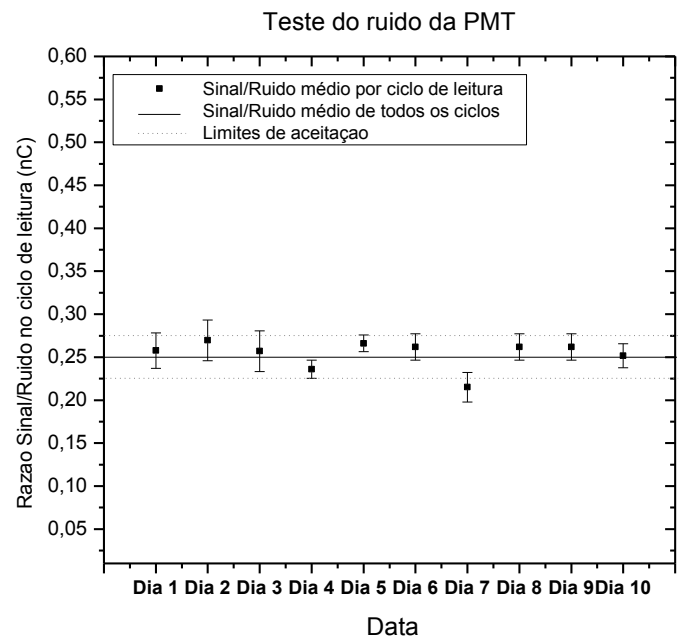

Figura 37. Resultados para o teste de ruído da PMT. Valores médios dos conjuntos de leituras para cada ciclo e para todas as leituras e respectivos limites de aceitação.

Os resultados das medições demonstram que a leitora TL utilizada apresentou boa estabilidade quanto aos testes de luz padrão de referência e razão sinal/ruído.

\subsection{Testes de estabilidade da Leitora OSL microStar $^{\mathrm{TM}}$ reader}

A Figura 38 apresenta os resultados do acompanhamento das contagens de fundo (Dark Counts) da leitora microStar ${ }^{\mathrm{TM}}$ reader no período de utilização do sistema. Foram calculadas as médias dos conjuntos de leituras para cada ciclo de leitura em função das datas de leitura e a média de todas as leituras de contagem de fundo.

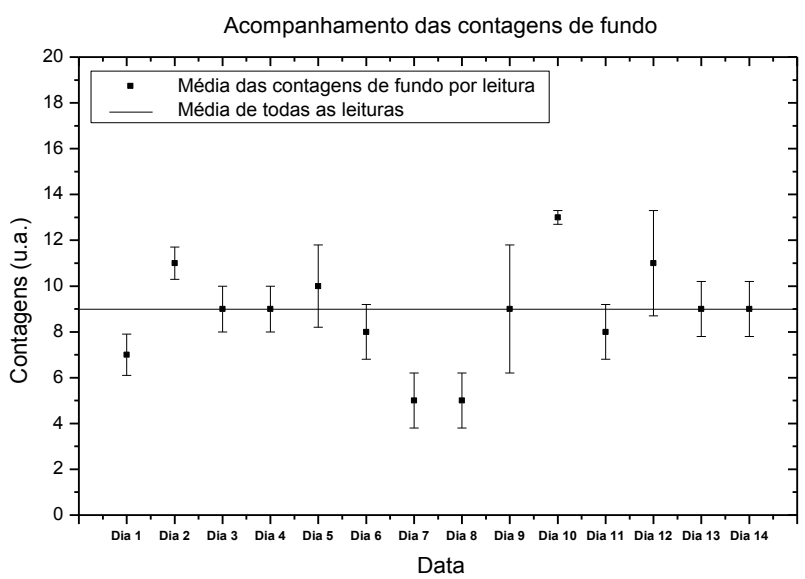

Figura 38. Acompanhamento das contagens de fundo da leitora microStar ${ }^{\mathrm{TM}}$ reader.

Não há limites de variação estatística a serem considerados, mas de acordo com o fabricante, o valor de contagens por segundo não deve ser superior $a \leq 20$ contagens. $O$ valor 
de contagens de fundo médio durante o período de utilização da leitora se manteve em $9 \pm 2$ contagens por segundo.

A Figura 39 apresenta os resultados do teste de análise das contagens da fotomultiplicadora (PMT Counts) da leitora microStar ${ }^{\mathrm{TM}}$ reader no período de utilização do sistema. Foram calculadas as médias dos conjuntos de leituras para cada ciclo em função das datas de leitura, a média de todas as leituras da análise da fotomultiplicadora, e os limites de aceitação, definidos pela variação máxima de $5 \%$ em relação à média de todas as leituras feitas.

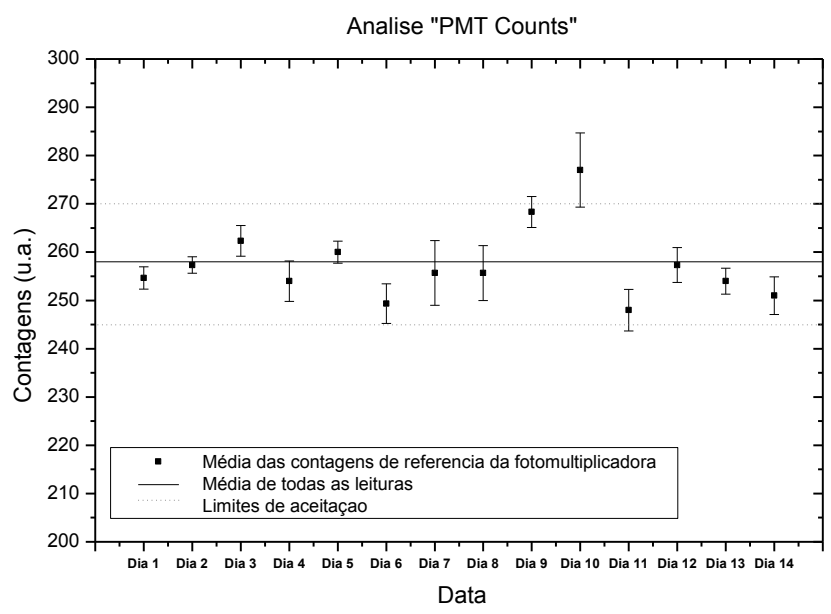

Figura 39. Análise das contagens da fotomultiplicadora. Valores médios dos conjuntos de leituras para cada ciclo e para todas as leituras e respectivos limites de aceitação.

Para este teste a leitora se manteve estável em praticamente todo o período de uso e, mesmo considerando o ponto acima do limite de variação de $5 \%$, o cálculo do CV por meio das medias de todas as medições se manteve em $2,98 \%$, valor dentro do limite de aceitação do fabricante.

A Figura 40 apresenta os resultados do teste de análise das contagens do LED de referência (LED Counts) da leitora microStar ${ }^{\mathrm{TM}}$ reader no período de utilização do sistema. Foram calculadas as médias dos conjuntos de leituras para cada ciclo em função das datas de leitura, a média de todas as leituras da análise do LED de referência, e os limites de aceitação, definidos pela variação máxima de $5 \%$ em relação à média de todas as leituras feitas.

Para este teste a leitora se manteve estável em todo o período de uso e, realizando o cálculo do $\mathrm{CV}$ por meio das medias de todas as medições, o resultado se manteve em 3,0 \%. 


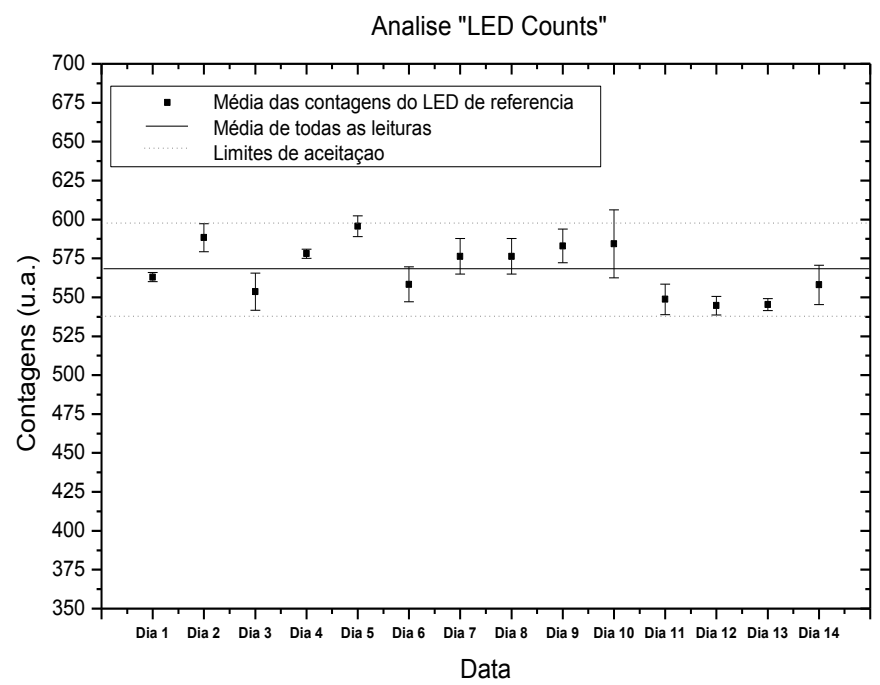

Figura 40. Análise "LED Counts". Valores médios dos conjuntos de leituras para cada ciclo e para todas as leituras e respectivos limites de aceitação.

Por meio da metodologia recomendada (item 4.3.5.2), a precisão intrínseca da leitora microStar $^{\mathrm{TM}}$ reader foi avaliada. Na Tabela 7 e na Figura 41 estão descritos os resultados individuais e médios obtidos em análise de três nanoDots ${ }^{\mathrm{TM}}$ com 1,8 Gy, 9,0 mGy e 2,5 mGy respectivamente.

Tabela 7. Resultados obtidos para o coeficiente de variância da leitora

\begin{tabular}{|c|c|c|c|}
\hline Medição & $\begin{array}{l}\text { Dose } 1 \\
(\mathrm{mGy})\end{array}$ & $\begin{array}{l}\text { Dose } 2 \\
(\mathrm{mGy})\end{array}$ & $\begin{array}{l}\text { Dose } 3 \\
(\mathrm{mGy})\end{array}$ \\
\hline Leitura 1 & 1824,512 & 9,245 & 2,592 \\
\hline Leitura 2 & 1832,160 & 8,896 & 2,575 \\
\hline Leitura 3 & 1808,547 & 9,212 & 2,566 \\
\hline Leitura 4 & 1832,160 & 9,404 & 2,522 \\
\hline Leitura 5 & 1785,563 & 9,188 & 2,647 \\
\hline Leitura 6 & 1791,910 & 9,166 & 2,538 \\
\hline Leitura 7 & 1832,160 & 9,347 & 2,597 \\
\hline Leitura 8 & 1819,086 & 9,159 & 2,584 \\
\hline Leitura 9 & 1846,270 & 9,371 & 2,546 \\
\hline Leitura 10 & 1813,648 & 9,461 & 2,515 \\
\hline Média & 1818,602 & 9,245 & 2,568 \\
\hline Desvio Padrão & 19,096 & 0,162 & 0,040 \\
\hline $\mathrm{CV}$ & $1,05 \%$ & $1,76 \%$ & $1,55 \%$ \\
\hline
\end{tabular}




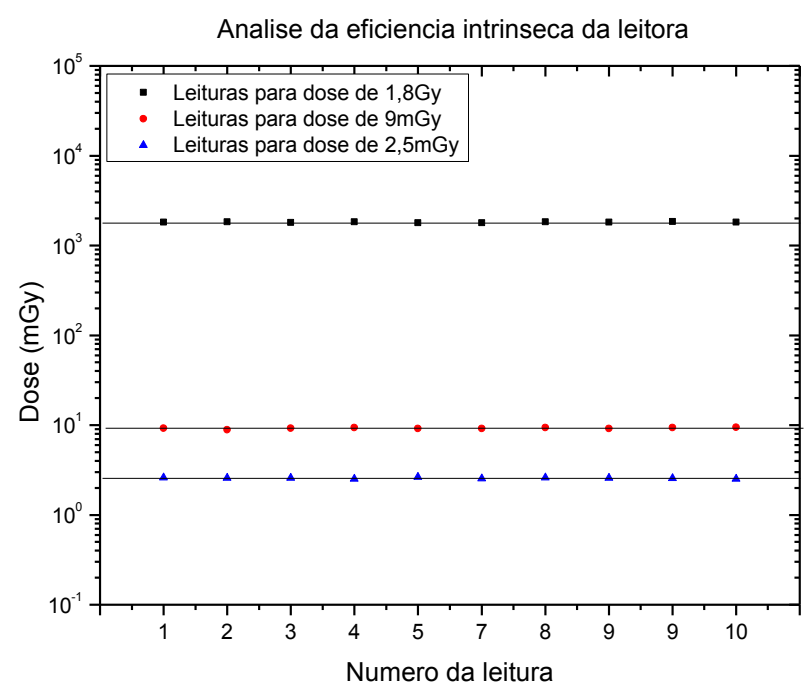

Figura 41. Análise gráfica dos resultados obtidos para o cálculo do coeficiente de variância da leitora microStar ${ }^{\mathrm{TM}}$ reader.

Os resultados das medições demonstram que a leitora OSL utilizada apresentou boa estabilidade quanto à análise das contagens de fundo, aos testes de fotomultiplicadora e LED padrão de referência. Vindo da análise da metodologia recomendada pelo fabricante, a leitora apresentou bons resultados de estabilidade intrínseca (na ordem de 1,5\%).

Tendo em vista os parâmetros analisados, a Figura 42 demonstra perfil de depreciação do sinal OSL dos nanoDots após 200 leituras consecutivas do mesmo dosímetro. Por meio do coeficiente angular obtido pelo ajuste linear das leituras $\left(\mathrm{R}^{2}=0,97\right)$, observou-se que, a cada leitura, o sinal é reduzido em 0,025 $\pm 0,002 \%$, valor este que está de acordo com o fabricante.

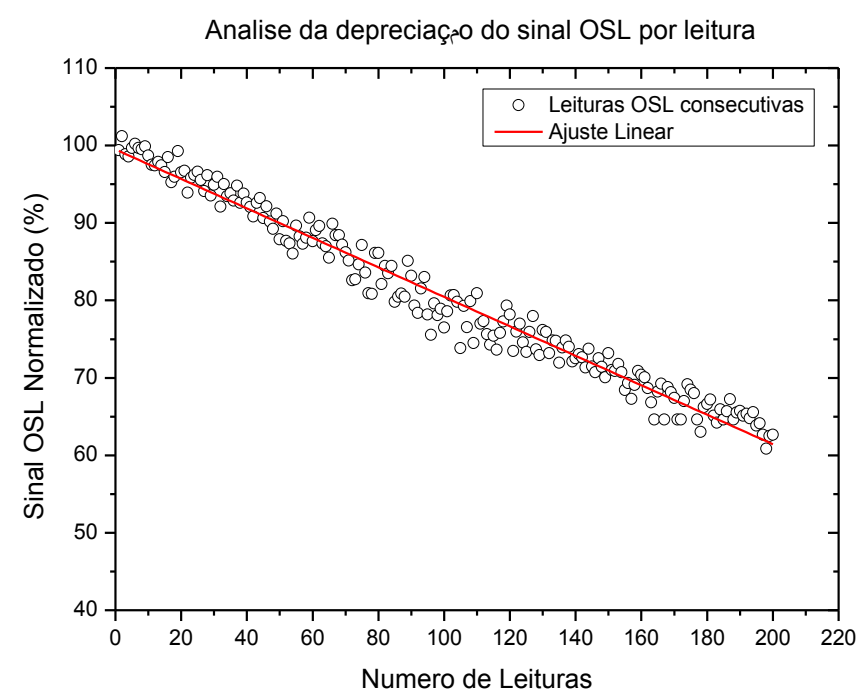

Figura 42. Estudo da depreciação do sinal OSL por leitura do dosímetro. 


\subsection{Testes de estabilidade da Leitora OSL RISØTMTL/OSL reader}

Durante o uso e manuseio rotineiro da leitora RIS $\varnothing$ TL/OSL reader, os pequenos testes de checagem de funcionamento foram realizados anteriormente a todas as leituras OSL, seguindo o manual de uso do fabricante (item 4.3.5.3). O equipamento não apresentou problemas no funcionamento dos botões e mecanismos de abrir e fechar a abertura do carrossel, tampouco no funcionamento do LED azul de estimulação. No acompanhamento das contagens de fundo da fotomultiplicadora, os resultados mantiveram dentro do esperado.

\subsection{Seleção dos dosímetros}

As Figuras 43 e 44 apresentam os histogramas das sensibilidades das respostas TL dos dosímetros de LiF:Mg,Ti (TLD-100) e do $\mathrm{CaSO}_{4}$ :Dy obtidos para a seleção dos dosímetros após a irradiação na fonte de ${ }^{137}$ Cs. Essas pastilhas já haviam sido previamente selecionadas e foram utilizadas em trabalhos anteriores ${ }^{(44,49)}$. Sendo assim, as pastilhas passaram por uma nova seleção para descarte de possíveis dosímetros saturados. Todos os dosímetros foram irradiados com $10 \mathrm{mGy}$, e para os lotes de uso foram selecionadas as amostras com sensibilidades nas variações de $(9,10 \pm 0,45)$ nC. $\mathrm{mGy}^{-1}$ e $(26,10 \pm 1,31)$ nC.mGy ${ }^{-1}$ para os TLD-100 e CaSO 4 :Dy respectivamente.

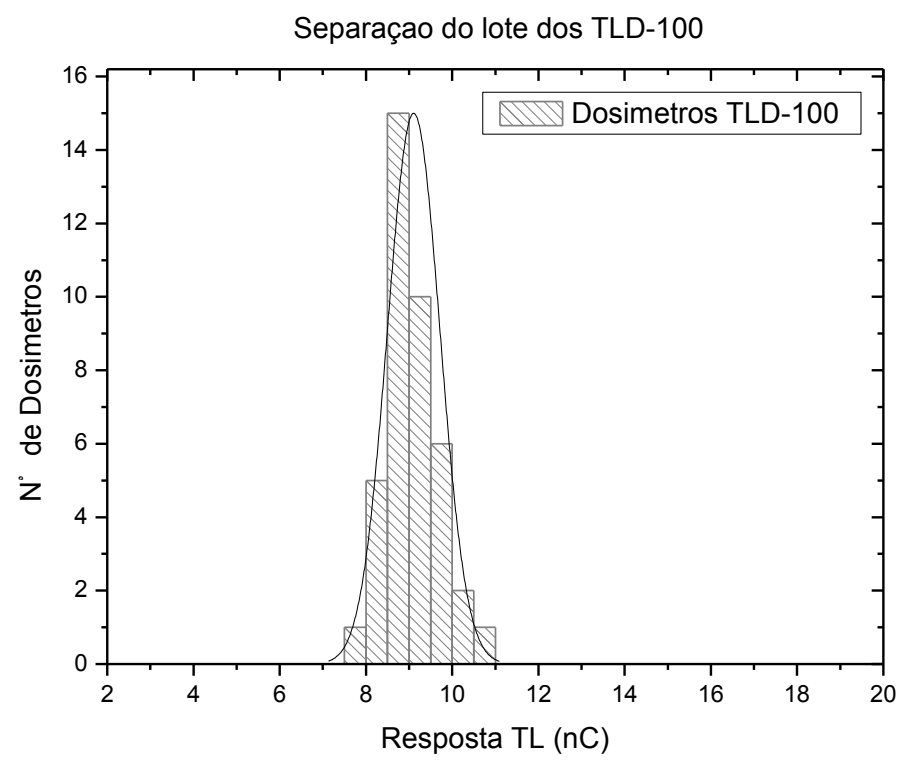

Figura 43. Histograma da média das três leituras TL para separação do lote dos dosímetros de LiF:Mg,Ti TLD-100. 


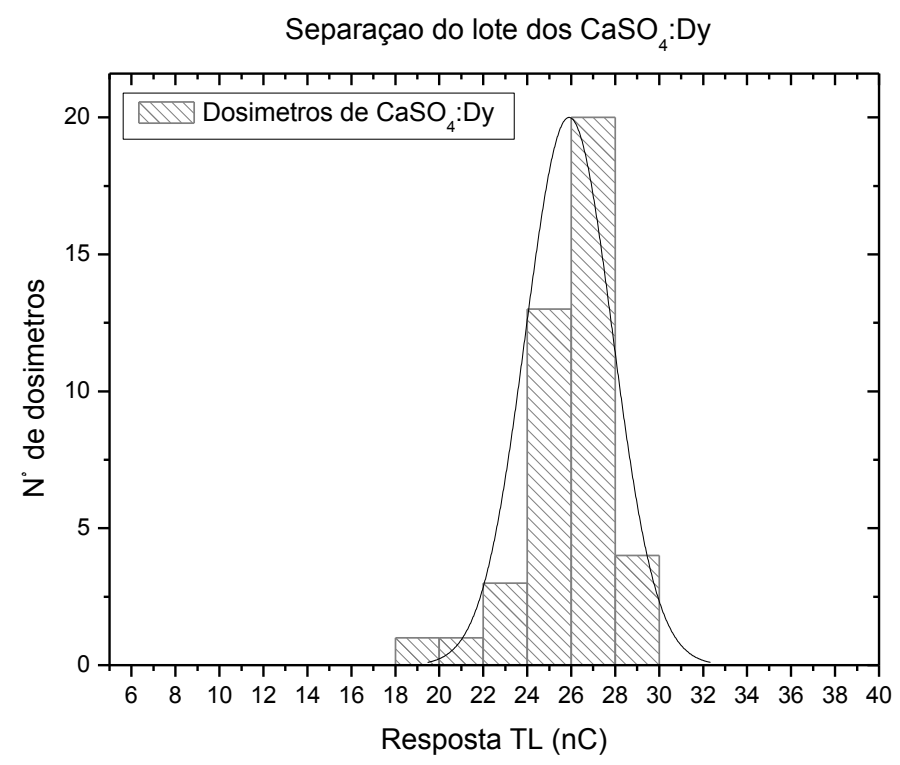

Figura 44. Histograma da média das três leituras TL para separação do lote dos dosímetros de $\mathrm{CaSO}_{4}: \mathrm{Dy}$.

O mesmo protocolo de seleção foi utilizado para definir o lote dos dosímetros de $\mathrm{Al}_{2} \mathrm{O}_{3}: \mathrm{C}$ TLD-500 (Figura 45). No entanto, devido às características do material, partindo de 45 pastilhas, foi obtido um lote de apenas 12 com sensibilidades variando em $5 \%$ em relação à média. Todos os dosímetros foram irradiados com $10 \mathrm{mGy}$, e para o lote de uso foram selecionadas as amostras com sensibilidades nas variações de $(5,38 \pm 0,18) \times 10^{6}$ contagens. $\mathrm{mGy}^{-1}$.

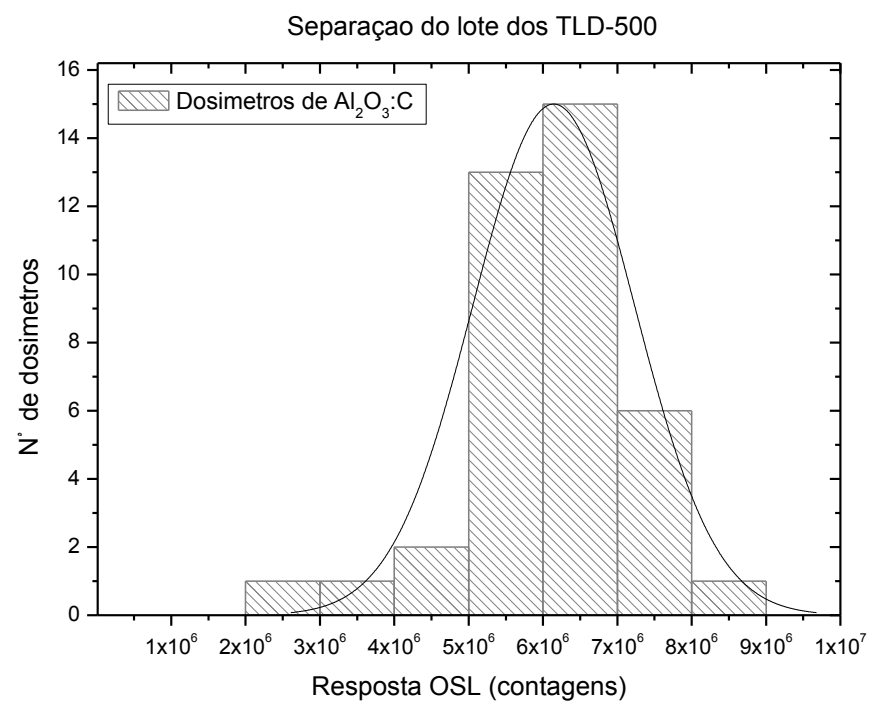

Figura 45. Histograma da média das três leituras OSL para separação do lote dos dosímetros de $\mathrm{Al}_{2} \mathrm{O}_{3}$ :C TLD-500. 
Os nanoDots já apresentam um fator de correção de sensibilidade por lote. Nesse estudo, dosímetros dos lotes "DN0.81", "DN0.90" e "DN0.94” foram utilizados. Para averiguação das sensibilidades individuais, e por recomendações do fabricante para uso em dosimetria oncológica $^{(94)}$, todos os nanoDots passaram pelo mesmo procedimento de seleção dos demais materiais e foram selecionadas as amostras com sensibilidades nas variações de 112,0 \pm 5,0 contagens. $\mathrm{mGy}^{-1}$ (Figura 46). Dessa maneira, além da repetibilidade das amostras, avalia-se o fator de correção dos lotes vindos da fábrica.

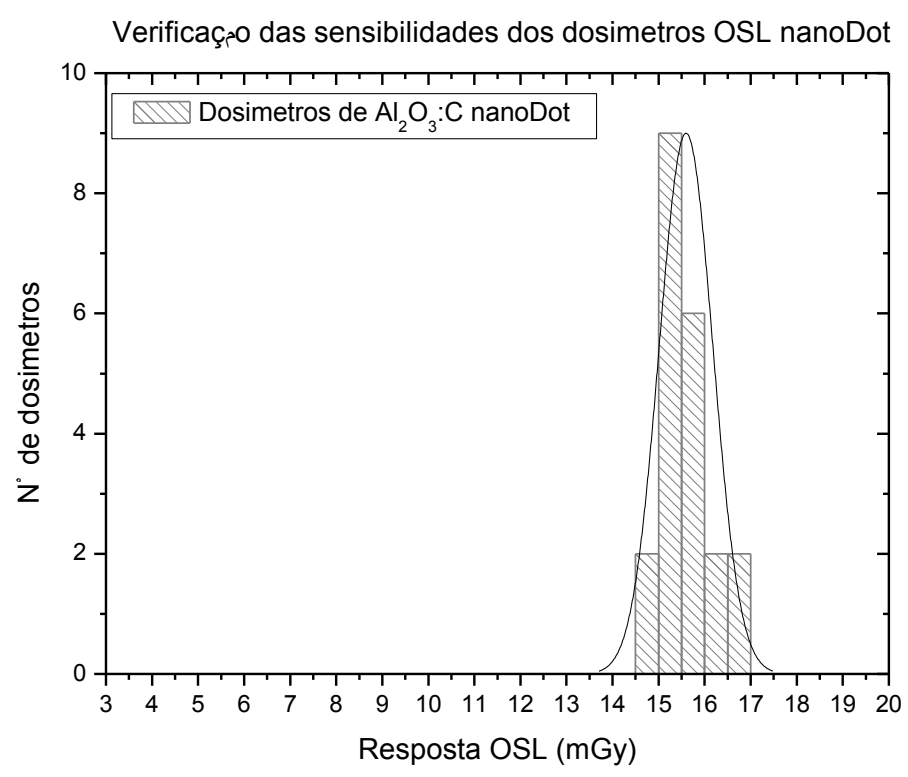

Figura 46. Histograma da média das três leituras OSL para verificação da sensibilidade dos dosímetros nanoDot utilizados

Com a análise dos resultados verificou-se que dois dosímetros encontravam-se fora da variação de sensibilidade, ambos do lote "DN0.81", e não foram utilizados. Vale ressaltar que todas as pastilhas selecionadas obtiveram valores de repetibilidade individuais melhores que $3 \%$.

Os valores de repetibilidade foram melhores que $\pm 4 \%$ para todos os dosímetros selecionados.

\subsection{Sensibilidades médias}

A sensibilidade $(S)$ de um dosímetro é definida pela razão da resposta $\left(R_{D}\right)$, seja TL ou OSL, pela dose de radiação $(D)$, definida pela Equação 9:

$$
S=\frac{R_{D}}{D}
$$


Desse modo, a sensibilidade média dos dosímetros a fótons gama do ${ }^{60} \mathrm{Co}$ foi obtida para diferentes doses. As sensibilidades TL dos dosímetros TLD-100 e CaSO 4 :Dy são expressas em $\mu \mathrm{C} . \mathrm{Gy}^{-1}$, e as sensibilidades OSL dos dosímetros TLD-500 e nanoDot em cps.Gy ${ }^{-1}$. As sensibilidades médias são apresentadas nas Figuras 47 e 48.

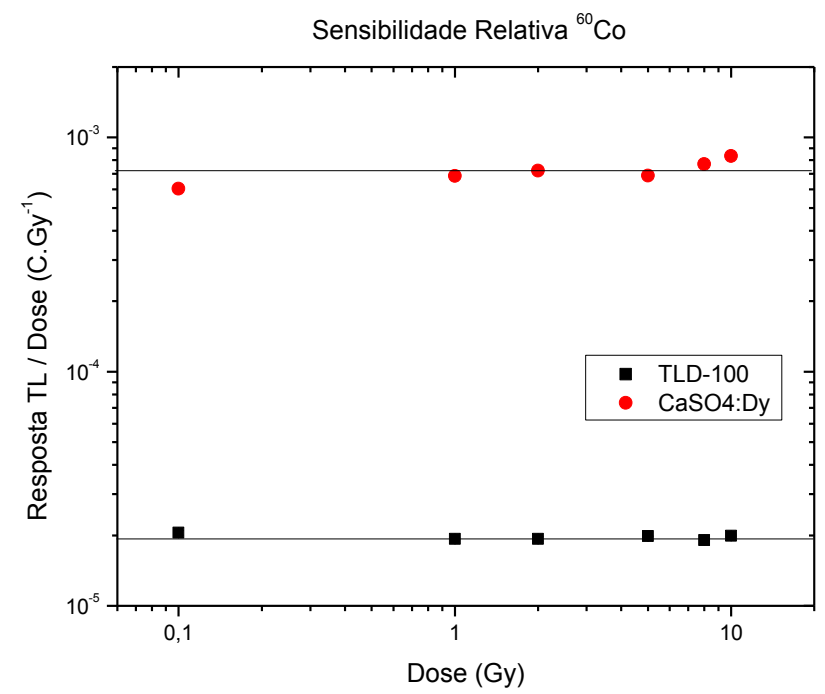

Figura 47. Sensibilidade TL dos dosímetros TLD-100 e CaSO 4 :Dy para feixe de fótons gama do ${ }^{60} \mathrm{Co}$

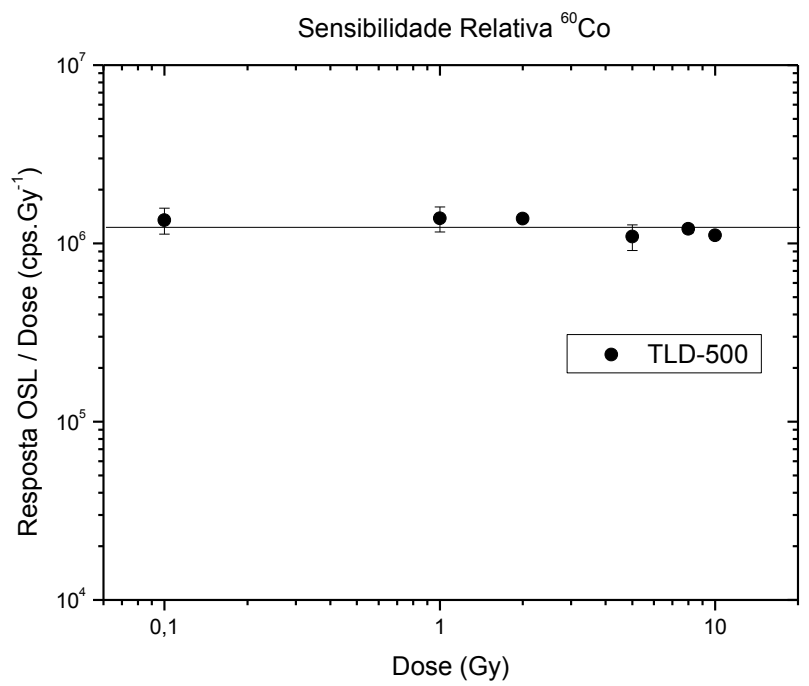

Figura 48. Sensibilidade OSL dos dosímetros de $\mathrm{Al}_{2} \mathrm{O}_{3}: \mathrm{C}$ TLD-500 e nanoDot ${ }^{\mathrm{TM}}$ para feixe de fótons gama do ${ }^{60} \mathrm{Co}$ 


\subsection{Teste dos colimadores}

$\mathrm{Na}$ Tabela 8 são apresentados os fatores de correção $\left(f_{c o l}\right)$ obtidos para os colimadores utilizados nas medias TL e OSL a fim de reduzir a intensidade de sinal emitido pelas pastilhas. Os fatores foram calculados por meio da Equação 10

$$
f_{\text {col }}=\frac{\bar{R}_{0}}{\bar{R}_{\text {col }}}
$$

Onde $\bar{R}_{0}$ é a resposta média dos dosímetros lidos sem uso do colimador e $\bar{R}_{\text {col }}$ a resposta média dos dosímetros lidos utilizando o colimador.

Tabela 8. Fatores de correção $\left(f_{c o l}\right)$ obtidos para as leituras TL do $\mathrm{CaSO}_{4}$ :Dy e OSL dos TLD500

\begin{tabular}{ccccc}
\hline Dosímetro & Colimador 1 & Colimador 2 & Colimador 3 & Colimador 4 \\
\hline $\mathrm{CaSO}_{4}: \mathrm{Dy}$ & $2,21^{\mathrm{a}}$ & $72,28^{\mathrm{a}}$ & & \\
$\mathrm{Al}_{2} \mathrm{O}_{3}: \mathrm{C}$ TLD-500 & $17,60^{\mathrm{b}}$ & $45,62^{\mathrm{b}}$ & $287,19^{\mathrm{b}}$ & $444,11^{\mathrm{b}}$ \\
\hline
\end{tabular}

a Valores de correção TL com os colimadores da Figura 38para leitora Harshaw 4500

${ }^{\mathrm{b}}$ Valores de correção OSL com os colimadores da Figura39para leitora RIS $\emptyset$ TL/OSL reader

\subsection{Estudo da correlação entre a resposta OSL dos dosímetros TLD-500 com a potência do arranjo de LEDs azuis de estimulação para a Leitora RISØ ${ }^{\mathrm{TM}}$ TL/OSL reader}

Um parâmetro que pode ser ajustado na leitora é a potência do estímulo óptico. Nas Figuras 49 e 50 estão demonstrados os resultados obtidos para a variação de 90 a $1 \%$ da potência do arranjo de LEDs azuis. As irradiações foram realizadas para uma dose de $10 \mathrm{mGy}$, sem os colimadores e os resultados demonstrados são a média de três espectros.

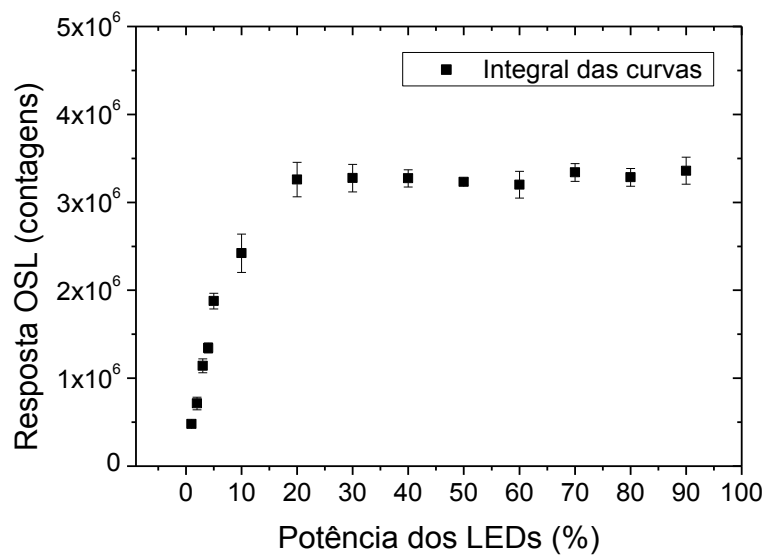

Figura 49. Comportamento das integrais das curvas de decaimento OSL variando a potência do arranjo de LEDs azuis. 

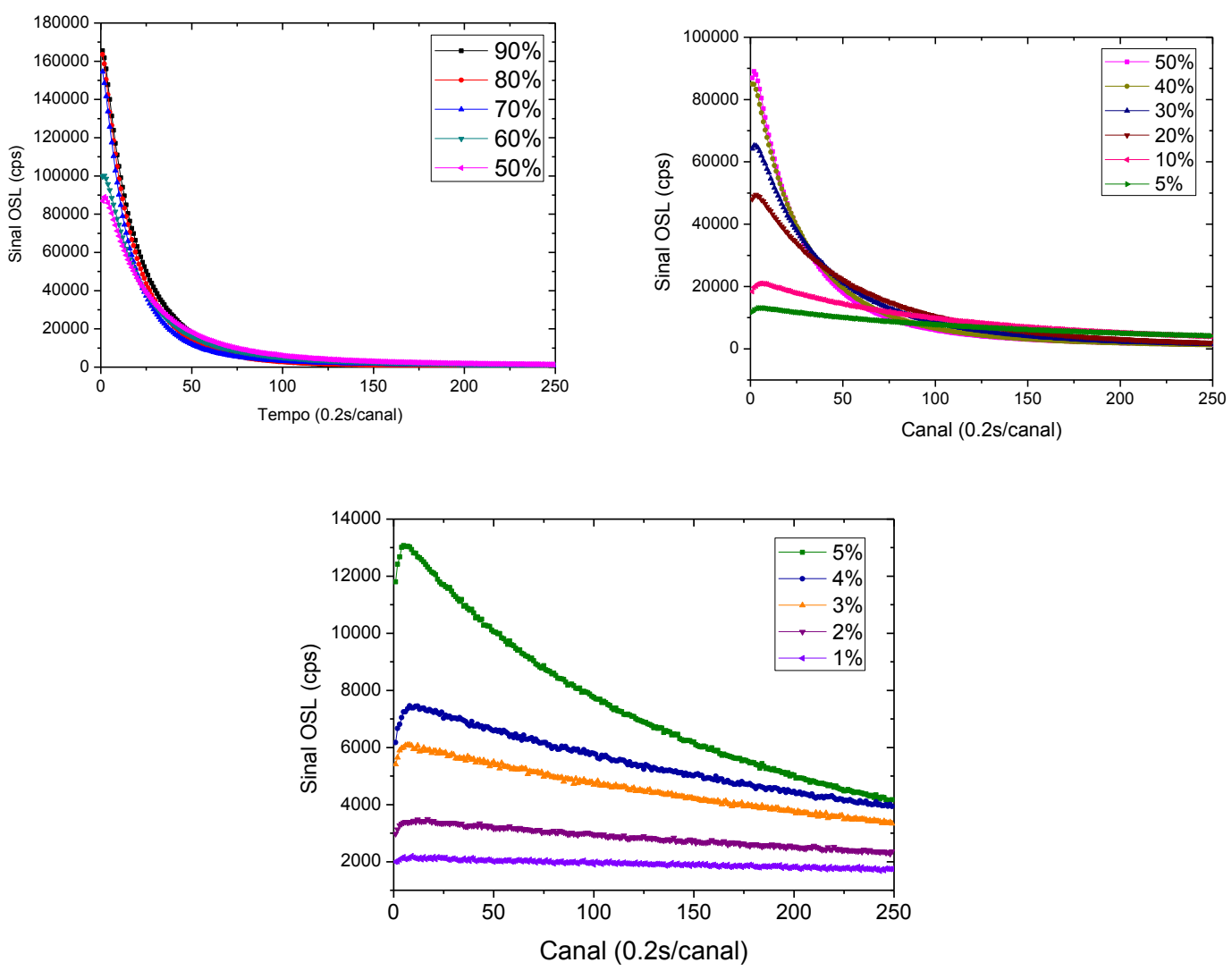

Figura 50. Curvas de decaimento OSL obtidas pela variação da potência do arranjo de LEDs azuis.

Por meio da análise das Figuras 49 e 50 fica evidenciado que, entre 90 e $20 \%$, independente da potência utilizada, os valores das integrais das curvas de decaimento OSL permanecem na mesma variação estatística e, portanto, pode ser verificado que o desarmadilhamento do mesmo número de cargas. O perfil decrescente de valor de contagem integrada de 15 a $1 \%$ mostra que, nesse intervalo, quanto menor a potência do estímulo, menor a recombinação das cargas nos dosímetros.

\subsection{Estudo da correlação entre a resposta OSL dos dosímetros TLD-500 com o tempo de leitura para a Leitora RISO ${ }^{\mathrm{TM}}$ TL/OSL reader}

Outro parâmetro que pode ser ajustado na leitora é o tempo do estímulo óptico. Na Figura 51 são demonstrados os resultados dos espectros (a) e das integrais das curvas (b) obtidas para a variação de 50 a 5 s do tempo de estímulo óptico. As irradiações foram realizadas para uma dose de $10 \mathrm{mGy}$, sem os colimadores e os resultados demonstrados são a média de três espectros. 

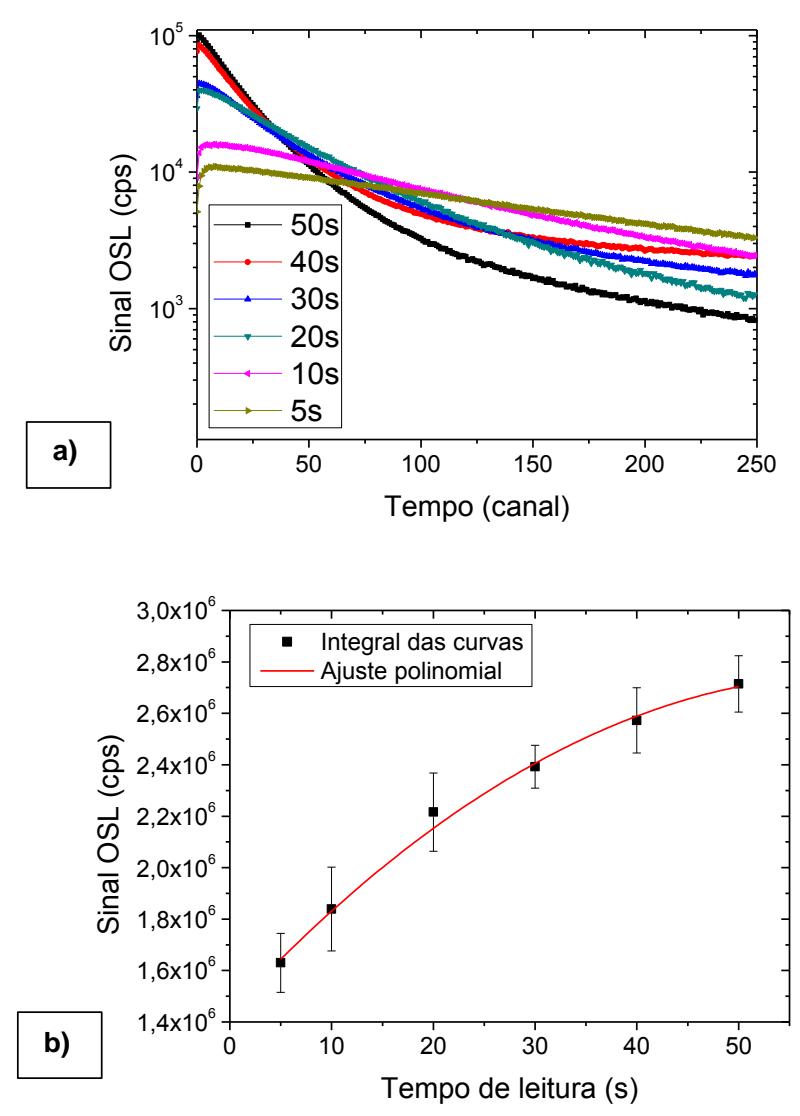

Figura 51. Comportamento das curvas de decaimento OSL (a) e das integrais das curvas de decaimento OSL (b) em função da variação do tempo de estímulo óptico.

Analisando a Figura 51 b fica evidenciado o comportamento polinomial dos valores das integrais e, que, quanto menor o tempo de estímulo, menor o desarmadilhamento das cargas no dosímetro. Analisando os resultados anteriormente descritos, pode-se afirmar que a utilização de $1 \%$ de potência do arranjo de LEDs azuis, e 5 segundos de estímulo de leitura são suficientes para caracterização dosimétrica do sistema. Entretanto, quanto menor o tempo de estimulação, menor a área de informações será integrada, se aproximando cada vez mais de apenas um ponto de leitura. Essa característica pode causar aumento de supralinearidade aparente do material dosimétrico em resposta com a dose, haja vista as considerações apresentadas no item 3.2.3 e os gráficos expressos na Figura 10. Sendo assim, para todo o estudo foram utilizadas as integrais das curvas de $50 \mathrm{~s}$ de tempo de estimulação. 


\subsection{Estudo da correlação entre o "bleaching" do sinal OSL e efetividade do tempo de iluminação para diferentes doses em dosimetria de fótons}

O tempo de tratamento óptico para reutilização das amostras foi determinado variando de 1 min a 24 h o tempo de exposição dos dosímetros OSL nanoDot e TLD-500 a uma lâmpada de 1,3 W de potência, composta por 30 LEDs azuis Ourolux ${ }^{\circledR}$. As leituras dos TLD-500 foram realizadas utilizando $1 \%$ de potência do arranjo de LEDs, e 5 segundos de leitura. Os resultados estão demonstrados na Figura 52 a e b.
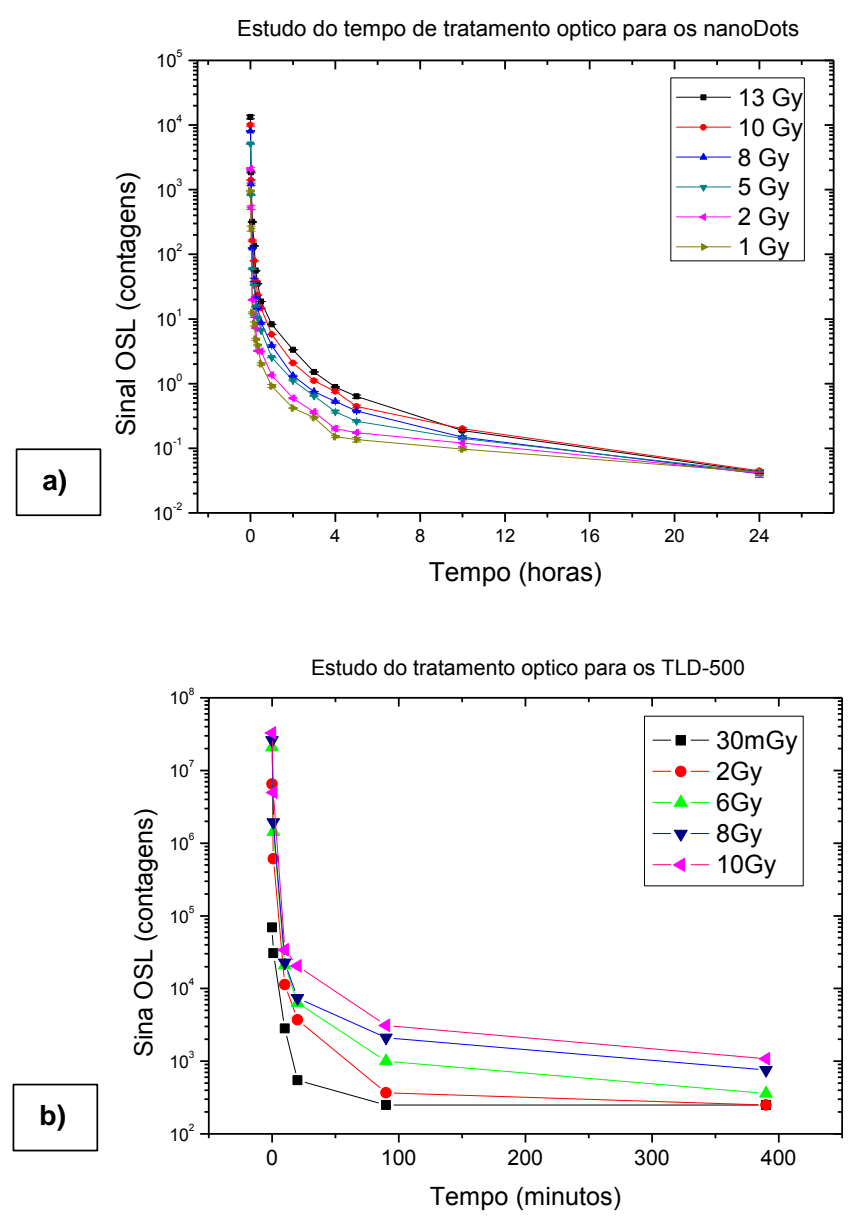

Figura 52. Comportamento das respostas OSL de acordo com o tempo de tratamento óptico. (a) Resultados obtidos para os nanoDots. (b) Resultados obtidos para os TLD-500.

Pode ser verificado que para a dose de $30 \mathrm{mGy}, 1 \mathrm{~h}$ e $30 \mathrm{~min}$ foram suficientes para limpar por completo as amostras irradiadas. Para doses de níveis de dosimetria clínica em terapia (2 Gy), para ambos dosímetros, são necessárias $\sim 6 \mathrm{~h}$. Por motivos práticos, para este estudo foi utilizado o tempo de $\sim 12 \mathrm{~h}$ (uma noite) em todos os casos de irradiação. 


\subsection{Caracterização dos Sistemas Dosimétricos}

As curvas de resposta TL em função da dose do TLD-100 e CaSO 500 e dos nanoDots à radiação gama do ${ }^{60} \mathrm{Co}$ para irradiação no ar e em equilíbrio eletrônico foi obtida como referência para doses de $1 \mathrm{mGy}$ a $10 \mathrm{~Gy}$. Os resultados estão demonstrados nas Figuras 53 e 54 . As Figuras 55 e 56 apresentam as curvas de resposta em função da dose para feixe de fótons de 6 MV do Acelerador Linear Varian NOVALIS TX no intervalo de 25 a 300 cGy em profundidade de máxima dose $\left(\mathrm{z}_{\max }\right)$.
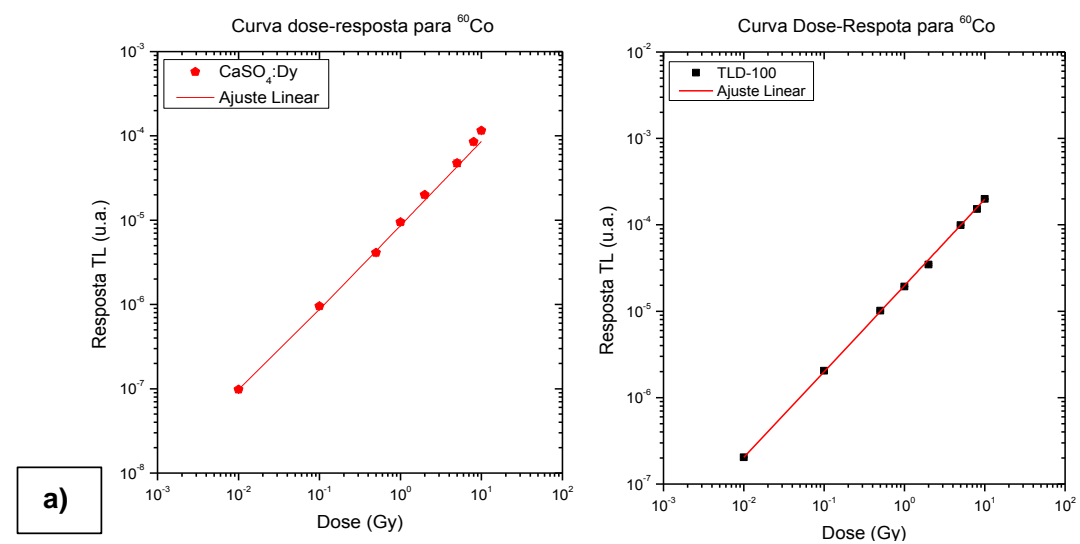

b)

Figura 53. Curvas de resposta TL em função da dose dos dosímetros $\mathrm{CaSO}_{4}$ :Dy (a) e TLD100 (b) para radiação gama do ${ }^{60}$ Co livres no ar e em equilíbrio eletrônico.
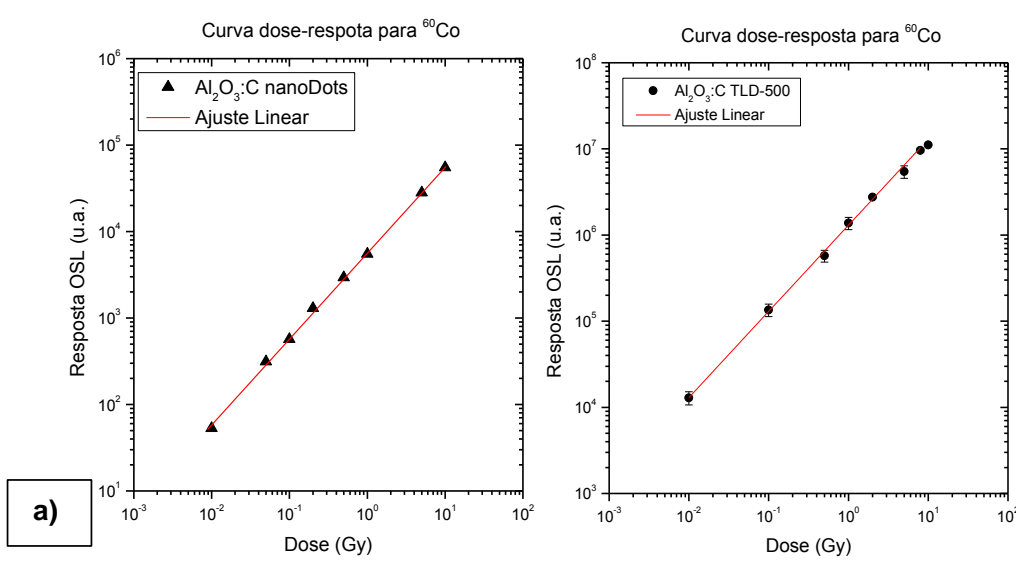

b)

Figura 54. Curvas de resposta OSL em função da dose dos dosímetros $\mathrm{Al}_{2} \mathrm{O}_{3}: \mathrm{C}$ nanoDot (a) e TLD-500 (b) para radiação gama do ${ }^{60}$ Co livres no ar e em equilíbrio eletrônico. 

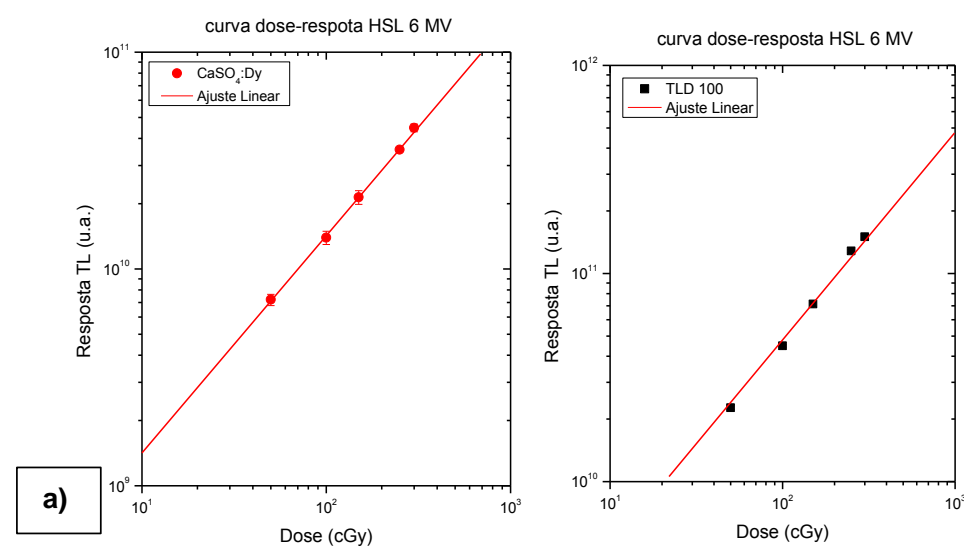

b)

Figura 55. Curvas de resposta TL em função da dose dos dosímetros $\mathrm{CaSO}_{4}$ :Dy (a) e TLD-100 (b) para fótons de $6 \mathrm{MV}$.
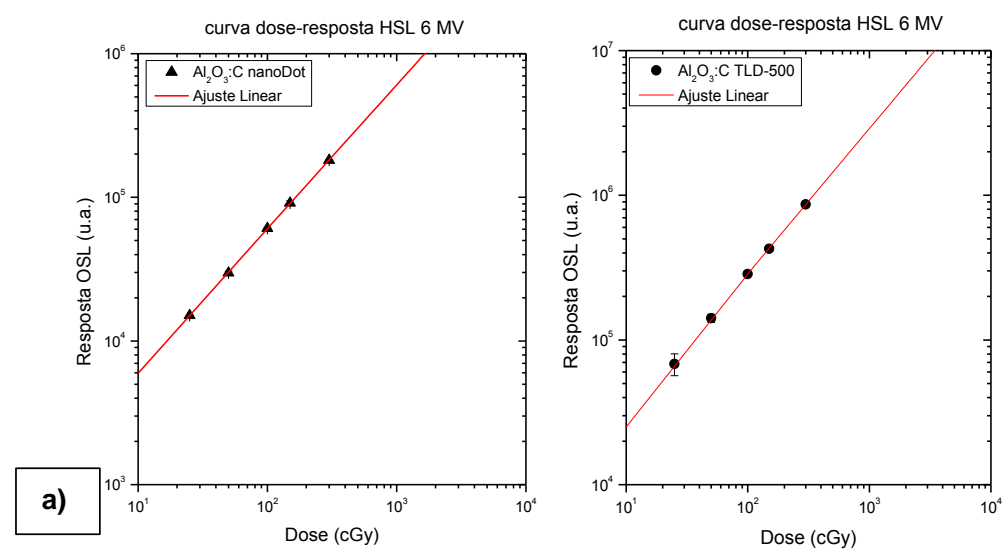

b)

Figura 56. Curvas de resposta OSL em função da dose dos dosímetros $\mathrm{Al}_{2} \mathrm{O}_{3}: \mathrm{C}$ nanoDot (a) e TLD-500 (b) para fótons de $6 \mathrm{MV}$.

Todos os materiais apresentam comportamento linear da resposta no intervalo de dose estudado, em atenção especial para as curvas obtidas para caracterização clínica com feixe de $6 \mathrm{MV}$.

\subsection{Limite inferior de detecção (LID)}

Por meio do ajuste linear nas curvas de resposta em função da dose, cujas inclinações são iguais a 1 , os fatores de calibração, $f_{c a l}$, foram obtidos e, portanto, os limites inferiores de detecção, $L I D$, foram determinados experimentalmente por pela Equação 11

$$
L I D=\left(R_{0}+3 \cdot \sigma_{0}\right) \cdot f_{c a l}
$$

onde $R_{0}$ é o valor médio de leituras de dosímetros não irradiados, e $\sigma_{0}$ o valor do desvio padrão da média correspondente. A Tabela 9 apresenta os resultados dos LID dos quatro dosímetros 
para radiação gama do ${ }^{60} \mathrm{Co}$ e fótons de $6 \mathrm{MV}$, e estão de acordo com os valores obtidos na literatura.

Tabela 9. Valores dos Limites Inferiores de Detecção (LID) de todos os dosímetros estudados para os feixes de radiação gama de ${ }^{60} \mathrm{Co}$ e fótons $6 \mathrm{MV}$.

\begin{tabular}{cccc}
\hline & & \multicolumn{2}{c}{$\boldsymbol{L I D}(\boldsymbol{\mu G} \mathbf{G})$} \\
& Dosímetro & ${ }^{\mathbf{6 0}} \mathbf{C o}$ & $\mathbf{6} \mathbf{~ M V}$ \\
\hline \multirow{2}{*}{$\mathrm{TL}$} & $\mathrm{CaSO}_{4}: \mathrm{Dy}$ & $26,5 \pm 0,9$ & $28,7 \pm 0,4$ \\
& $\mathrm{TLD}-100$ & $15,1 \pm 0,2$ & $16,9 \pm 0,6$ \\
\multirow{2}{*}{ OSL } & TLD-500 & $5,3 \pm 0,3$ & $5,8 \pm 0,5$ \\
& nanoDots & $4,5 \pm 0,2$ & $4,8 \pm 0,1$ \\
\hline
\end{tabular}

\subsection{Planejamento de tumor cerebral utilizando o simulador antropomórfico $S T E E V^{\mathrm{TM}}$}

Na Figura 57 estão apresentadas as imagens fornecidas pelo sistema de planejamento VARIAN Eclipse 10.0 do tratamento VMAT, pelo qual os dosímetros foram irradiados utilizando o simulador STEEV. Na Tabela 10 são encontrados os valores de dose prescritos, com seus valores máximos, mínimos e médios para o volume alvo.

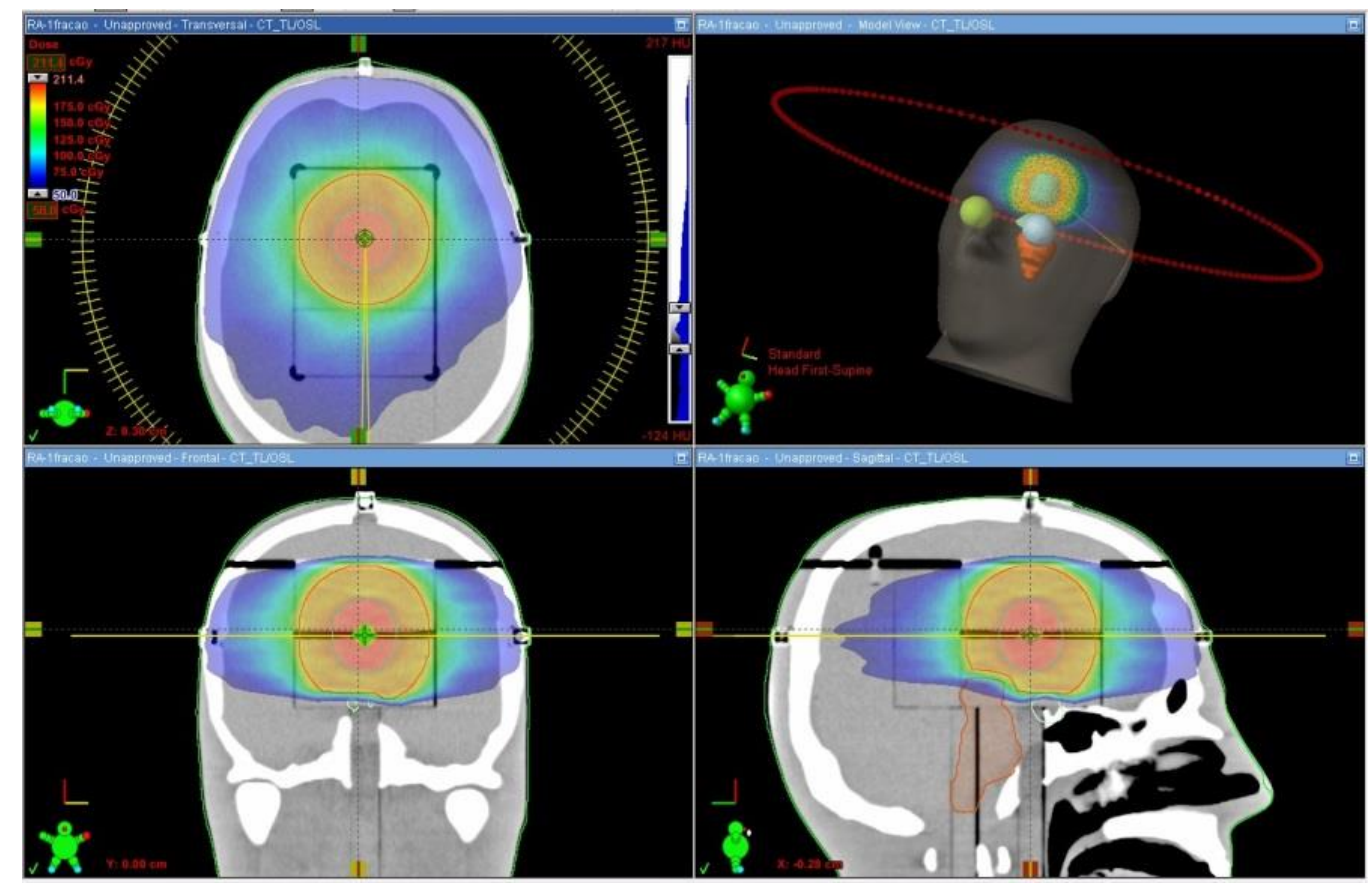

Figura 57. Distribuição de dose no simulador STEEV fornecida pelo sistema de planejamento Eclipse 10.0. 
Tabela 10. Doses planejadas no simulador STEEV fornecidas pelo sistema de planejamento Eclipse 10.0.

\section{Planejamento (cGy)}

\begin{tabular}{cccc} 
Máximo & Mínimo & Média & Max/Min (\%) \\
\hline 205,8 & 202,4 & 203,7 & $-1,7$ \\
\hline
\end{tabular}

Os valores de dose medidos pelos quatro dosímetros utilizados nesse estudo, além dos valores obtidos com a câmara de ionização PTW PinPoint3D, com seus máximos, mínimos, médias e desvios das médias em relação ao valor médio do planejamento estão apresentados na Tabela 11.

Tabela 11. Doses Médias, Mínimas e Máximas obtidas pelos dosímetros TL de LiF:Mg,Ti (TLD-100) e $\mathrm{CaSO}_{4}: \mathrm{Dy}$, OSL de $\mathrm{Al}_{2} \mathrm{O}_{3}: \mathrm{C}$ nanoDots e TLD-500 e câmara de ionização PinPoint3D.

\section{Dose absorvida (cGy)}

\begin{tabular}{cccccc}
\hline Dosímetro & $\begin{array}{c}\text { Máximo } \\
(\mathbf{c G y})\end{array}$ & $\begin{array}{c}\text { Mínimo } \\
(\mathbf{c G y})\end{array}$ & $\begin{array}{c}\text { Média } \pm \text { DPM } \\
(\mathbf{c G y})\end{array}$ & $\begin{array}{c}\text { Desvio da } \\
\text { média* }\end{array}$ & $\begin{array}{c}\text { Max/Min } \\
(\boldsymbol{\%})\end{array}$ \\
\hline TLD-100 & 205,7 & 199,82 & $202,0 \pm 1,0$ & $-0,8$ & $-2,95$ \\
CaSO $_{4}$ :Dy & 205,0 & 198,6 & $202,0 \pm 1,3$ & $-0,8$ & $-3,24$ \\
nanoDots & 205,5 & 201,6 & $204,2 \pm 0,7$ & $+0,2$ & $-1,91$ \\
TLD-500 & 201,2 & 198,7 & $201,4 \pm 1,9$ & $-1,1$ & $-1,24$ \\
PinPoint3D & 203,9 & 202,3 & $203,0 \pm 0,3$ & $-0,3$ & $-0,82$ \\
\hline
\end{tabular}

*Desvio entre o valor médio planejado pelo Eclipse e o valor médio obtido experimentalmente com os dosímetros.

Os desvios entre os valores médios de dose absorvida obtidos pelos dosímetros e o valor médio de dose prescrito pelo sistema de planejamento foi de $-0,82 \%,-0,83 \%,+0,23 \%$, - $1,13 \%$ e - 0,33 \% para os TLD-100, $\mathrm{CaSO}_{4}: \mathrm{Dy}$, nanoDots, TLD-500 e câmara de ionização PinPoint3D respectivamente. A razão Max/Min (\%) mostra que os dosímetros de $\mathrm{CaSO}_{4}: \mathrm{Dy}$ apresentaram maior variação percentual entre seus maiores e menores valores de dose medidos, e, como esperado, a câmara de ionização obteve o menor valor. A visualização gráfica dos resultados obtidos e a concordância com o planejamento está demonstrada na Figura 58. 


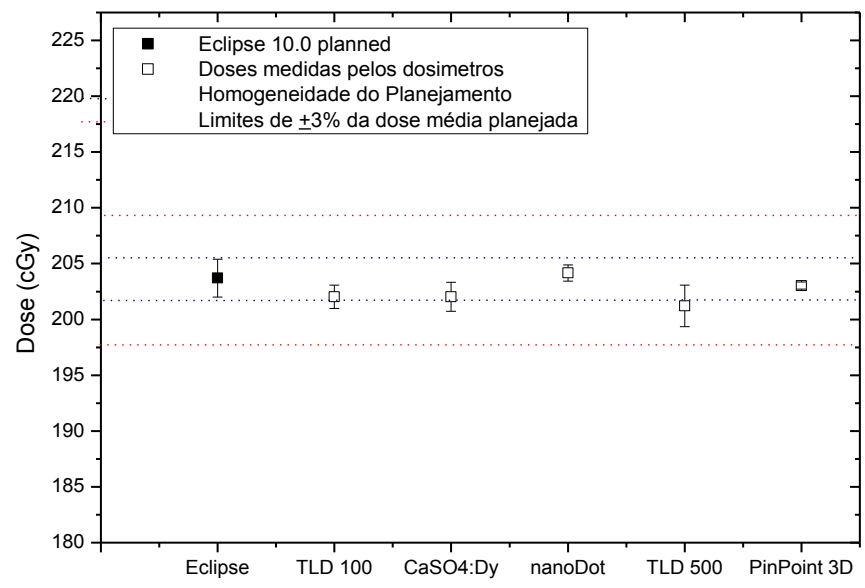

Figura 58. Homogeneidade do planejamento e concordância dos valores medidos com os quatro dosímetros de estudo e a câmara de ionização PinPoint 3D.

Por meio da análise dos resultados apresentados, pode-se notar que as medições dos nanoDots e da câmara de ionização variam dentro da homogeneidade do tratamento planejado, e, apesar de maiores variações dos dosímetros TL TLD-100, $\mathrm{CaSO}_{4}$ :Dy e OSL $\mathrm{Al}_{2} \mathrm{O}_{3}: \mathrm{C}$ TLD500 , todos os valores obtidos para variaram menos do que $\pm 3 \%$ da dose média planejada.

Os resultados mostraram que ambos os tipos de $\mathrm{Al}_{2} \mathrm{O}_{3}: \mathrm{C}$ apresentaram boa repetibilidade e concordância entre a dose medida e o tratamento planejado doses prescritas pelo Eclipse 10.0 [95,96]. Todas as incertezas estavam dentro de $\pm 3 \%$, de modo que ambas as técnicas concordam com os requisitos de desempenho internacionais. Para os dosímetros TL de $\mathrm{LiF}: \mathrm{Mg}, \mathrm{Ti}$ e $\mathrm{CaSO}_{4}: \mathrm{Dy}$, os valores concordam com o esperado pela literatura e com resultados obtidos em pesquisas anteriores

\subsection{Planejamento de tumor de próstata utilizando o simulador antropomórfico de Pelve e dosimetria de entrada na pele do paciente}

A Figura 59 são apresentadas as imagens fornecidas pelo sistema de planejamento VARIAN Eclipse 10.0 do tratamento VMAT pelo qual os dosímetros foram irradiados utilizando o simulador antropomórfico de Pelve ExacTrac. Na Tabela 12 são mostrados os valores de dose prescritos médios e suas incertezas para o volume de cada um dos dosímetros posicionados na entrada da pele do simulador, com as variações de cálculo sem mesa, com mesa original, e com a mesa editada. 

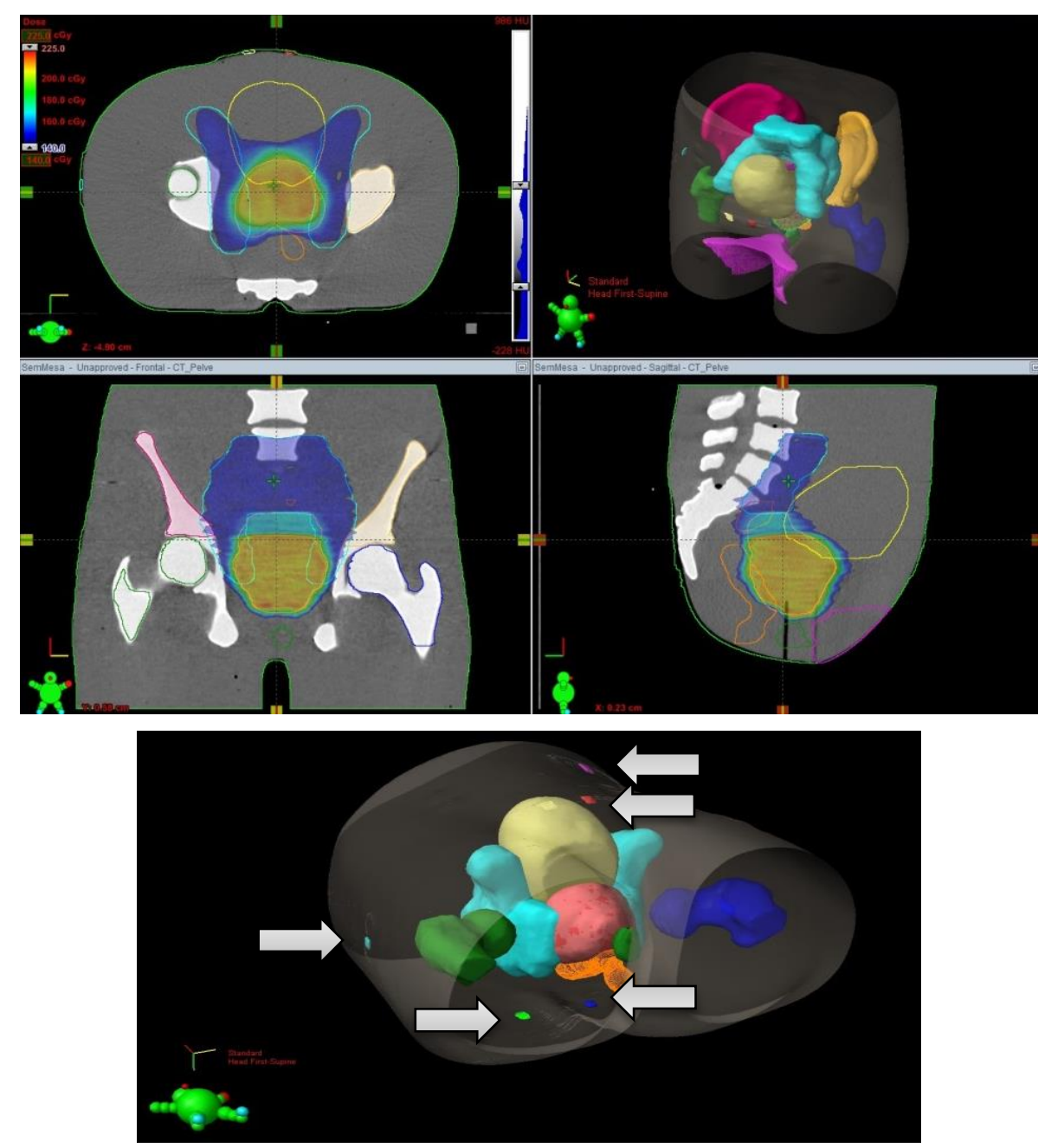

Figura 59. (a) Distribuição de dose no simulador antropomórfico de Pelve ExacTrac fornecida pelo sistema de planejamento Eclipse 10.0.(b) localização dos dosímetros no simulador com indicações por setas

Tabela 12. Variação nos valores de dose prescritos nas variações sem a mesa, com a mesa original e com a mesa editada.

\begin{tabular}{cccc}
\hline & $\begin{array}{c}\text { Planejamento Sem } \\
\text { Mesa }\end{array}$ & $\begin{array}{c}\text { Planejamento Com Mesa } \\
\text { Original }\end{array}$ & $\begin{array}{c}\text { Planejamento Com Mesa } \\
\text { Editada }\end{array}$ \\
\hline Posição do & $\begin{array}{c}\text { Média } \pm \text { DP } \\
\text { (cGy) }\end{array}$ & $\begin{array}{c}\text { Média } \pm \text { DP } \\
(\mathbf{c G y})\end{array}$ & $\begin{array}{c}\text { Média } \pm \text { DP } \\
(\mathbf{c G y})\end{array}$ \\
\hline dosímetro & $14,9 \pm 2,0$ & $14,7 \pm 2,0$ & $14,6 \pm 2,0$ \\
Puperior & $58,9 \pm 4,4$ & $66,6 \pm 3,6$ & $70,5 \pm 3,4$ \\
Post Esq & $59,3 \pm 4,2$ & $71,0 \pm 3,1$ & $76,1 \pm 2,8$ \\
LatDir & $26,2 \pm 2,1$ & $25,9 \pm 2,2$ & $25,8 \pm 2,1$ \\
AntEsq & $32,9 \pm 1,5$ & $32,8 \pm 1,8$ & $32,6 \pm 1,7$ \\
AntDir & $35,1 \pm 2,7$ & $34,9 \pm 2,7$ & $34,8 \pm 2,7$ \\
\hline
\end{tabular}


Analisando os dados fornecidos, pode ser observado que as variações mais significativas dos valores de dose prescritos nas três formas de cálculo estão nas posições posteriores direita e esquerda, as quais estão em contato direto com a mesa de tratamento. A seguir, nas Tabela 13 e 14 e nas Figura 60 e 61 estão apresentados os resultados obtidos pelos nanoDots e pelos dosímetros de $\mathrm{CaSO}_{4}:$ Dy respectivamente.

Tabela 13. Comparação das respostas OSL dos nanoDot com as três variações de cálculo de planejamento.

\begin{tabular}{ccccc}
\hline $\begin{array}{c}\text { Posição do } \\
\text { dosímetro }\end{array}$ & $\begin{array}{c}\text { Média } \pm \mathbf{D P} \\
(\mathbf{c G y})\end{array}$ & $\begin{array}{c}\text { Desvio 1 } \\
(\boldsymbol{\%})\end{array}$ & $\begin{array}{c}\text { Desvio 2 } \\
(\boldsymbol{\%})\end{array}$ & $\begin{array}{c}\text { Desvio 3 } \\
(\boldsymbol{\%})\end{array}$ \\
\hline Superior & $12,2 \pm 0,2$ & $-22,3$ & $-20,7$ & $-19,9$ \\
PostEsq & $70,7 \pm 1,1$ & $+16,7$ & $+5,8$ & $+0,3$ \\
PostDir & $75,5 \pm 4,4$ & $+21,4$ & $+5,9$ & $-0,8$ \\
LatDir & $23,1 \pm 0,7$ & $-13,4$ & $-12,1$ & $+11,7$ \\
AntEsq & $28,4 \pm 0,2$ & $-15,8$ & $-15,4$ & $-14,7$ \\
AntDir & $33,8 \pm 0,9$ & $-3,8$ & $-3,2$ & $-2,9$ \\
\hline
\end{tabular}

Tabela 14. Comparação das respostas TL dos $\mathrm{CaSO}_{4}$ :Dy com as três variações de cálculo de planejamento.

\begin{tabular}{ccccc}
\hline $\begin{array}{c}\text { Posição do } \\
\text { dosímetro }\end{array}$ & $\begin{array}{c}\text { Média } \pm \text { DP } \\
(\mathbf{c G y})\end{array}$ & $\begin{array}{c}\text { Desvio 1 } \\
(\mathbf{\%})\end{array}$ & $\begin{array}{c}\text { Desvio 2 } \\
\mathbf{( \% )}\end{array}$ & $\begin{array}{c}\text { Desvio 3 } \\
\mathbf{( \% )}\end{array}$ \\
\hline Superior & $13,8 \pm 1,6$ & $-21,6$ & $-20,0$ & $-19,2$ \\
PostEsq & $70,4 \pm 1,1$ & $+17,6$ & $+6,8$ & $+1,4$ \\
PostDir & $79,4 \pm 2,2$ & $+23,1$ & $+8,0$ & $+1,4$ \\
LatDir & $22,1 \pm 2,2$ & $-8,0$ & $-6,8$ & $-6,3$ \\
AntEsq & $26,9 \pm 1,7$ & $-15,1$ & $-14,8$ & $-14,1$ \\
AntDir & $36,8 \pm 2,7$ & $+3,0$ & $+2,4$ & $+2,1$ \\
\hline
\end{tabular}

Chamou-se de Desvio 1 os valores de desvio obtidos comparando a média dos valores medidos com os nanoDots com os valores do planejamento sem a mesa; de Desvio 2 os valores de desvio obtidos comparando a média dos valores medidos com os nanoDots com os valores do planejamento com a mesa original do software Eclipse 10.0 e; de Desvio 3, os valores de desvio obtidos comparando a média dos valores medidos com os nanoDots com os valores do planejamento com a mesa editada pelos físicos do HSL. 


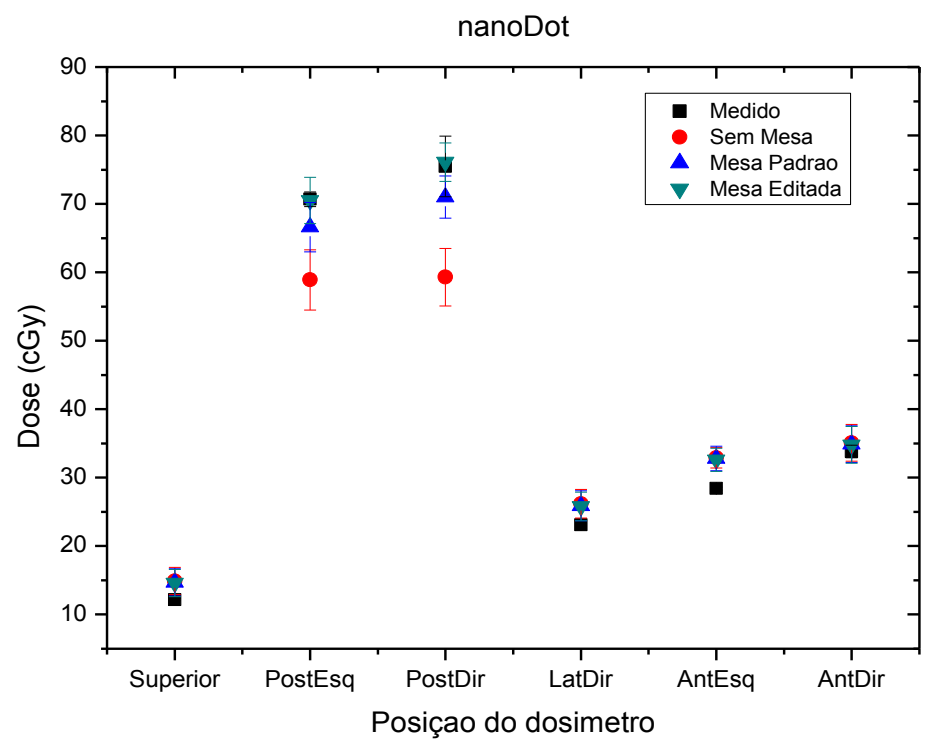

Figura 60. Análise gráfica dos valores de dose planejados e a concordância obtida com os valores de dose medidos com os nanoDots.

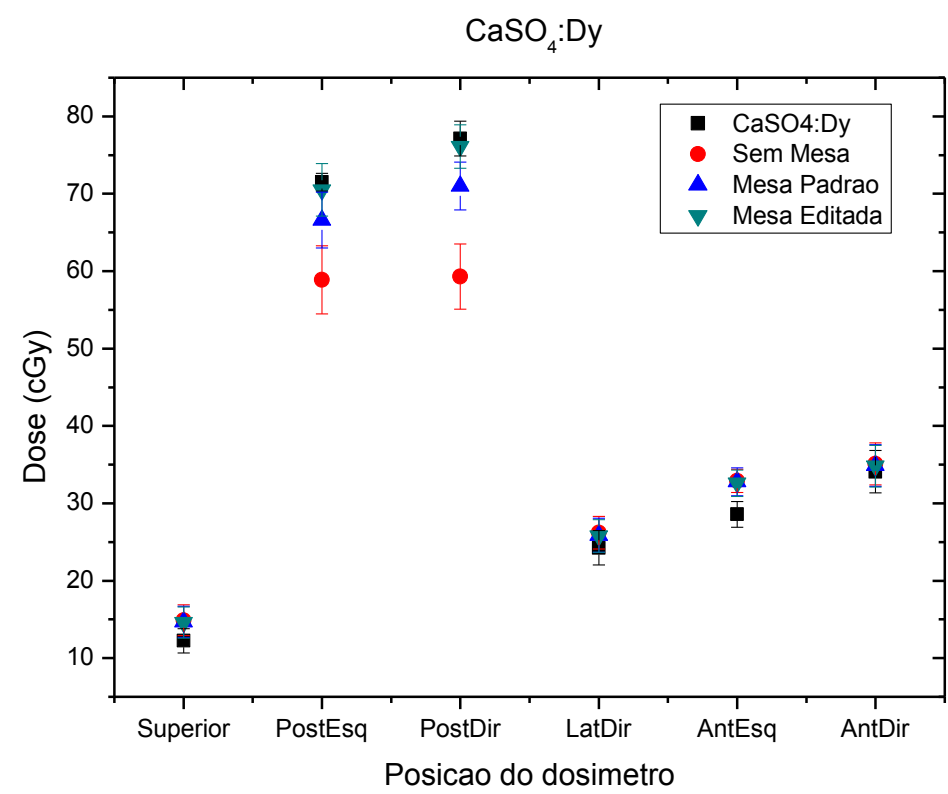

Figura 61. Análise gráfica dos valores de dose planejados e a concordância obtida com os valores de dose medidos com os dosímetros de $\mathrm{CaSO}_{4}$ :Dy. 
É possível observar que os valores de planejamento com a mesa editada são os que melhor concordam com os valores de dose medidos pelos nanoDots, com desvios de $+0,3 \%$ para a posição Posterior Esquerda e - 0,8 \% para a posição Posterior Direita. O mesmo ocorre com os dosímetros de $\mathrm{CaSO}_{4}: \mathrm{Dy}$, com desvios de $+1,4 \%$ para a posição Posterior Esquerda e $+1,4 \%$ para a posição Posterior Direita.

Vale ressaltar que a técnica VMAT de tratamento não possui feixes homogêneos de entrada e saída da pele do paciente, podendo haver pontos quentes não determinados pelo sistema de planejamento.

\subsection{Outras aplicações da dosimetria OSL}

5.14.1 Aplicação da técnica de Luminescência Opticamente Estimulada (OSL) na monitoração de área de uma sala de exame de mamografia

As curvas de resposta em função da dose com as qualidades de mamografia e a qualidade de referência $H^{*}$, com respectivos ajustes lineares, são apresntadas na Figura 62.

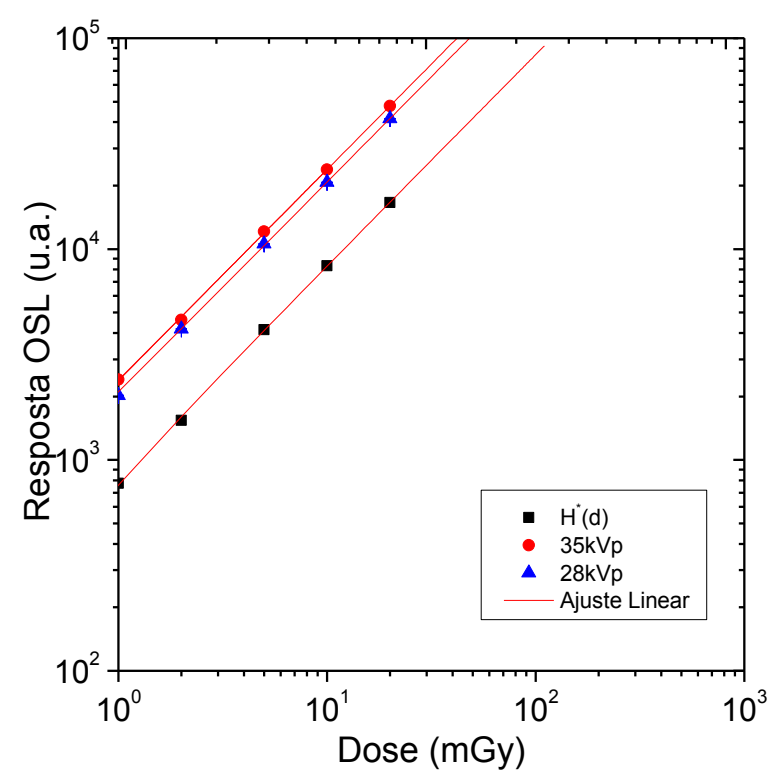

Figura 62. Curvas de resposta em função da dose para as qualidades RQR-2M (28 kVp); RQR-4M (35 kVp) e referência $\mathrm{H}^{*}$.

Como esperado, fica evidenciado o comportamento linear da resposta OSL para o intervalo estudado de 1 a 20 mGy, e, as três qualidades plotadas juntas no gráfico, respeitando as unidades, mostram existência de dependência energética também esperada pelas diferenças 
de energias efetivas de feixe. As respostas OSL para diferentes inclinações, relativas a $0^{\circ}$, e a curva Tandem estão demonstradas na Figura 63 a e b respectivamente.
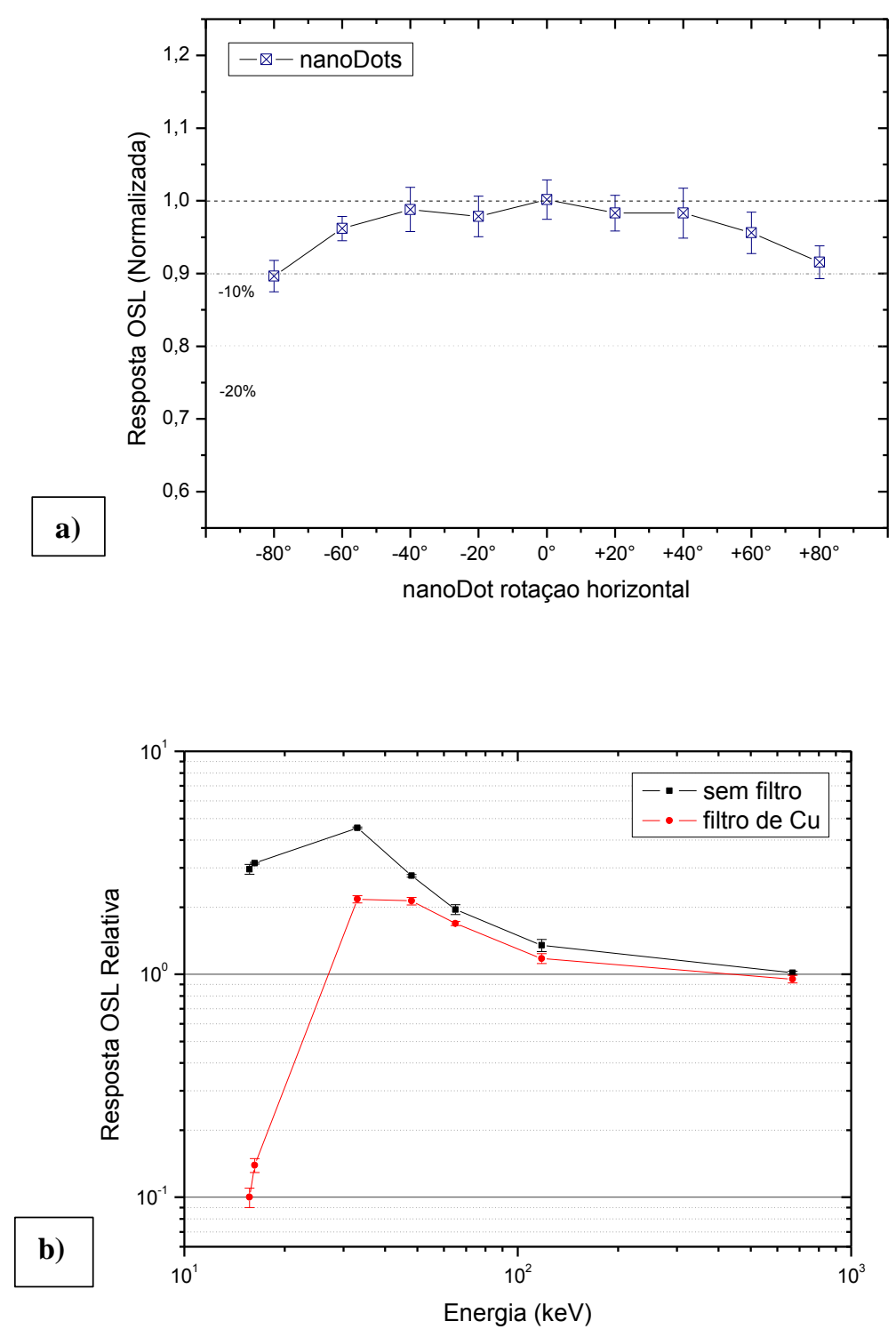

Figura 63. (a) Dependência angular da resposta OSL dos nanoDots ${ }^{\mathrm{TM}}$ para a qualidade N-80. (b) Resposta OSL do sistema Tandem em função da energia - relativa à ${ }^{137} \mathrm{Cs}$.

Pode ser observado que a dependência angular da resposta não superara 11,9 $\pm 2,3 \%$ para feixe diagnóstico. Na Figura 63 b pode ser observado o perfil Tandem de dependência energética da resposta OSL dos nanoDots ${ }^{\mathrm{TM}}$ relativa à ${ }^{137} \mathrm{Cs}$, que apresenta comportamento de acordo com o fabricante [79,97]. A Figura 64 a e b demonstra os resultados obtidos com os nanoDots para o perfil de distribuição de dose no campo do mamógrafo. 

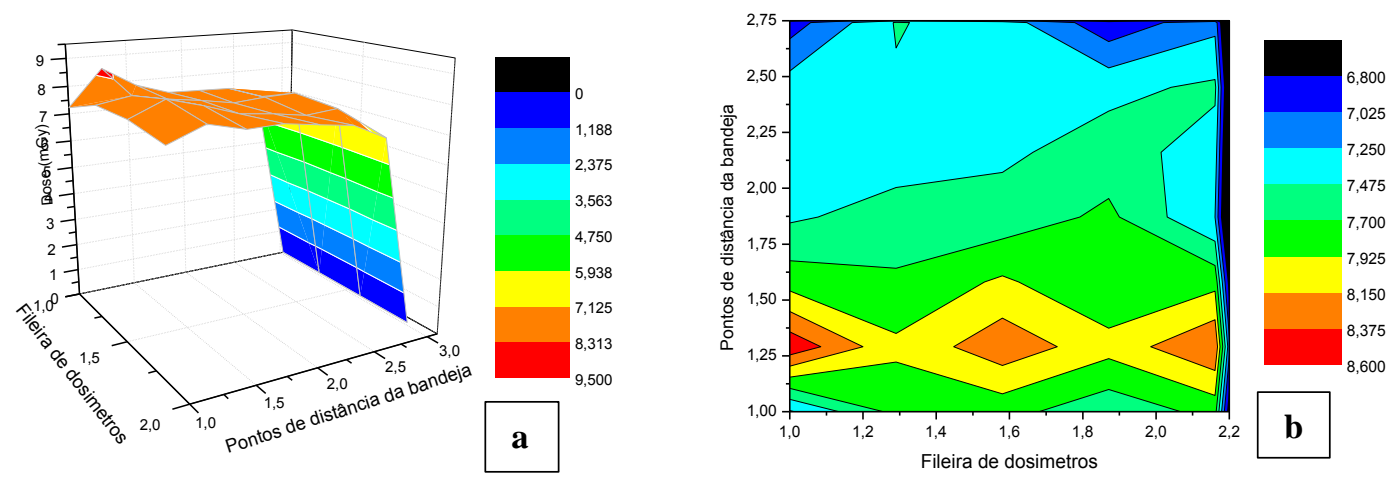

Figura 64. Perfil da distribuição de dose dada pelo campo do mamógrafo

Analisando a Figura 645, podemos observar que o perfil de distribuição do campo de radiação do mamógrafo está dentro do esperado, evidenciando o Efeito Heel causado pela posição catodo-anodo do arranjo do mamógrafo. Esse mesmo comportamento foi obtido experimentalmente por Corrêa et al. [98], utilizando dosímetros de $\mathrm{CaSO}_{4}: \mathrm{Dy}$.

Os valores de dose de entrada na pele e de espalhamento obtidos são apresentados na Tabela 15. Pode ser observado que na frente do mamógrafo foi avaliado um valor de dose maior que nas laterais, justificáveis pelo Efeito Heel do arranjo, e pela não utilização do cone colimador durante os disparos.

Tabela 15. Dose de entrada na pele (DEP) e radiação espalhada para os pontos de medida

\begin{tabular}{lcccccc}
\hline & $\begin{array}{c}\text { Dose de } \\
\text { entrada } \\
(\mathbf{m G y})\end{array}$ & $\begin{array}{c}\text { Direita } \\
(\mathbf{m G y})\end{array}$ & $\begin{array}{c}\text { Esquerda } \\
(\mathbf{m G y})\end{array}$ & $\begin{array}{c}\text { Frente } \\
(\mathbf{m G y})\end{array}$ & $\begin{array}{c}\text { Trazeira } \\
(\mathbf{m G y})\end{array}$ & $\begin{array}{c}\text { Posição do Operador } \\
(\mathbf{m G y})\end{array}$ \\
\hline Média de 4 leituras & 8,283 & 1,558 & 1,538 & 1,956 & 0,119 & 0,077 \\
$\sigma$ de 4 leituras & 0,006 & 0,020 & 0,020 & 0,018 & 0,004 & 0,002 \\
\hline
\end{tabular}

No cálculo das energias efetivas por meio da curva Tandem, as incertezas totais foram de $\pm 26 \%$, que denota a sua eficácia no auxilio da estimativa da energia efetiva do feixe pelo qual os dosímetros foram expostos. Considerando os resultados, pode-se concluir que os nanoDots $^{\mathrm{TM}}$, bem como o sistema comercial Inlight ${ }^{\mathrm{TM}}$ System apresentam valores de estabilidade e repetibilidade que atendem as exigências nacionais (CASMIE/IRD) [99] para serem aplicados para monitoração de área de feixe de radiodiagnóstico. 
5.14.2 Avaliação das doses de entrada na pele e das doses glandulares médias em uma unidade de mamografia digital comparando as técnicas TL e OSL

A resposta à dose de pastilhas de $\mathrm{CaSO}_{4}$ :Dy e dos nanoDots foi obtida em função do Kerma no ar incidente $\left(K_{i}\right)$ de radiação X para o sistema Lorad M-IV para tensão de pico nominal de $27 \mathrm{kVp}$, tensão de pico medida de $28 \mathrm{kVp}$ (Mo/Mo). As Figuras 65 e 66 mostram os resultados obtidos. Todas as irradiações foram feitas sob ar. Em ambos os casos, a resposta TL e OSL varia linearmente no intervalo de Kerma no ar estudado e as curvas mostram sua utilidade em todo o intervalo de dose testado.

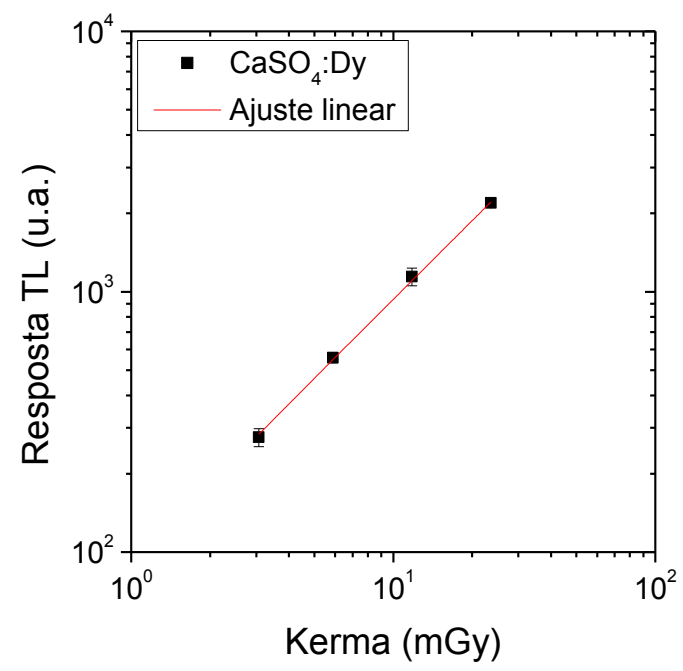

Figura 65. Curva de resposta em função do Kerma no ar dos dosímetros de $\mathrm{CaSO}_{4}$ :Dy para o mamógrafo LORAD M-IV.

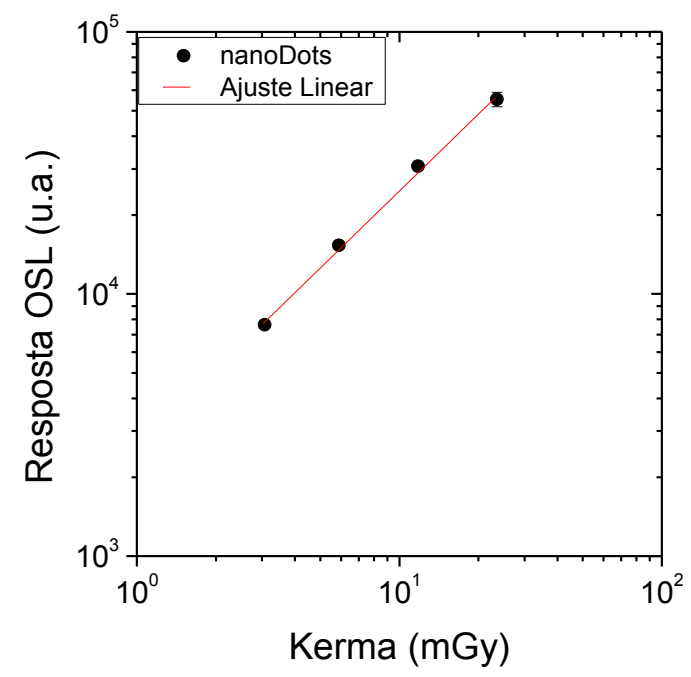

Figura 66. Curva de resposta em função do Kerma no ar dos dosímetros nanoDots para o mamógrafo LORAD M-IV.

A camada semi-redutora foi determinada utilizando filtros de alumínio de espessuras diferentes, para tensões de tubo de $27 \mathrm{kVp}$ na unidade mamográfica digital Lorad M-IV, com as 
amostras TL, OSL e o medidor PTW All-in-one QC meter. As amostras e o medidor QC foram colocados livres no ar, sob a pá de compressão. A distância entre o ponto focal e o receptor da imagem foi de $65 \mathrm{~cm}$. Cada exposição foi realizada com quatro pastilhas de $\mathrm{CaSO}_{4}$ :Dy e dois nanoDots, que foram avaliados três vezes cada. A HVL foi calculada utilizando a Equação 12 $[100,101]$.

$$
H V L=\frac{x_{b} \cdot \ln \left(\frac{2 L_{a}}{L_{0}}\right)-x_{a} \cdot \ln \left(\frac{2 L_{b}}{L_{0}}\right)}{\ln \left(\frac{2 L_{a}}{L_{b}}\right)}
$$

onde $L o$ é a leitura de exposição inicial, $L a$ é a leitura de exposição imediatamente superior após $L o / 2, L b$ é a leitura de exposição imediatamente inferior após $L o / 2$, o $x_{a}$ é a espessura do filtro correspondente à leitura de exposição $L a, x_{b}$ é o filtro de espessura correspondente à leitura de exposição $L b$. De acordo com as recomendações nacionais, os valores de HVL devem estar entre $\mathrm{kVp} / 100+0,03 \mathrm{mmAl}$ e kVp/100 + C. mmAl, em que C é 0,12 mmAl para a combinação alvo Mo e filtro Mo. Os resultados obtidos são apresentados na Tabela 16.

Tabela 16. Valores de $\mathrm{HVL}$ obtidos com $\mathrm{CaSO}_{4}$ :Dy, nanoDots e PTW Diavolt Universal Allin-one QC Meter.

\begin{tabular}{cc}
\hline Materiais & HVL $(\mathbf{m m A l})$ \\
\hline $\mathrm{CaSO}_{4}: \mathrm{Dy}$ & $0,31 \pm 0,01$ \\
$\mathrm{Al}_{2} \mathrm{O}_{3}: \mathrm{C}$ & $0,32 \pm 0,01$ \\
PTW All-in-one QC meter & $0,31 \pm 0,01$ \\
\hline
\end{tabular}

A dose de entrada na pele (ESD) é um parâmetro importante que determina a dose de radiação absorvida pela pele onde o feixe de raios $\mathrm{X}$ entra no paciente. Esta grandeza física é considerada como um nível de referência de diagnóstico, e é determinada de acordo com a Equação 13.

$$
E S D=K_{i} \cdot B
$$

onde $K_{i}$ é o kerma no ar incidente com a bandeja de compressão, e $B$ é o fator de retroespalhamento [100,101].

A ESD foi determinada de acordo com as recomendações [100,101], utilizando o medidor QC e as amostras TL e OSL. As medidas foram realizadas com o equipamento os 
dosímetros sobre o simulador de mama (exposição de entrada), utilizando-se a mesma técnica selecionada automaticamente pelo equipamento (Auto-kV) ao realizar o teste de qualidade da imagem. Quatro dosímetros $\mathrm{CaSO}_{4}$ :Dy e dois nanoDots foram utilizados em cada exposição. Os resultados obtidos são apresentados na Tabela 17.

Tabela 17. ESD obtidas com $\mathrm{CaSO}_{4}$ :Dy, nanoDots e PTW Diavolt Universal All-in-one QC Meter.

\begin{tabular}{cc}
\hline Materiais & ESD $(\mathbf{m G y})$ \\
\hline $\mathrm{CaSO}_{4}: \mathrm{Dy}$ & $10,25 \pm 0,57$ \\
$\mathrm{Al}_{2} \mathrm{O}_{3}: \mathrm{C}$ & $10,50 \pm 0,03$ \\
PTW All-in-one QC meter & $10,45 \pm 0,10$ \\
\hline
\end{tabular}

A dose glandular média (MGD) é derivada de medições do kerma de ar incidente na superfície do simulador de mama e do HVL, utilizando coeficientes de conversão tabelados. Foi calculada para simular as doses que são submetidas mamas de $4,5 \mathrm{~cm}$ de espessura pressurizadas utilizando a Equação 14 [102,103,104].

$$
M G D=K_{i} \cdot g \cdot c \cdot s
$$

onde $K_{i}$ é o kerma no ar incidente com a bandeja de compressão, $g$ é o fator de conversão que dá a MGD para uma mama de granularidade 50\% e depende da HVL, $c$ é o coeficiente de conversão que corrige para qualquer diferença na composição da mama a partir de $50 \%$ de grandularidade e $s$ um fator de correção que depende da combinação ânodo/filtro. Com um filtro e ânodo Molibdênio/Molibdênio, o fator $s$ é 1,00 [104].

As amostras TLD e os nanoDots foram colocados na superfície do simulador que estava posicionada na mesa de exames com a placa de compressão trazida para baixo. O simulador foi exposto às mesmas condições usadas clinicamente para a obtenção da imagem de mama. $\mathrm{O}$ medidor de QC foi colocado sob a pá de compressão resultando uma espessura de 4,5 cm com a mesa. Para obter o kerma no ar incidente, foram determinadas as leituras médias das amostras. O produto de $g$ e $c$ para simuladores de PMMA foi obtido a partir de Dance et al [104] e é mostrado na Tabela 18. A Tabela 19 mostra os resultados experimentais obtidos para a MGD com as amostras TL e OSL e o medidor All-in-one de QC para o simulador de 4,5 cm. 
Tabela 18. Produto dos fatores g e c para simuladores de PMMA

\begin{tabular}{ccccccccc}
\hline PMMA & Granularidade & \multicolumn{7}{c}{ HVL $(\mathrm{mmAl})$} \\
\cline { 3 - 9 }$(\mathrm{cm})$ & $(\%)$ & 0.3 & 0.35 & 0.4 & 0.45 & 0.5 & 0.55 & 0.6 \\
\cline { 3 - 9 } 2 & 97 & 0,336 & 0,377 & 0,415 & 0,450 & 0,482 & 0,513 & 0,539 \\
3 & 67 & 0,245 & 0,277 & 0,308 & 0,338 & 0,368 & 0,399 & 0,427 \\
4 & 41 & 0,191 & 0,217 & 0,241 & 0,268 & 0,296 & 0,322 & 0,351 \\
4,5 & 29 & 0,172 & 0,196 & 0,218 & 0,242 & 0,269 & 0,297 & 0,321 \\
5 & 20 & 0,157 & 0,179 & 0,198 & 0,221 & 0,245 & 0,269 & 0,296 \\
6 & 9 & 0,133 & 0,151 & 0,168 & 0,187 & 0,203 & 0,230 & 0,253 \\
7 & 4 & 0,112 & 0,127 & 0,142 & 0,157 & 0,173 & 0,194 & 0,215 \\
8 & 3 & 0,097 & 0,110 & 0,124 & 0,136 & 0,159 & 0,169 & 0,188 \\
\hline
\end{tabular}

Tabela 19. MGD obtidas com $\mathrm{CaSO}_{4}$ :Dy, nanoDots e PTW Diavolt Universal All-in-one QC Meter.

\begin{tabular}{cc}
\hline Materiais & MGD (mGy) \\
\hline $\mathrm{CaSO}_{4}: \mathrm{Dy}$ & $1,64 \pm 0,09$ \\
$\mathrm{Al}_{2} \mathrm{O}_{3}: \mathrm{C}$ & $1,68 \pm 0,05$ \\
PTW All-in-one QC meter & $1,67 \pm 0,05$ \\
\hline
\end{tabular}

Apesar de não existirem requisitos nacionais para a MGD no Brasil, os resultados obtidos estão de acordo com as recomendações internacionais $[105,106]$. Os resultados obtidos demonstraram que os sistemas de dosimetria TL e OSL utilizados são capazes de avaliar com precisão a dose de entrada na pele (ESD), bem como as doses glandulares médias (MGD) numa unidade de mamografia digital, e podem ser consideradas ferramentas práticas e simples para verificação desses itens em um Programa de Garantia de Qualidade. Todas as características dosimétricas dos dosímetros $\mathrm{CaSO}_{4}$ :Dy e nanoDots, como a repetibilidade da resposta e as curvas de calibração, mostram a utilidade desses dosímetros. 
VI Conclusões 


\section{CONCLUSÕES}

- Os testes realizados nas leitoras TL e OSL demonstraram uma boa estabilidade para a realização das leituras, bem como uma boa eficiência intrínseca e repetibilidade.

- As curvas de dose-resposta obtidas para todos os materiais, em todas as qualidades de feixe testadas, apresentaram comportamento linear no intervalo de dose estudado. Comportamentos supralineares puderam ser observados, em alguns casos, em regiões próximas de $10 \mathrm{~Gy}$.

- A seleção criteriosa dos dosímetros pelas suas sensibilidades e repetibilidade variando em até $\pm 5 \%$ se mostrou, como esperado, adequada para aplicações em dosimetria clínica, bem como para radiodiagnóstico e monitoração de área.

- Os LIDs de todos os tipos de dosímetros avaliados encontram-se dentro dos valores esperados na literatura

- Por meio dos testes de desempenho realizados, análise das respostas e comparações com os valores de dose prescritos pelo sistema de planejamento Eclipse 10.0, pode concluirse que, ambos os dosímetros OSL de $\mathrm{Al}_{2} \mathrm{O}_{3}: \mathrm{C}$ apresentam incertezas melhores que $\pm 3 \%$, demonstrando sua aplicabilidade em dosimetria clínica de fótons em tratamentos VMAT.

- Como esperado, os dosímetros TL de LiF:Mg,Ti e $\mathrm{CaSO}_{4}:$ Dy obtiveram resultados compatíveis, auxiliando na validação dos dados, junto com a dosimetria com câmara de ionização.

- Nos estudos clínicos com os simuladores antropomórficos, os menores valores de incerteza entre os quatro materiais dosimétricos estudados foram obtidos com os nanoDots, o que demonstra sua excelente caracterização, junto ao sistema de dosimetria comercial Landauer InLight ${ }^{\mathrm{TM}}$ System.

- Nos estudos de teste de desempenho, monitoração de área e controle de qualidade em mamografia digital, o sistema comercial Landauer InLight ${ }^{\mathrm{TM}}$ System, bem como os nanoDots obtiveram resultados satisfatórios com os requisitos técnicos e pode ser considerado uma ferramenta alternativa para auxilio de validação dos dados de controle de qualidade tradicionais. 
Referências Bibliográficas 


\section{Referências Bibliográficas}

1. Ford, E. C., Gaudette, R., Myers, L., Vanderver, B., Engineer, L., Zellars, R., ... \& DeWeese, T. L. (2009). Evaluation of safety in a radiation oncology setting using failure mode and effects analysis. International Journal of Radiation Oncology* Biology* Physics, 74(3), 852-858.

2. Furnari, L. (2009). Controle de qualidade em radioterapia. Revista Brasileira de Física Médica, 3(1), 77-90.

3. Teixeira, F. C., Faria, A. L., Pereira, D. P., \& MI, F. (2013). Análise qualitativa do risco no processo de tratamento em radioterapia para as etapas executadas pelo técnico/tecnólogo na radioterapia de intensidade modulada (IMRT). In Proceedings of the IX Latin American IRPA Regional Congress on Radiation Protection and Safety-IRPA (Vol. 2013).

4. de Oliveira Barbosa, P. (2011). IMPLEMENTAÇÃO DO CONTROLE DE QUALIDADE PARA SISTEMAS DE PLANEJAMENTO DE TRATAMENTO EM RADIOTERAPIA NAS AVALIAÇÕES LOCAIS DO PQRT/INCA (Tese de doutorado, Universidade Federal do Rio de Janeiro).

5. Broggi, S., Cantone, M. C., Chiara, A., Di Muzio, N., Longobardi, B., Mangili, P., \& Veronese, I. (2013). Application of failure mode and effects analysis (FMEA) to pretreatment phases in tomotherapy. Journal of Applied Clinical Medical Physics, 14(5).

6. Goffman, T. E., \& Glatstein, E. (2002). Intensity-modulated radiation therapy. Radiation research, 158(1), 115-117.

7. Xing, L., Thorndyke, B., Schreibmann, E., Yang, Y., Li, T. F., Kim, G. Y., ... \& Koong, A. (2006). Overview of image-guided radiation therapy. Medical Dosimetry, 31(2), 91-112.

8. Tsai, J. S., Buck, B. A., Svensson, G. K., Alexander, E., Cheng, C. W., Mannarino, E. G., \& Loeffler, J. S. (1991). Quality assurance in stereotactic radiosurgery using a standard linear accelerator. International Journal of Radiation Oncology* Biology* Physics, 21(3), 737-748.

9. Verbakel, W. F., Cuijpers, J. P., Hoffmans, D., Bieker, M., Slotman, B. J., \& Senan, S. (2009). Volumetric intensity-modulated arc therapy vs. conventional IMRT in head-and-neck cancer: a comparative planning and dosimetric study. International Journal of Radiation Oncology ${ }^{*}$ Biology ${ }^{*}$ Physics, 74(1), 252-259.

10. Podgorsak, E. B. (2005). Radiation oncology physics. a handbook for teachers and students/EB Podgorsak.-Vienna: International Atomic Energy Agency, 657.

11. Otto, K. (2008). Volumetric modulated arc therapy: IMRT in a single gantry arc. Medical physics, 35(1), 310-317.

12. Lee, T. F., Ting, H. M., Chao, P. J., \& Fang, F. M. (2012). Dual arc volumetric-modulated arc radiotherapy (VMAT) of nasopharyngeal carcinomas: a simultaneous integrated boost treatment plan comparison with intensity-modulated radiotherapies and single arc VMAT. Clinical Oncology, 24(3), 196-207.

13. Krishna Murthy, K., Anandagiribabu, A., Prasad, P. B. L. D., \& Kaviarasu, K. (2012). Patient-specific quality assurance of RapidArc treatments: Portal prediction dosimetry compared with phantom studies. Biomed Imaging Interv J, 8.

14. Walter, C., Boda-Heggemann, J., Wertz, H., Loeb, I., Rahn, A., Lohr, F., \& Wenz, F. (2007). Phantom and in-vivo measurements of dose exposure by image-guided radiotherapy (IGRT): MV portal images vs. kV portal images vs. cone-beam CT. Radiotherapy and Oncology, 85(3), 418-423. 
15. Ishikura, S. (2008). Quality assurance of radiotherapy in cancer treatment: toward improvement of patient safety and quality of care. Japanese journal of clinical oncology, 38(11), 723-729.

16. Kutcher, G. J., Coia, L., Gillin, M., Hanson, W. F., Leibel, S., Morton, R. J., ... \& Weller, M. (1994). Comprehensive QA for radiation oncology: report of AAPM radiation therapy committee task group 40. Medical physics, 21(4), 581-618.

17. Huyskens, D., Bogaerts, R., Verstraete, J., Lööf, M., Nyström, H., Fiorino, C., ... \& Twaithes, D. I. (2001). Practical guidelines for the implementation of in vivo dosimetry with diodes in external radiotherapy with photon beams (entrance dose).

18. VanDam, J., \& Marinello, G. (1994). Methods for in vivo dosimetry in external radiotherapy. Garant Publ. Physics for Clinical Radiotherapy Booklet 1; ESTRO: Brussels: Belgium. 1994.

19. Berger, M. J. et al. Electron Dosimetry with Ionization Chambers. NBS SP456, Proceed. of NBS Symposium, p. 307-312, 1976.

20. Kase, K. R., Adler, G. J., Bjarngard, B. E. Electron Dosimetry with lonization Chambers. Med. Phys. v. 2 n. 1, p.13-19, 1982.

21. Ehrlich, M., Lamperti, P. J. Electron-Therapy Dosimetry. NBS456, Proceed of NBS Symposium, p. 365-370, 1976.

22. Low, D. A., Moran, J. M., Dempsey, J. F., Dong, L., \& Oldham, M. (2011). Dosimetry tools and techniques for IMRT. Medical physics, 38(3), 1313-1338.

23. Fregene, A. O. Fricke Dosimetry in Radiotherapy. Med. Phys. v. 3, n. 5, p. 360-363, 1976.

24. Boudou, C., Biston, M. C., Adam, J. F., Joubert, A., Corde, S., Charvet, A. M., ... \& Elleaume, H. (2004). Fricke dosimetry for synchrotron stereotactic radiotherapy. In Journal of Physics: Conference Series (Vol. 3, No. 1, p. 209). IOP Publishing.

25. Oberhofer, M., \& Scharmann, A. (1981). Applied thermoluminescence dosimetry. Adam Hilger Ltd.

26. Campos, L. L., and M. F. Lima. "Dosimetric properties of CaSO4: Dy teflon pellets produced at IPEN." Radiation Protection Dosimetry 14.4 (1986): 333-335.

27. Campos, L. L., \& Lima, M. F. (1987). Thermoluminescent CaSO4: Dy Teflon pellets for beta radiation detection. Radiation protection dosimetry, 18(2), 95-97.

28. Campos, L. L. (1983). Preparation of CaSO4: Dy TL single crystals. Journal of luminescence, 28(4), 481-483.

29. Bravim, A., \& Campos, L. L. (2009). Dosimetric evaluation of thermoluninescent LiF: Mg, Ti and CaSO4: Dy dosimeters and LiF microdosimeters for application in in vivo dosimetry of clinical electron beams. In Proceedings of the 2009 International Nuclear Atlantic Conference-INAC (Vol. 2009).

30. Rivera, T. (2012). Thermoluminescence in medical dosimetry. Applied Radiation and Isotopes, 71 , 30-34.

31. McKeever, S. W. S. (2001). Optically stimulated luminescence dosimetry. Nuclear Instruments and Methods in Physics Research Section B: Beam Interactions with Materials and Atoms, 184(1), 29-54.

32. McKeever, S. W. S. (2011). Optically stimulated luminescence: a brief overview. Radiation Measurements, 46(12), 1336-1341.

33. McKeever, S. W. S., \& Moscovitch, M. (2003). Topics under Debate-On the advantages and disadvantages of optically stimulated luminescence dosimetry and thermoluminescence dosimetry. Radiation protection dosimetry, 104(3), 263-270. 
34. Akselrod, M. S., Bøtter-Jensen, L., \& McKeever, S. W. S. (2006). Optically stimulated luminescence and its use in medical dosimetry. Radiation Measurements, 41, S78-S99.

35. Aznar, M. C., Andersen, C. E., Bøtter-Jensen, L., Bäck, S. Å. J., Mattsson, S., Kjær-Kristoffersen, F., \& Medin, J. (2004). Real-time optical-fibre luminescence dosimetry for radiotherapy: physical characteristics and applications in photon beams. Physics in medicine and biology, 49(9), 1655.

36. Aznar, M. C., Hemdal, B., Medin, J., Marckmann, C. J., Andersen, C. E., Bøtter-Jensen, L., ... \& Mattsson, S. (2014). In vivo absorbed dose measurements in mammography using a new real-time luminescence technique. The British journal of radiology.

37. Viamonte, A., Da Rosa, L. A. R., Buckley, L. A., Cherpak, A., \& Cygler, J. E. (2008). Radiotherapy dosimetry using a commercial OSL system. Medical physics, 35(4), 1261-1266.

38. Timar-Gabor, A., \& Trandafir, O. (2013). On optically stimulated luminescence properties of household salt as a retrospective dosemeter. Radiation protection dosimetry, 155(4), 404-409.

39. Mrčela, I., Bokulić, T., Izewska, J., Budanec, M., Fröbe, A., \& Kusić, Z. (2011). Optically stimulated luminescence in vivo dosimetry for radiotherapy: physical characterization and clinical measurements in 60Co beams. Physics in medicine and biology, 56(18), 6065.

40. Giglioti, R. Utilização da dosimetria opticamente estimulada (OSL) na avaliação de parâmetros de qualidade de feixe em radioterapia (Dissertação de Mestrado, Universidade de São Paulo). 2010.

41. INTERNATIONAL COMISSION ON RADIATION UNITS AND MEASUREMENTS - ICRU. Report 24: Determination of Absorbed Dose in a Patient Irradiated by Beams of $X$ or Gamma Rays in Radiotherapy Procedures. Bethesda, Maryland: ICRU Publications, 1976.

42. Yukihara, E. G., Gasparian, P. B. R., Sawakuchi, G. O., Ruan, C., Ahmad, S., Kalavagunta, C., ... \& Titt, U. (2010). Medical applications of optically stimulated luminescence dosimeters (OSLDs). Radiation Measurements, 45(3), 658-662.

43. Nunes, M. G. Avaliação do Desempenho dos detectores termoluminescentes deCaSO4:Dy e LiF:Mg,Ti na dosimetria de feixes clínicos de elétrons. (Dissertação de Mestrado. Instituto de Pesquisas Energéticas e Nucleares - IPEN/USP). 2008.

44. Bravim, A. Avaliação de dosímetros termoluminescentes empregando objetos simuladores equivalentes à água para aplicação da dosimetria de feixes clínicos de elétrons. (Dissertação de Mestrado. Instituto de Pesquisas Energéticas e Nucleares - IPEN/USP). 2010.

45. Bravim, A., Sakuraba, R. K., Cruz, J. C., \& Campos, L. L. (2011). Study of LiF: Mg, Ti and CaSO 4: Dy dosimeters TL response to electron beams of $6 \mathrm{MeV}$ applied to radiotherapy using PMMA and solid water phantoms. Radiation Measurements, 46(12), 1979-1981.

46. Matsushima, L. C. Avaliação da resposta de detectores termoluminescentes na dosimetria de feixes clínicos utilizando diferentes objetos simuladores. (Dissertação de Mestrado. Instituto de Pesquisas Energéticas e Nucleares - IPEN/USP). 2010.

47. Nunes, M. G. Desenvolvimento do dosímetro termoluminescente de CaSO4:Ce,Eu para a monitoração individual e dosimetria clínica de fótons e elétrons. (Tese de Doutorado. Instituto de Pesquisas Energéticas e Nucleares - IPEN/USP). 2012.

48. Matsushima, L. C. Determinação das curvas de isodose e confirmação do planejamento em Radioterapia de Intensidade Modulada - IMRT convencional empregando as técnicas de termoluminescência opticamente estimulada e detectores semicondutores. (Tese de Doutorado. Instituto de Pesquisas Energéticas e Nucleares - IPEN/USP). 2015. 
49. Bravim, A. Aplicação das técnicas de dosimetria termoluminescente (TL) e luminescência opticamente estimulada (OSL) na determinação de curvas de isodose em uma simulação de tratamento de câncer pela técnica de radioterapia em arco modulado volumétrico - VMAT. (Tese de Doutorado. Instituto de Pesquisas Energéticas e Nucleares - IPEN/USP). 2015.

50. Sakuraba, R. K. Desenvolvimento de um sistema de verificação dosimétrica tridimensional utilizando Solução Fricke gel na aplicação para a verificação da Radioterapia em Arco Modulado Volumétrico (VMAT) nos tratamentos com movimentação do alvo pela respiração. (Tese de Doutorado. Instituto de Pesquisas Energéticas e Nucleares - IPEN/USP). 2015.

51. Yukihara, E. G., \& McKeever, S. W. (2011). Optically stimulated luminescence: fundamentals and applications. John Wiley \& Sons.

52. Yukihara, E. G., Whitley, V. H., Polf, J. C., Klein, D. M., McKeever, S. W. S., Akselrod, A. E., \& Akselrod, M. S. (2003). The effects of deep trap population on the thermoluminescence of Al 2 O 3 : C. Radiation measurements, 37(6), 627-638.

53. Yukihara, E. G., \& McKeever, S. W. S. (2006). Spectroscopy and optically stimulated luminescence of Al 2 O 3: C using time-resolved measurements. Journal of applied physics, 100(8), 083512.

54. Yukihara, E. G., Whitley, V. H., Polf, J. C., Klein, D. M., McKeever, S. W. S., Akselrod, A. E., \& Akselrod, M. S. (2003). The effects of deep trap population on the thermoluminescence of $\mathrm{Al}_{2} \mathrm{O}_{3}: \mathrm{C}$. Radiation measurements, 37(6), 627-638.

55. McKeever, S. W., Moscovitch, M., \& Townsend, P. D. (1995). Thermoluminescence dosimetry materials: properties and uses.

56. Rudén, B. Evaluation of the clinical use of TLD. (1976). Acta Radiol Ther. Thys. Biol. 15, 447-467.

57. Nunes, M. G., \& Campos, L. L. (2008). Study of CaSO4: Dy and LiF: Mg, Ti detectors TL response to electron radiation using a SW Solid Water phantom. Radiation Measurements, 43(2), 459-462.

58. McKinlay, A. F. (1981). Thermoluminescence dosimetry. Medical Physics Handbooks. Adam Hilger: Bristol.

59. Mahesh, K., Weng, P. S., \& Furetta, C. (1989). Thermoluminescence in Solids and its Applications. Nuclear Technology Pub..

60. Metcalf, P., Kron, T., \& Hoban, P. (2004). The physics of Radiotherapy X-rays from Linear Accelerator.

61. Campos, L L. (1998). Termoluminescência de materiais e sua aplicação em dosimetria da radiação. Cerâmica, 44(290), 244-251.

62. Khan, F. M. (1994). The Physics of Radiation Therapy 2nd edn (Baltimore, MD: Williams and Wilkins).

63. Bøtter-Jensen, L., McKeever, S. W., \& Wintle, A. G. (2003). Optically stimulated luminescence dosimetry. Elsevier.

64. Akselrod, M. S., \& Gorelova, E. A. (1993). Deep traps in highly sensitive a-Al2O3: C TLD crystals. Nuclear Tracks and Radiation Measurements, 21(1), 143-146.

65. Rieke, J. K., \& Daniels, F. (1957). Thermoluminescence Studies of Aluminum Oxide. The Journal of Physical Chemistry, 61(5), 629-633.

66. Buckman, W. G. (1972). ALUMINUM OXIDE THERMOLUMINESCENCE PROPERTIES FOR DETECTING RADIATION. Western Kentucky Univ., Bowling Green. 
67. McDougall, R. S., \& Rudin, S. (1970). Thermoluminescent dosimetry of aluminum oxide. Health physics, 19(2), 281-283.

68. Mehta, S. K., \& Sengupta, S. (1976). Gamma dosimetry with $\mathrm{Al}_{2} \mathrm{O}_{3}$ thermoluminescent phosphor. Physics in medicine and biology, 21(6), 955.

69. Osvay, M., \& Biró, T. (1980). Aluminium oxide in TL dosimetry. Nuclear Instruments and Methods, 175(1), 60-61.

70. Lapraz, D., lacconi, P., Sayadi, Y., Keller, P., Barthe, J., \& Portal, G. (1988). Some thermoluminescence properties of an $\alpha-\mathrm{Al}_{2} \mathrm{O}_{3}$ sample. Sensitization effects. physica status solidi (a), 108(2), 783-794.

71. Pokorny, P., \& Ibarra, A. (1993). On the origin of the thermoluminescence of $\mathrm{Al}_{2} \mathrm{O}_{3}: \mathrm{Cr}, \mathrm{Ni}$. Journal of Physics: Condensed Matter, 5(40), 7387.

72. Akselrod, M. S., Kortov, V. S., Kravetsky, D. J., \& Gotlib, V. I. (1990). Highly sensitive thermoluminescent anion-defect alpha- $\mathrm{Al}_{2} \mathrm{O}_{3}: \mathrm{C}$ single crystal detectors. Radiation protection dosimetry, 33(1-4), 119-122.

73. McKeever, S. W. S., Akselrod, M. S., \& Markey, B. G. (1996). Pulsed optically stimulated luminescence dosimetry using alpha- $\mathrm{Al}_{2} \mathrm{O}_{3}: \mathrm{C}$. Radiation Protection Dosimetry, 65(1-4), 267-272.

74. Akselrod, M. S., \& McKeever, S. W. S. (1999). A radiation dosimetry method using pulsed optically stimulated luminescence. Radiation Protection Dosimetry, 81(3), 167-175.

75. McKeever, S. W. S., Bøtter-Jensen, L., Larsen, N. A., \& Duller, G. A. T. (1997). Temperature dependence of OSL decay curves: experimental and theoretical aspects. Radiation Measurements, 27(2), 161-170.

76. Bøtter-Jensen, L. (1997). Luminescence techniques: instrumentation and methods. Radiation Measurements, 27(5), 749-768.

77. Guide to "The RIS $\varnothing$ TL/OSL Reader". RIS $\varnothing$ DTU. Denmark. Agosto 2010.

78. Jursinic, P. A. (2007). Characterization of optically stimulated luminescent dosimeters, OSLDs, for clinical dosimetric measurements. Medical physics, 34(12), 4594-4604.

79. Perks, C. A., Le Roy, G., \& Prugnaud, B. (2007). Introduction of the InLight monitoring service. Radiation protection dosimetry, 125(1-4), 220-223.

80. SCAFF, L. A. M. Física da Radioterapia. (1997). São Paulo: Sarvier.

81. INTERNATIONAL COMMISSION ON RADIATION UNITS AND MEASUREMENTS - ICRU Report 83: Prescribing, Recording, and Reporting Intensity-Modulated Photon-Beam Therapy (IMRT) Bethesd, Maryland: ICRU Publications, 2010.

82. AMERICAN ASSOCIATION OF PHYSICS IN MEDICINE. AAPM'S TG-51 protocol for clinical reference dosimetry of high-energy photon and electron beams. Med Phys. 1999;26(9):1847-70.

83. INTERNATIONAL ATOMIC ENERGY AGENCY. TRS-398. Absorbed dose determination in external beam radiotherapy. An International Code of Practice for Dosimetry Based on Standards of Absorbed Dose to Water. Vienna, 2000.

84. Yukihara, E. G., \& McKeever, S. W. S. (2008). Optically stimulated luminescence (OSL) dosimetry in medicine. Physics in medicine and biology, 53(20), R351.

85. Landauer Inc. InLight microStar User Manual. Disponível em: <www.landauer.com>. 
86. Al-Senan, R. M., \& Hatab, M. R. (2011). Characteristics of an OSLD in the diagnostic energy range. Medical physics, 38(7), 4396-4405.

87. Vrieze, T. J., Sturchio, G. M., \& McCollough, C. H. (2012). Technical note: Precision and accuracy of a commercially available CT optically stimulated luminescent dosimetry system for the measurement of CT dose index. Medical physics, 39(11), 6580-6584.

88. Zhang, D., Li, X., Gao, Y., Xu, X. G., \& Liu, B. (2013). A method to acquire CT organ dose map using OSL dosimeters and ATOM anthropomorphic phantoms. Medical physics, 40(8).

89. Endo, A., Katoh, T., Vasudeva, S. B., Kobayashi, I., \& Okano, T. (2013). A preliminary study to determine the diagnostic reference level using dose-area product for limited-area cone beam CT. Dentomaxillofacial Radiology, 42(4), 20120097.

90. Sanchez, R. M., Vano, E., Fernandez, J. M., Ginjaume, M., \& Duch, M. A. (2014). Measurements of eye lens doses in interventional cardiology using OSL and electronic dosemeters. Radiation protection dosimetry, nct368.

91. Yahnke, C. J. Calibrating the microStar (2009). InLight ${ }^{\mathrm{TM}}$ Systems manual. Disponível em: http://www.landauer.com/uploadedFiles/Resource_Center/microStar\%20Calibration\%20and\%20Usag e\%20Instructions\%2010-Jun-09.pdf

92. GUM, I. (2012). Avaliação de dados de medição: guia para a expressão de incerteza de medição. Duque de Caxias, RJ.

93. Vuolo, J. H. (1992). Fundamentos da Teoria de Erros-Editora Edgard BI ucher. São Paulo.

94. Yahnke, C. J. Calibrating the microStar (2009). InLight ${ }^{\top M}$ Systems manual. Disponível em: http://www.landauer.com/uploadedFiles/Resource_Center/microStar\%20Calibration\%20and\%20Usag e\%20Instructions\%2010-Jun-09.pdf

95. Villani, D., Mancini, A., Haddad, C. M., \& Campos, L. L. Comparative study of different $\mathrm{Al}_{2} \mathrm{O}_{3}: \mathrm{C}$ dosimeters using OSL technique for dosimetry on Volumetric Modulated Arc Radiotherapy Treatment (VMAT). In.: XXI Congresso Brasileiro de Física Médica. 2016. ID: 3045.

96. Villani, D., Mancini, A., Haddad, C. M., \& Campos, L. L. (2017). Application of optically stimulated luminescence 'nanoDot'dosimeters for dose verification of VMAT treatment planning using an anthropomorphic stereotactic end-to-end verification phantom. Radiation Measurements. (in press). http://dx.doi.org/10.1016/i.radmeas.2017.03.027

97. Landauer microStar user manual. Disponível em <www.landauer.com>.

98. Corrêa, E. L., Silva, J. O., Vivolo, V., Potiens, M. P. A., Daros, K. A. C., \& Medeiros, R. B. (2014). Intensity variation study of the radiation field in a mammographic system using thermoluminescent dosimeters TLD-900 (CaSO 4: Dy). Radiation Physics and Chemistry, 95, 116-118.

99. CASMIE, C. D. A. D. S. (1995). Sistemas de Monitoração Individual-Critérios e Condições. Rio de Janeiro: Comissão Nacional de Energia Nuclear, Instituto de Radioproteção e Dosimetria.

100. ANVISA - Agência Nacional de Vigilância Sanitária, Ministério da Saúde, Brasília, 2005. Radiodiagnóstico Médico: Segurança e Desempenho de Equipamentos.

101. International Atomic Energy Agency. IAEA, Vienna, 2007. Technical Reports Series, no.457. Dosimetry in diagnostic radiology: an international code of practice.

102. da Silva, S. D., Joana, G. S., Oliveira, B. B., de Oliveira, M. A., Leyton, F., \& do Socorro Nogueira, M. (2015). Dosimetry and image quality in digital mammography facilities in the State of Minas Gerais, Brazil. Radiation Physics and Chemistry, 116, 292-299. 
103. Dance, D. R., Skinner, C. L., \& Carlsson, G. A. (1999). Breast dosimetry. Applied Radiation and isotopes, 50(1), 185-203.

104. Dance, D. R., Skinner, C. L., Young, K. C., Beckett, J. R., \& Kotre, C. J. (2000). Additional factors for the estimation of mean glandular breast dose using the UK mammography dosimetry protocol. Physics in medicine and biology, 45(11), 3225.

105. SEFM (Sociedad Española de Fisica Medica), 2011. Protocol Español de Control de Calidad en Radiodiagnóstico - Revisión. Madri.

106. Perry, N., Broeders, M., de Wolf, C., Törnberg, S., Holland, R., Von Karsa, L., editors, 2006. European Commission. European Guidelines for Quality Assurance in Breast Cancer Screening and Diagnosis. 4th Edition. Office for Official Publications of the European Communites. Luxembourg. 
ANEXO I 


\section{Dosimetria Absoluta - Protocolo IAEA TRS 398}

Físicos:

Máquina de Tratamento

Acelerador Linear: NovalisTx

Energia:

$\mathrm{X} 6$

Condições de Referência

Campo $=10 \times 10 \mathrm{~cm}^{2}$

$\mathrm{SSD}=100 \mathrm{~cm}$

Zref $=\frac{10}{c m}$

$\mathrm{UM}=\frac{100}{100}$
HOSPITAL SÍRIO-LIBANÊS

DATA:

9-Dec-15

Fantoma $=\quad$ Água

$\operatorname{PDP}(10 \times 10$, Zref $)=66.0 \%$

\section{Condições de Medida}

Conjunto Dosimétrico:

Tensão: $\quad-300 \mathrm{~V}$

$N_{D, w, C o}=\overline{5.341} \mathrm{cGy} / \mathrm{nC}$

PTW TW30013-7127 e Unidos 90310 (Amarelo) Tipo da C.I.:

Certificado de Calibração:

$\frac{\text { Farmer }}{\text { IPEN-Set/2015 }}$

Medir Ks e Kpol ? Não

\begin{tabular}{|ll|}
\hline \multicolumn{2}{|c|}{ Valores de Referència: } \\
\hline Ks $1.000 \quad$ Kpol 1.001 \\
\hline
\end{tabular}

Condições Atmosféricas - Fator de Correção da Pressão e Temperatura
$\mathrm{P}=27.26 \mathrm{pol} \mathrm{Hg}=692.4 \mathrm{mmHg}$
$\mathrm{T}=22.0^{\circ} \mathrm{C}$
$\rightarrow k_{T}$
$=\frac{(273,15+\mathrm{T})}{\left(273,15+T_{0}\right)}\left(\frac{P_{0}}{P}\right)=$
$\underline{1.105}$

Medidas

\begin{tabular}{|c|c|c|c|c|c|c|c|c|c|c|}
\hline & & & \multicolumn{7}{|c|}{ Leituras M (nC) } & \\
\hline Zref $(\mathrm{cm})$ & Potencial (V) & Medida & 1 & 2 & 3 & \begin{tabular}{|l|}
4 \\
\end{tabular} & 5 & 6 & $\bar{M}$ & Max/Min \\
\hline 10 & -300 & $M 1=M-=D 10=$ & 11.360 & 11.320 & 11.360 & 11.370 & & & 11.353 & -0.442 \\
\hline & & & & & & & & & & \\
\hline 20 & -300 & $\mathrm{D} 20=$ & 6.567 & 6518 & 6.480 & 6480 & 6.499 & & 6.509 & 0586 \\
\hline
\end{tabular}

\section{Cálculos}

1- Qualidade do Feixe e Fator de Correção da Dependência Energética:

Fótons

$\mathrm{PDD} 20,10=\frac{\mathrm{D} 20}{\mathrm{D} 10}=\frac{\underline{6.509}}{11.353}=\underline{0.573} \rightarrow \mathrm{TPR} 20,10=1,2661 \times(\mathrm{PDD} 20,10)-0,0595=\underline{0.666} \quad k_{Q, C_{o}}=\underline{0.991}$

2 - Fator de Correção da Recombinação de ĺons

$$
k_{s}=2,337-3,636\left(\frac{M_{1}}{M_{2}}\right)+2,299\left(\frac{M_{1}}{M_{2}}\right)^{2}=1.000 \quad \text { (valor de referência) }
$$

3 - Fator de Correção do Efeito Polarização

$$
k_{p o l}=\frac{\left(\left|M_{+}\right|+\left|M_{-}\right|\right)}{2\left|M_{-}\right|}=\quad \underline{1.001} \quad \begin{aligned}
& \text { (valor de } \\
& \text { referência) }
\end{aligned}
$$

4 - Dose Medida

$D_{w, Q, \text { Zref }}=\left(\bar{M} \cdot k_{T, P} \cdot k_{S} \cdot k_{p o l}\right) \cdot N_{D, w, C o} \cdot k_{Q, C o}=\quad(11.353 \times 1.105 \times 1 \times 1.001) \times 5.341 \times 0.991=66.454 \quad \mathrm{cGy}$

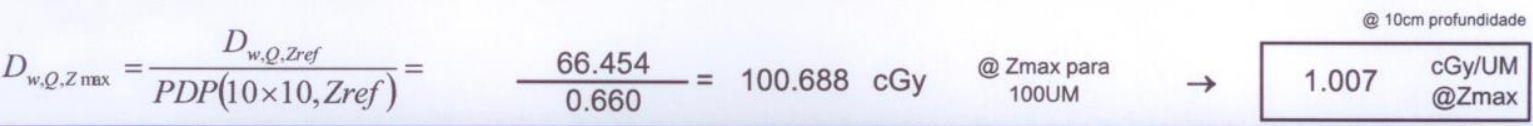

\begin{tabular}{|c|c|c|c|c|}
\hline & Valor Medido & Valor Esperado & Diferença (\%) & Será feito \\
\hline Fator Calibração do Feixe (cGy/UM) & 1.007 & 1.000 & 0.7 & ajuste? \\
\hline Qualidade do Feixe $\quad$ (PDD20,10) & 0.573 & 0.5733 & 0.0 & Não \\
\hline
\end{tabular}

Resultados

Data: 